BABELAO 3 (2014), p. 45-107

(C) ABELAO (Belgium)

\title{
Christologie et ecclésiologie dans le Commentaire sur le Cantique des Cantiques d'Épiphane le Scolastique ${ }^{1}$
}

Par

\section{Maïté Lecat}

Université catholique de Louvain, Louvain-la-Neuve

\begin{abstract}
Pil est un texte biblique dont on a le plus parlé de tout temps, c'est bien le Cantique des Cantiques. En effet, cet épithalame a fait couler - et ne cesse encore de faire couler à l'heure actuelle - beaucoup d'encre, comme l'a rappelé B. Arminjon: «ce texte très court, l'un des plus courts de toute la Bible (117 versets, 1251 mots, 5148 caractères...) a non seulement été le plus commenté probablement de toute la Sainte Écriture, mais aussi le plus passionnément controversé ${ }^{2} »$. Il faut
\end{abstract}

${ }^{1}$ Nous tenons à remercier Jean-Marie Auwers, professeur de patrologie à l'Université catholique de Louvain, pour son aide dans la publication de cet article.

2 B. Arminjon, La Cantate de l'Amour. Lecture suivie du Cantique des Cantiques (Christus, 56), Paris-Montréal, Desclée de Brouwer-Bellarmin, 1983, p. 30. Concernant les commentaires du Cantique des Cantiques, A.-M. Pelletier apporte une petite nuance: selon elle, aucun livre de l'Ancien Testament n'a été autant commenté que le Cantique, à l'exception des Psaumes. Cf. A.-M. Pelletier, Le Cantique des Cantiques (Cahiers Évangile, 85), Paris, Cerf, 1993, p. 36. 
notamment souligner l'importance du "plus beau Chant» dans l'Antiquité chrétienne: lu, cité ou paraphrasé, c'est dans quatre domaines différents - la liturgie, l'hymnologie, le discours épistolaire et le commentaire - que le Cantique est présent à l'époque patristique ${ }^{3}$. Pour ce qui est du commentaire, la plupart des Pères ${ }^{4}$ lisent le chant de Salomon dans un sens spirituel, développé dans deux directions complémentaires ${ }^{5}$ : transposant l'interprétation juive qui voit dans le Cantique une allégorie des rapports entre Dieu et son peuple, nombreux sont ceux qui font une lecture ecclésiale de l'œuvre, mettant ainsi en avant la relation entre le Christ et l'Église. À côté de cette lecture, ou plutôt en complément de celle-ci, s'est développée une lecture mystique du Cantique, plus individuelle: les Pères comprennent l'échange entre l'Époux et l'Épouse comme le dialogue entre chaque âme chrétienne et le Verbe, tout croyant s'efforçant d'arriver à l'union d'amour avec Dieu. Telles sont les deux tendances de l'interprétation spirituelle du Cantique, les «deux applications, soit isolées soit associées qui, pendant toute la période patristique, seront plus ou moins heureusement commentées ${ }^{6} »$. De nombreux commentaires de cet épithalame ont ainsi vu le jour dès les premiers siècles de la chrétienté. Cet article sera consacré à l'étude de l'un d'entre eux, occupant une place toute particulière: le Commentaire sur le Cantique des Cantiques d'Épiphane le Scolastique. En effet, datant du milieu du $\mathrm{VI}^{\mathrm{e}}$ siècle, il s'agit du plus ancien commentaire latin complet du Cantique connu à l'heure actuelle, avec celui de son contemporain Juste d'Urgel (vers 546). Le commentaire d'Épiphane précède ainsi l'œuvre

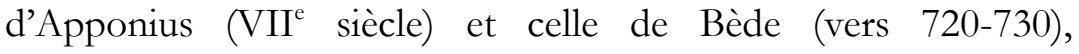

3 Sur le Cantique à l'époque patristique et ses quatre domaines d'utilisation, voir A.-M. Pelletier, Lectures du Cantique des Cantiques. De l'énigme du sens aux figures du lecteur (Analecta Biblica, 121), Rome, Editrice Pontificio Istituto Biblico, 1989, p. 143-287.

4 Certaines interprétations profanes ont également vu le jour dans l'Antiquité, dont celle de Théodore de Mopsueste († 428) pour qui le Cantique n'est qu'un écrit de circonstance rédigé par Salomon pour faire accepter au peuple son mariage avec la fille de Pharaon. Cf. J.-M. AUwERS, «Lectures patristiques du Cantique des cantiques", in J. NieuviarTs et P. DeBERGÉ (éd.), Les nouvelles voies de l'exégèse. En lisant le Cantique des cantiques, XIX congrès de l'Association catholique pour l'étude de la Bible (Toulouse, septembre 2011) (Lectio divina, 190), Paris, Cerf, 2002, p. 131-133.

5 J.-M. Auwers et W. Gallas, "Les Pères devant le Cantique des cantiques ", in J.-M. AUWERS (éd.), Regards croisés sur le Cantique des cantiques (Le livre et le rouleau, 22), Bruxelles, Lessius, 2005, p. 13-16; F. CAVALLERA, «Cantique des Cantiques. II. Histoire de l'interprétation spirituelle. 1. À l'époque patristique ", in Dictionnaire de spiritualité ascétique et mystique. Doctrine et histoire, t. 2, 1, Paris, Beauchesne, 1953, col. 93-94.

${ }^{6}$ F. Cavallera, «Cantique des Cantiques », col. 93. Outre l’Église ou l'âme du chrétien, notons-le également, certains exégètes interprètent l'Épouse du Cantique comme la Vierge Marie, l'âme du Christ ou l'âme cosmique. Cf. M. W. ELLIOTT, The Song of Songs and Christology in the Early Church 381-451 (Studien und Texte zu Antike und Christentum, 7), Tübingen, J.C.B. Mohr (Paul Siebeck), 2000, p. 120. Concernant l'interprétation de l'Épouse comme Marie, voir l'article de G. BARDY, "Marie et le Cantique chez les Pères », in Bible et vie chrétienne, 7 (sept./nov. 1954), p. 32-41. 
également consacrées à commenter la totalité du livre biblique. Ce commentaire latin d'Épiphane est en réalité l'adaptation de l'œuvre grecque de Philon de Carpasia (vers 400), un des trois commentaires grecs sur l'ensemble du Cantique conservés aujourd'hui dans leur intégralité, les deux autres étant celui de Nil d'Ancyre (vers 400 également) et celui de Théodoret de Cyr (vers 432).

Que sait-on d'Épiphane le Scolastique ? Pas grand-chose, si ce n'est qu'il est traducteur entre 540 et $570^{7}$, séjournant au monastère du Vivarium fondé par Cassiodore - pour certains en tant qu'hôte ${ }^{8}$, alors que selon d'autres il y est moine ${ }^{9}$ - lorsque Cassiodore compose et remanie ses Institutiones (de 560 à 580). Peut-être Épiphane est-il déjà le compagnon de Cassiodore lors de l'exil de celui-ci à Constantinople entre 540 et 555. Le fondateur du Vivarium qualifie en général Épiphane de uir disertissimus $^{10}$, ainsi qu'une fois de scolasticus $^{11}$. Ce nom lui est d'ailleurs resté, mais pour Cassiodore, il s'agit d'un simple qualificatif synonyme de disertissimus ${ }^{12}$. Au Vivarium, Épiphane travaille pour le fondateur du monastère, mettant à sa disposition ses talents de traducteur afin de conserver en langue latine d'importants écrits grecs. À l'heure actuelle, cinq traductions d'Épiphane sont conservées, œuvres dont la paternité ne peut être remise en cause puisque Cassiodore lui-même les mentionne dans ses écrits ${ }^{13}$ :

* Le commentaire de Didyme l'Aveugle sur les Proverbes, Expositio Didymi in Prouerbia (cf. Instit., I, 5, 2);

* Le commentaire de Didyme l'Aveugle sur les Épîtres catholiques, Expositio Didymi in Epistolas Catholicas (cf. Instit., I, 8, 6);

* Le commentaire de Philon de Carpasia sur le Cantique des Cantiques (attribué à tort à Épiphane de Chypre), Expositio Epiphanii Cyprii in Canticum Canticorum (cf. Instit., I, 5, 4) ;

* Le Codex Encyclius du concile de Chalcédoine (cf. Instit., I, 11, 2). Il s'agit d'un ensemble de lettres adressées par différents synodes à l'empereur Léon afin de défendre les décrets du concile de Chalcédoine contre Timothée Aelurus $^{14}$;

${ }^{7}$ D. M. CAPpuYns, «Épiphane le Scolastique », in Dictionnaire d'Histoire et de Géographie Ecclésiastiques, t. 15, Paris, Letouzey et Ané, 1963, col. 631.

${ }^{8}$ D. M. CAPPUYNS, "Épiphane le Scolastique », col. 631.

${ }^{9}$ P. SinisCalco, «Épiphane le Scolastique », in A. DiBERARdino (éd.), Dictionnaire encyclopédique du christianisme ancien. Volume I. A-I, adaptation française sous la direction de F. Vial, Paris, Cerf, 1990, p. 843.

${ }^{10}$ Instit., I, 5, $2 ; 8,6 ; 11,2 ; 17,1$.

${ }^{11}$ Hist. tripart., praef.

${ }^{12}$ D. M. CAPPUYNS, «Épiphane le Scolastique », col. 631.

${ }^{13}$ D. M. CAPPUYNS, «Épiphane le Scolastique », col. 631-632.

14 W. Milligan, "Epiphanius Scholasticus », in Dictionary of christian biography, literature, sects and doctrines, vol. 2, New York-Millwood, AMS PressKraus Reprint, 1974, p. 160. 
* Les Historiae ecclesiasticae de Socrate, Sozomène et Théodoret, également connues sous le nom d'Historia tripartita, douze livres pour lesquels l'Historia tripartita de Théodore le Lecteur a servi de modèle (cf. Instit., I, 17, 1 et Hist. tripart., praef.). Tous ne s'accordent pas quant au rôle joué respectivement par Épiphane et par Cassiodore dans la réalisation de ce travail, consistant en un résumé et une compilation des trois histoires afin d'établir une seule histoire continue de l'Église ${ }^{15}$. Quoi qu'il en soit, publiée sous le nom de Cassiodore, l'œuvre a connu un grand succès et est devenue le manuel de l'histoire de l'Église pour le clergé occidental durant des siècles.

Il est difficile, dans l'état actuel des recherches, de se faire une idée précise du talent d'Épiphane dans son travail de traduction. Selon D. M. Cappuyns ${ }^{16}$, ce collaborateur de Cassiodore «comprend souvent mal les textes grecs et son latin n'est pas toujours suffisamment littéral ». On en a donc conclu que c'est un non-Grec de culture médiocre. Il faut en revanche souligner que ses sources manuscrites ne sont certainement pas des plus faciles à déchiffrer, qu'il traduit probablement sur audition - selon la pratique courante à l'époque ${ }^{17}$ - et que Cassiodore n'hésite pas à corriger lui-même la traduction latine fournie par Épiphane.

Puisque le Commentaire sur le Cantique des Cantiques rédigé en latin par Épiphane le Scolastique est en réalité la traduction de l'œuvre grecque de Philon de Carpasia, il convient donc, avant d'étudier le commentaire latin, de se pencher quelque peu sur la version originale écrite en grec. En ce qui concerne l'auteur, sa vie n'est que très mal connue ${ }^{18}$ : Philon aurait vécu dans la deuxième moitié du $\mathrm{IV}^{\mathrm{e}}$ siècle et au début du $\mathrm{V}^{\mathrm{e}}$ siècle, il aurait été choisi vers 382 (ou 400 ${ }^{19}$ ) comme évêque de Carpasia (Chypre) par Épiphane, évêque de Salamine. Il aurait fait preuve d'une activité pastorale soutenue afin de défendre l'orthodoxie et d'éliminer les cultes païens, tout ceci accompagné de prodiges et de miracles. Après sa mort à Carpasia même, on l'aurait enseveli dans son église. Plusieurs œuvres lui sont attribuées ${ }^{20}$ : un Commentaire $d u$ Cantique des Cantiques, une Epistola ad Eucarpium concernant la vie

15 W. Milligan, «Epiphanius Scholasticus », p. 159 ; P. SINISCALCO, «Épiphane le Scolastique », p. 843.

${ }^{16}$ D. M. CAPPUYNS, «Épiphane le Scolastique », col. 631.

17 Voir à ce sujet l'article d'E. DEKKERS, «Les autographes des Pères latins », in B. FisCHER et V. FiALA (éd.), Colligere fragmenta. Festschrift Alban Dold zum 70. Geburtstag am 7.7.1952 (Texte und Arbeiten, 1. Beiträge zur Ergründung des älteren lateinischen christlichen Schrifttums und Gottesdienstes, 2), Beuron, Beuroner Kunstverlag, 1952, p. 127-139.

18 A. Ceresa-Gastaldo, "Philon de Carpasia », in Dictionnaire de spiritualité ascétique et mystique. Doctrine et histoire, t. 12, 1, Paris, Beauchesne, 1984, col. 1374.

19 P. CourCelle, Les lettres grecques en Occident de Macrobe à Cassiodore (Bibliothèque des Écoles françaises d'Athènes et de Rome, 159), Paris, E. De Boccard, 1948, 2e édition, p. 364.

20 A. Ceresa-Gastaldo, « Philon de Carpasia », col. 1375-1376. 
érémitique et la discrétion dans l'ascèse, une Histoire ecclésiastique et un Commentaire sur l'Hexameron, ces deux derniers étant perdus.

Tandis que la paternité des autres écrits est contestée, le Commentaire sur le Cantique est sûrement authentique ${ }^{21}$. Cette œuvre est d'un grand intérêt car non seulement elle couvre l'ensemble du Cantique des Cantiques - bien que le commentaire de Philon soit assez bref - mais elle a également été conservée dans son intégralitée $e^{22}$. En effet, certains autres commentaires ne concernent qu'une partie du texte biblique et/ou nous sont parvenus de façon incomplète ${ }^{23}$. L'œuvre s'ouvre par une vaste préface présentant «le critère fondamental de l'interprétation allégorique, qui est de révéler le mystère des noces du Christ et de l'Église ». Philon commente ensuite, de manière plus ou moins étendue (il s'agit parfois d'une seule phrase), chaque verset du Cantique cité selon la version des Septante. Pour cela, il s'inspire de ses prédécesseurs tels Hippolyte ${ }^{24}$, Origène et Grégoire de Nysse, mais il réélabore librement les notations trouvées chez ceux-ci. Il fait également preuve d'originalité en ce qui concerne l'image de l'Église comme épouse du Christ et il accorde plus d'importance que ses devanciers au thème du martyre, un thème fortement lié à la mort du Christ et présent à maintes reprises dans le commentaire. Le Commentaire du Cantique des Cantiques de Philon de Carpasia connait ensuite une large diffusion comme en témoignent les chaînes exégétiques: quarante-huit extraits du commentaire se retrouvent dans la chaîne de Procope, trente-sept dans celle du Pseudo-Eusèbe et quatre dans la Topographie chrétienne de Cosmas Indicopleustès ${ }^{25}$.

Comme mentionné plus haut, Épiphane le Scolastique réalise, au $\mathrm{VI}^{\mathrm{e}}$ siècle, une traduction latine du Commentaire sur le Cantique des Cantiques, à la demande de Cassiodore. Celui-ci fait part, dans les Institutiones, de son entreprise de faire copier trois

21 A. Ceresa-Gastaldo, «Philon de Carpasia », col. 1376.

22 Précisons que le commentaire de Philon a été conservé dans son intégralité dans la version latine d'Épiphane, mais non dans sa version originale grecque. Cf. infra, p. 51 sq.

${ }^{23}$ Pour un aperçu des différents commentaires patristiques grecs sur le Cantique des Cantiques, voir www.uclouvain.be/367265.html (page consultée le 24 juillet 2013).

${ }^{24}$ Ainsi, en faisant un commentaire sur les seins du Bien-aimé (Ct 1,2), Philon se rattache à la tradition remontant à Hippolyte. Cf. P. MELONI, Il profumo dell'immortalità. L'interpretazione patristica di Cantico 1,3 (Verba Seniorum, 7), Rome, Studium, p. 299.

${ }^{25}$ Pour plus de détails sur les extraits du commentaire dans les chaînes exégétiques, voir Philonis Carpasii Commentarium in Canticum Canticorum ex antiqua uersione latina Epiphanii Scholastici (Corona patrum, 6), editionem criticam cum prolegomenis, italica interpretatio, notis et indicibus curauit A. CeresaGastaldo, Turin, Società editrice internazionale, 1979, p. 14-21, où l'auteur reprend l'ensemble des extraits présents dans les chaînes et les met en parallèle avec le commentaire. Voir aussi J.-M. AuWERS, L'interprétation du Cantique des Cantiques à travers les chaînes exégétiques grecques (Instrumenta Patristica et Medievalia, 56), Turnhout, Brepols, 2011, p. 359-387. 
commentaires sur le Cantique dans un seul $\operatorname{codex}^{26}$ : il s'agit de deux homélies d'Origène traduites par Jérôme, du commentaire d'Origène en trois livres, traduit par Rufin, et du commentaire attribué à Épiphane de Chypre, mais dont l'auteur est Philon de Carpasia $^{27}$. De fait, au début de la préface ainsi qu'un peu plus loin en tête du commentaire proprement dit, Épiphane mentionne comme auteur de l'œuvre son homonyme grec, évêque de Salamine dans l'île de Chypre ${ }^{28}$. Pour certains, c'est cette homonymie avec le traducteur latin qui a favorisé l'attribution du commentaire à Épiphane de Salamine ${ }^{29}$. Selon d'autres, en revanche, Cassiodore aurait souhaité faire figurer le nom de l'évêque de Salamine en raison de sa renommée plus importante que celle de l'évêque de Carpasia ${ }^{30}$.

Quelle était la façon de procéder d'Épiphane pour rendre en latin ce commentaire grec? Une remarque s'impose d'emblée ${ }^{31}$ : pour pouvoir juger pleinement de la technique de traduction d'Épiphane, il faudrait comparer le texte original grec et la version latine. Cependant, le texte du commentaire de Philon de Carpasia dont on dispose actuellement ne semble pas être l'original, mais plutôt une compilation. La version latine d'Épiphane, quant à elle, serait plus proche du texte original car elle comporte des parties plus développées. Malgré ce problème, on peut remarquer qu'Épiphane traduit de façon très littérale les citations bibliques en se basant sur la Vetus Latina ${ }^{32}$. Concernant les lemmes du Cantique, nous sommes en présence d'une version très intéressante: il s'agit d'une version revue par Jérôme avant la rédaction de la Vulgate, se basant sur les Hexaples d'Origène. Pour la traduction du commentaire en lui-même, on repère quelques passages abrégés, ainsi que des additions et de rares omissions causées par la distraction ${ }^{33}$. En raison des nombreuses divergences avec la version grecque connue actuellement, on peut croire qu'Épiphane a utilisé un texte différent de celui de nos

26 S. SAgOT, "Une récente édition du "Commentaire sur le Cantique des Cantiques" ", in Vigiliae Christianae, 35 (1981), p. 359.

${ }^{27}$ Instit. I, 5, $4:$ : Post quos Epiphanius antistes Cyprius totum librum Graeco sermone uno uolumine sub breuitate complexus est. Hunc nos ut alios in Latinam linguam per amicum nostrum uirum disertissimus Epiphanium fecimus Domino iuuante transferri » (Cassiodori Senatoris Institutiones, edited from the Manuscripts by R. A. B. Mynors, Oxford, Clarendon, 1961, p. 24).

28 «Incipit expositio sancti Epifanii episcopi Cyprorum super canticum canticorum » (Préface, 1. 1-2) ; «Incipit expositio Epiphanii episcopi Cyprii in canticis canticorum» (I, 1. 88-89). La numérotation des lignes correspond à celle de la traduction française présentée dans la suite de cet article.

29 A. Ceresa-Gastaldo, «Philon de Carpasia », col. 1375.

30 E. Prinzivalli, «Philon de Carpasia », in A. DiBerardino (éd.), Dictionnaire encyclopédique du christianisme ancien. Volume II. J-Z, adaptation française sous la direction de F. Vial, Paris, Cerf, 1990, p. 2020.

31 S. SAGOT, «Une récente édition du "Commentaire sur le Cantique des Cantiques" ", p. 364.

32 S. SAGOT, "Une récente édition du "Commentaire sur le Cantique des Cantiques" », p. 365.

33 S. SAGOT, "Une récente édition du "Commentaire sur le Cantique des Cantiques" », p. 365-366. 
éditions modernes. Pour le reste, les versions grecque et latine à notre disposition sont assez semblables. Remarquons simplement les nombreuses erreurs ${ }^{34}$ facilement explicables lorsque l'on sait qu'Épiphane traduit sur audition. En conclusion, on peut dire que «la caractéristique essentielle est une extrême liberté, procédé courant à l'époque où l'“adaptation" était une voie normale pour la diffusion d'un texte ${ }^{35} »$. En ce qui concerne le latin utilisé par Épiphane, il est dans l'ensemble traditionnel au point de vue de la phonétique, de la morphologie et de la syntaxe, même si de nombreux indices ${ }^{36}$ du passage progressif au latin médiéval sont déjà visibles ${ }^{37}$. Quant aux figures de style, celles présentes chez Philon (métonymie, apostrophe, anaphore, antithèse, allitération...) se retrouvent également dans la version latine.

Observons à présent la tradition manuscrite ainsi que les éditions réalisées de chaque version de ce Commentaire sur le Cantique des Cantiques. Pour ce qui est du texte grec de Philon de Carpasia $^{38}$, l'editio princeps paraît à Rome en 1772 ; l'éditeur, M. Giacomelli, archevêque de Chalcédoine, accompagne le texte grec de sa propre traduction latine. Cette édition est ensuite reprise par A. Galland ainsi que dans le quarantième tome de la Patrologie Grecque, puis récemment par K. Hadjioannou qui a remplacé la traduction latine par une traduction en grec moderne ${ }^{39}$. Une édition critique est en préparation à Louvain-la-Neuve (prof. J.-M. Auwers). Comme évoqué plus haut, l'œuvre de Philon est aussi connue grâce aux mentions qui en sont faites dans les chaînes exégétiques $^{40}$. Outre la traduction d'Épiphane le Scolastique, une autre traduction latine du commentaire est réalisée en 1537 à Paris par S. Salutatus, traduction réimprimée et utilisée à plusieurs reprises. Cependant, malgré ce que laisse présumer le titre, il ne

${ }^{34}$ Relevons notamment des erreurs dues à la prononciation iotacisante du grec : Epiphane utilise le terme puritas pour traduire ó $\gamma v \varepsilon i a$ qui est en réalité äyora. La confusion entre voyelles est également observable: le terme

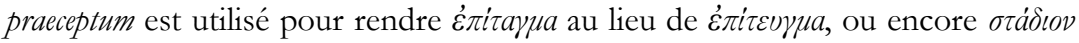
est traduit erronément par studium. Voir Philonis Carpasii Commentarium in Canticum Canticorum, p. 28.

35 S. SAGot, «Une récente édition du "Commentaire sur le Cantique des Cantiques" », p. 366.

${ }^{36} \mathrm{On}$ peut noter des changements de voyelles (perfice pour perfeci, aut pour $u t$ ), de consonnes ( $b$ pour $u$ et inversement), de genres (malum pour malus, sacramentus pour sacramentum), de conjugaisons (repellent pour repellunt) etc. Pour d'autres exemples, voir Philonis Carpasii Commentarium in Canticum Canticorum, p. 29-30.

${ }^{37} \mathrm{~S}$. SAGOT, «Une récente édition du "Commentaire sur le Cantique des Cantiques" », p. 366.

38 A. Ceresa-Gastaldo, «Philon de Carpasia », col. 1375 ; S. SAgot, "Une récente édition du "Commentaire sur le Cantique des Cantiques" », p. 358. Notons également l'existence d'une version éthiopienne. Cf. T. ABRAHA, «La versione ge'ez (etiopica) del commento al Cantico dei Cantici 1,2-14a di Filone di Carpasia », in Laurentianum, 49 (2008), p. 71-119.

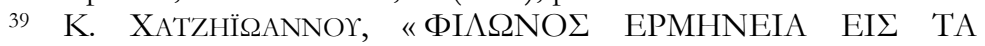
A $\Sigma$ MATA T $\Omega N$ A $\Sigma M A T \Omega N$ », in H APXAIA KभПPO $\Sigma$ EI $\Sigma$ TA $\Sigma$ E $\Lambda \Lambda H-$ NIKA $\Sigma$ ПНГА $\Sigma$, III, 1, Leucosie, 1974.

${ }^{40}$ Cf. supra, p. 49. 
s'agit pas d'une traduction de l'œuvre de Philon, mais on y trouve de nombreux passages abrégés empruntés à Grégoire le Grand.

Concernant la traduction latine du commentaire réalisée par Épiphane le Scolastique, on a conservé un manuscrit datant de la seconde moitié du $\mathrm{VI}^{\mathrm{e}}$ siècle, le Vaticanus latinus 5704. Selon P. Courcelle $^{41}$, on serait là en présence d'un original du Vivarium. En effet, le commentaire d'Épiphane est aujourd'hui seul dans le Vaticanus, mais il était auparavant précédé d'autres textes car il occupe les quaternions XXIX à XL de ce manuscrit. Après avoir effectué quelques opérations mathématiques, P. Courcelle en est venu à la conclusion que l'espace laissé libre avant le commentaire d'Épiphane correspond très bien à celui qu'auraient occupé les deux homélies et le commentaire sur le Cantique des Cantiques d'Origène car, comme vu précédemment, Cassiodore a fait copier ces trois commentaires l'un à la suite de l'autre ${ }^{42}$. Il est donc très probable que le Vaticanus latinus 5704 soit le manuscrit même où Épiphane a rédigé sa traduction. La diffusion de cette version latine du commentaire de Philon n'est ensuite que très réduite. Même si pour certains la traduction aurait été diffusée à Rome dans un premier temps, puis dans d'autres régions d'Italie et peutêtre également en France, la seule copie connue de cette œuvre se situe dans le petit codex Parisinus graecus 3092 du XVII ${ }^{\mathrm{e}}$ siècle (contenant une copie du Vaticanus latinus 5704) ${ }^{43}$. G. Bianchini découvre l'œuvre d'Épiphane au XVIII ${ }^{\mathrm{e}}$ siècle et P. F. Foggini publie l'editio princeps en 1750 à Rome ${ }^{44}$. À la suite de Cassiodore, P. F. Foggini attribue le commentaire original à Épiphane de Salamine, et ce n'est que lors de la publication du texte grec de Philon en 1772 par M. Giacomelli que l'on constate qu'il s'agit de la même œuvre. En 1979, A. Ceresa-Gastaldo réalise une édition critique du commentaire, accompagnée d'une traduction italienne et de notes ; c'est cette édition qui sera ici utilisée pour l'étude du commentaire.

Le texte du commentaire de Philon de Carpasia est problématique, on l'a vu, car l'édition actuelle de ce commentaire et celle de l'adaptation latine réalisée par Épiphane le Scolastique ne concordent pas. C'est pourquoi une nouvelle édition critique de Philon, prenant en compte l'ensemble de la tradition manuscrite, serait nécessaire. De même, il faudrait prendre en considération des scholies philoniennes qu'offrent l'Épitomé de Procope sur le Cantique - qui vient tout juste d'être édité ${ }^{45}-$,

${ }^{41}$ P. CourCelLe, Les lettres grecques en Occident, p. 365.

${ }^{42}$ Cf. supra, p. $49-50$.

43 A. Ceresa-Gastaldo, "Philon de Carpasia », col. 1376-1377; S. SAGOT, «Une récente édition du "Commentaire sur le Cantique des Cantiques" ", p. 362.

44 A. Ceresa-Gastaldo, «Philon de Carpasia », col. 1375 ; S. SAgot, "Une récente édition du "Commentaire sur le Cantique des Cantiques" », p. 359-360.

45 Voir à présent : Procopii Gazaei Epitome in Canticum canticorum (Corpus Christianorum, Series Graeca, 67), edita a J.-M. Auwers cum praefatione a J.-M. Auwers et M.-G. Guérard curata, Turnhout, Brepols, 2011. 
ainsi que la Chaîne dite d'Eusèbe dont l'édition critique est préparée par le prof. J.-M. Auwers. Toute la question est de savoir si le texte «original» de Philon est celui aujourd'hui reproduit dans la Patrologie grecque - en traduisant le commentaire en latin, Épiphane aurait alors apporté de nombreux ajouts personnels -, ou si Épiphane disposait d'un texte grec plus long, l'édition de l'abbé Migne étant alors un résumé du commentaire de Philon.

Il ne sera pas question ici d'une comparaison entre les deux œuvres, mais tout l'intérêt sera porté au commentaire latin pour lui-même. Ainsi, quand il sera fait mention d'Épiphane, c'est toujours le commentaire latin qui sera visé. Il ne s'agira pas non plus de prendre en considération la totalité du Commentaire sur le Cantique des Cantiques d'Épiphane, mais uniquement la préface et le premier chapitre de cette œuvre. De fait, c'est dans ce premier chapitre qu'Épiphane expose et met en pratique sa méthode, le reste ne présentant plus le même intérêt herméneutique. Une traduction française de cette section sera tout d'abord présentée ; il s'agit là d'une première puisque le commentaire d'Épiphane n'a encore jamais été traduit en français. Ensuite, une analyse des éléments christologiques et ecclésiologiques présents dans cette partie de l'œuvre sera effectuée. En effet, développant une lecture ecclésiale du Cantique, le commentaire conçoit la relation entre le Bien-aimé et la Bien-aimée comme l'image de l'union du Christ et de l'Église ; l'œuvre contient donc toute une christologie et toute une ecclésiologie.

\section{Traduction française}

Pour cette étude du Commentaire sur le Cantique des Cantiques d'Épiphane le Scolastique, l'édition utilisée est celle réalisée par A. Ceresa-Gastaldo en $1979^{46}$. Le texte latin ne sera pas reproduit ici, mais le lecteur pourra se référer à cette édition (p. 42 à 88 pour la préface et le premier chapitre). En voici une traduction française $^{47}$, où figurent les références scripturaires telles qu'on les trouve dans l'édition d'A. Ceresa-Gastaldo ${ }^{48}$. Lorsque, dans la suite de l'article, un renvoi à un passage du commentaire sera effectué, on utilisera la numérotation des lignes telle qu'elle figure dans cette traduction.

46 Philonis Carpasii Commentarium in Canticum Canticorum ex antiqua uersione latina Epiphanii Scholastici (Corona patrum, 6), editionem criticam cum prolegomenis, italica interpretatio, notis et indicibus curauit A. CeresaGastaldo, Turin, Società editrice internazionale, 1979.

${ }^{47}$ Le premier verset du deuxième chapitre du Cantique figure également ici, étant donné la continuité entre le commentaire du dernier verset du premier chapitre et ce premier verset du deuxième chapitre.

${ }^{48} \mathrm{La}$ numérotation utilisée pour les Psaumes est celle de la Septante et de la Vulgate ; dans ces versions, les Psaumes 9 et 10 n'en forment qu'un. 
Commencement de l'exposé de saint Épiphane, évêque de Chypre, sur le Cantique des Cantiques

Comme un cavalier qui talonnerait son cheval l'excite à courir, force cette bête rétive à être rapide et l'habitue dans la course à presser l'allure, ainsi aussi je me rends compte que ma misérable intelligence est incitée à la hâte par de nobles pieds ${ }^{49}$, quand, à l'invitation d'hommes admirables, l'un prêtre et l'autre diacre, j'entreprends l'interprétation spirituelle du Cantique des Cantiques, forcé de quitter ma paresse. Maintenant donc, je leur

10 demande à tous deux non seulement de stimuler dès à présent mon empressement pour le commentaire, mais aussi, par leurs prières, de guider mon esprit vers une formulation exacte, afin que, d'une course régulière, nous accomplissions un parcours irréprochable et que, employant un discours salutaire, irréprochables ${ }^{50}$, 15 comme le dit l'Apôtre, en recueillant les fruits de nos réflexions, nous méritions de parvenir à la cité immortelle des bienheureux. En effet, nous ne possédons rien par nous-mêmes, mais rendant grâces à celui qui nous en a fait don, nous en arrivons à l'étude de la présente œuvre. Ainsi donc, lorsque chacun aura consacré sa 20 pensée au Seigneur et qu’il aura écarté de la sagesse terrestre son esprit ainsi que toute son intelligence, lorsqu'il aura bien disposé son âme par la vertu de chasteté et accueilli sur son front la couronne céleste des grâces, qu'il aborde le texte saint des Cantiques spirituels.

25 Assurément le titre lui-même détourne aussitôt d'une compréhension charnelle ceux qui s'approchent de cette œuvre avec un esprit droit. En effet, elle n'est pas simplement intitulée et n'est certainement pas appelée Cantiques, mais Cantiques des Cantiques, comme on parle des Saints des Saints. Car, de même

30 que ceux-ci possèdent l'honneur de mystères plus élevés et plus secrets, étant donné surtout quand le grand prêtre entrait dans les Saints des Saints une seule fois dans l'année, ainsi aussi les Cantiques des Cantiques détiennent le mystère spirituel et vraiment profond des significations cachées. De même, il est bien 35 connu que les Sabbats des sabbats représentent le repos des biens futurs, supérieur à la sécurité présente. Par Sabbats des sabbats, je le pense en effet, la sainte Écriture veut désigner le repos futur dans ce siècle-là et les biens promis de sa sécurité, car c'est là que se trouvent les Sabbats des sabbats, le repos du siècle futur et la 40 consommation de ces sabbats actuels ici accomplis dans la faiblesse des péchés. En effet, ceux qui s'abstiennent de pécher ici-bas jouiront pleinement du repos parfait dans le siècle futur. De même donc que ces sabbats-là sont de beaucoup supérieurs à ces sabbats-ci, de même aussi les Cantiques des Cantiques 45 possèdent manifestement quelque grandeur spirituelle supérieure surpassant les cantiques que l'on trouve écrits dans d'autres livres.

\footnotetext{
${ }^{49} \operatorname{Rm} 10,15$.

50 Tt 2,8 .
} 
Assurément de nombreux cantiques ont été écrits dans les livres divins. Écoute le cantique de Moïse : Chantons - dit-il - pour le Seigneur car il a été convert de gloire ${ }^{51}$; et on trouve de même d'autres cantiques dans la Loi. Écoute aussi le cantique d'Isaïe qui dit: Je chanterai pour mon bien-aimé le cantique de ma vigne chérie ${ }^{52}$. Écoute aussi le cantique chanté par Anna : Mon cour - dit-elle - a été réconforté dans le Seigneur ${ }^{53}$. D'autres cantiques sont présents dans les psaumes: Chantons pour le Seigneur un cantique nouveau ${ }^{54}$, et tu trouves des cantiques dans les Écritures divines. Mais les Cantiques des Cantiques ont été honorés d'un titre beaucoup plus important et plus noble, comme les Saints des Saints et les Sabbats des sabbats. C'est pourquoi, me semble-t-il, il faut comprendre de manière plus subtile le sens de cette Écriture sacrée et excessivement haute, puisqu'on n'a pas dit Cantiques des Cantiques qu'a faits Salomon ou qu'a dits Salomon, mais (v. 1) Cantiques des Cantiques qui sont de Salomon lui-même.

En effet, puisque Salomon signifie pacificateur ou pacifiste, on reconnaît que ces Cantiques des Cantiques ont été composés 65 pour toute personne apaisée et privée des scandales de la débauche intellectuelle. De fait, celui qui ne garde pas ses sens loin des passions, les Cantiques des Cantiques, les Saints des Saints et les Sabbats des sabbats ne sont pas faits pour lui. En revanche, si quelqu'un repousse tout ce qui fait scandale, désire la

70 paix véritable et couronne son âme ainsi que son corps de la vertu de chasteté, les Cantiques des Cantiques sont faits pour lui, puisqu'il a compris qu'il n'y a rien de terrestre, rien de charnel en ceux-ci, mais considérant spirituellement tout ce qui fut écrit, il sera véritablement apaisé. En effet, on dit: Grande paix pour ceux qui aiment ton nom, Seigneur, et pour eux, pas de scandale ${ }^{55}$.

Comme il y a dans une demeure quelques vestibules, des portes, un portique, des salles à manger et de splendides cours, il y a aussi dans toutes celles-ci une chambre à coucher appelée chambre nuptiale dans laquelle l'épouse, se reposant avec l'époux,

80 lui dit des secrets d'une intelligence plus élevée. Ainsi aussi dans les Cantiques des Cantiques, comme si elle était installée dans la chambre nuptiale, la sainte épouse l'Église dit à son époux les paroles profondes des mystères de la foi, dans lesquelles elle dit: Qu'il m'embrasse des baisers de sa bouche.

85 Se termine la préface

${ }^{51}$ Ex 15,1 .

${ }^{52}$ Is 5,1 .

$531 \mathrm{~S} 2,1$.

${ }^{54}$ Ps 95,1 (=97,1;149,1).

55 Ps $118,165$. 
Commencement de l'exposé d'Épiphane, évêque de Chypre, sur les Cantiques des Cantiques

I. (v. 2) Voici le début tel qu'il a été mentionné : Qu'il m'embrasse des baisers de sa bouche. C'est comme si des entremetteurs avaient été envoyés par le fiancé céleste à sa fiancée très chère et lui décrivaient la beauté du fiancé - ainsi Isaïe quand il lui

95 proclame: Celui-là est beau dans son vêtement ${ }^{56}$. Et quand un autre dit: Il est d'une beauté qui surpasse les fils des hommes ${ }^{57}$; et de nouveau quand un autre lui dit pour la persuader: Un ami fidèle est une protection forte, un ami fidèle est un remède pour la vie, un ami fidèle ne demande pas de compensation ${ }^{58}$; et quand David s'entretient avec elle :

100 Écoute, ma fille, regarde, tends l'oreille et oublie ton peuple et la maison de ton père; le roi a désiré ardemment ta beauté, parce qu'il est lui-même Seigneur ${ }^{59}$. Et pour la seconde fois, quand Isaie fait l'éloge des noces conformes à la loi et dit: Et comme l'époux se réjouira de son épouse, ainsi le Seigneur se réjouira de to ${ }^{60}$. Ainsi donc, comme si 105 l'épouse entendait leurs conversations ou se rappelait les paroles similaires dites par d'autres, elle s'exclame et dit: Qu'il m'embrasse d'un baiser de sa bouche.

Toi donc qui liras le Cantique spirituel, qui que tu sois, lorsque tu entendras le baiser spirituel et non souillé par la chair,

110 n'offense pas ton esprit par un désir charnel. En vérité, le baiser spirituel est grandement et incomparablement différent du baiser charnel : en effet, comme le jour surpasse davantage la nuit de par la lumière et comme il y a un corps physique et un corps spirituel ${ }^{61}$, ainsi il y a un baiser corporel et un baiser spirituel et, de même qu'il y a

115 des corps terrestres et des corps célestes ${ }^{62}$ selon l'Apôtre, ainsi il y a des baisers terrestres et des baisers célestes. Mais certes un baiser provenant de la terre rabaisse vers la terre, tandis qu'un baiser provenant du ciel attire en haut vers le ciel. Mais autre est l'éclat des corps célestes - dit-il - et autre celui des corps terrestres ${ }^{63}$ : autre est

120 l'amour qui engendre des pensées terrestres au sujet de ce qui est inférieur, de l'argent, des biens et de la passion du désir, et autre est celui qui, tourné avec un esprit éthéré vers les choses célestes, suscite l'intelligence volant vers les biens d'en haut et l'amour pour le Seigneur qui nous a aimés ${ }^{64}$.

125 L'amour est donc un mélange de bien et de mal : bon en effet est l'amour pour le mariage, mauvais cependant celui pour la débauche. Tous en effet ne sont pas attirés selon leur désir vers les uniques épouses qui leur ont été unies légitimement par Dieu; de fait, pour ceux à qui elles suffisent, c'est un bien, mais

\footnotetext{
${ }^{56}$ Is $63,1$.

57 Ps 44,3 .

${ }^{58}$ Si 6,14.16.15.

${ }^{59}$ Ps $44,11-12$.

${ }^{60}$ Is 62,5 .

61 Co 15,44 .

621 Co 15,40.

${ }^{6} 1$ Co 15,40

${ }^{64}$ Ep 5,2 ; Ap 1,5.
} 
130 beaucoup contractent aussi dans leur impiété des unions secrètes dans lesquelles ils se souillent très fortement. Transformé en inimitiés, cet amour les accusera lorsque le jugement de Dieu, dévoilant les secrets de tous sans exception, adviendra et rendra à chacun ce qu'il mérite. En revanche, l'amour des choses célestes 135 est saint, possède des charmes éternels, suscite des joies permanentes, produit des ardeurs infinies, détient une gloire ineffable, accorde des honneurs égaux à ceux des saints anges et nous dévoile comme en un miroir le Seigneur lui-même qui nous a aimés $^{65}$; il procure les dons de l'éminente grâce, engendre la 140 confiance dans le Seigneur, fournit le sommet de la justice et nous prépare sur la terre l'honneur et dans les cieux la gloire éternelle.

$\mathrm{Tu}$ as entendu la différence ainsi que la réflexion concernant le baiser: prends connaissance de la distinction, choisis le meilleur, fuis ce qui fait du tort, garde ce qui sauve. Qu'il m'embrasse des

145 baisers - dit-elle - de sa bouche. En effet, l'Apôtre dit : Nous ne savons pas prier comme il faut, mais l'Esprit s'adresse pour nous à Dieu en des plaintes indicibles; et celui qui scrute les cours sait quel est le sentiment de l'Esprit et qu'il intercède pour les saints selon la volonté de Dieu ${ }^{66}$. Comprends donc par là que le Saint-Esprit intercède au préalable

150 en faveur de l'Église avant son union avec le Seigneur et qu'il dit à Dieu, comme en son nom à elle, avec une intention favorable : Qu'il m'embrasse des baisers de sa bouche. Vraiment en effet, il allait de soi pour elle de rechercher les preuves de l'amour divin dans la mesure où elle en était indigne : de fait, elle était devenue ennemie

155 en raison de la folie des idoles, et elle s'efforce de restaurer l'entente. Qu'il m'embrasse - dit-elle - des baisers de sa bouche. C'est-àdire le Fils, comme si elle disait: Je ne veux pas être embrassée seulement par la bouche des prophètes, mais qu'il s'approche luimême et qu'il m'embrasse des baisers de sa bouche.

160 Dirige maintenant l'œil de ta pensée vers le haut: ce n'est pas charnel, mais spirituel ce qui est dit. En effet, elle ne veut pas seulement être instruite par la bouche des prophètes, mais : Que le Fils lui-même, dit-elle, s'approche et m'instruise des baisers de sa bouche. En effet, ma mère l'Église disait jadis : Je ne serai pas 165 sauvée de façon médiocre, je rechercherai un médecin grand et parfait car j'ai été plongée en plein ténèbres. Il y a bien la lampe de la loi et les prophètes - on dit en effet : Ta loi est une lampe pour mes pas et une lumière pour mes chemins ${ }^{67}$ - mais ils ne pourront m'éclairer que si la lumière parfaite arrive, afin que la supériorité 170 de la clarté abolisse la supériorité des ténèbres et que je perçoive le chemin qui me mène de nouveau au paradis.

Qu'il m'embrasse des baisers de sa bouche : l'Église passe outre à la loi, distance également les prophètes par son zèle et demande d'être embrassée par le Fils unique lui-même. En effet, la bouche 175 de Dieu, c'est le Fils : d'où aussi, comme il est Dieu, il est appelé

\footnotetext{
65 Ep 5,2 ; Ap 1,5.

${ }^{66} \mathrm{Rm} 8,26-27$.

67 Ps $108,105$.
} 
Verbe, puisque le Père exprime toutes ses volontés par l'intermédiaire du Fils. Qu'il m'embrasse - dit-elle - des baisers de sa bouche; et elle n'a pas dit : d'un baiser de sa bouche, mais : des baisers de sa bouche, comme de ces baisers qui existaient déjà jadis. Des baisers

180 - dit-elle - de sa bouche : c'est-à-dire de ceux par lesquels il a embrassé les anciens justes, les patriarches et les prophètes, qu'il m'embrasse moi aussi. Avant qu'elle ne soit formée par rassemblement des nations, l'Église disait: Qu'il m'embrasse, comme si elle disait : non seulement par les prophètes, mais aussi 185 par le Fils comme aussi les prophètes. Et finalement elle reçut ce qu'elle demanda avec foi.

Retire-toi donc, retire-toi à présent, homme, et ne prétends pas comprendre ces choses selon la lettre: En effet, la lettre tue, mais l'esprit vivifie ${ }^{68}$. En effet, il ne faut pas comprendre cela de manière charnelle, mais de manière spirituelle : en effet, par les baisers par lesquels il a embrassé Abel pour ses offrandes de moutons ${ }^{69}$, il a aussi embrassé celle qui offre des moutons doués de raison au Seigneur, c'est-à-dire ses fils. Mais Abel a obtenu la gloire de la mort en raison de l'amour qu'il eut envers le Seigneur et 195 pareillement, les martyrs de celle-ci sont morts par amour du Seigneur.

Qu'il m'embrasse des baisers de sa bouche: de ses baisers par lesquels il a embrassé Énoch, qu'il m'embrasse moi aussi. Aie confiance, ô bienheureuse : en effet, il t’a embrassée comme aussi Énoch. En

200 effet, de même que, transporté par Dieu, on ne le trouva plus sur terre $^{70}$, ainsi toi aussi, transportée loin de l'ignorance, on te trouvera seulement dans la connaissance de Dieu. Mais toi aussi tu as été enlevée de la terre car tu possèdes la beauté des cieux au sujet de laquelle l'Apôtre dit: Notre demeure est dans les cieux ${ }^{71}$. Le

205 Christ te revêt dans le ciel et tu es également revêtue de lui en ton âme, quand bien même tu sembles être sur terre. Mais l'époux te prendra tout entière au ciel, lorsqu'il viendra t'apporter la résurrection et relever de leurs propres enveloppes tous tes membres endormis: alors tu seras emportée vers les chambres 210 célestes et tu jouiras perpétuellement avec le Fils ton époux et le Père tout-puissant lui-même de festins ineffables. Tous les désirs de la chair seront alors condamnés, lorsqu'arriveront les noces spirituelles; des festins éternels seront alors ouverts à des liens indissolubles, c'est-à-dire à tes membres.

215 Qu'il m'embrasse des baisers de sa bouche: des baisers par lesquels il a embrassé Noé, qu'il m'embrasse moi aussi. Ô frères, immense est l'amour du Seigneur pour Noé, un amour qui trouve sa preuve dans la construction d'une arche ${ }^{72}$. De fait, alors que le monde entier avait été détruit, il fut sauvé pour l'avènement d'une

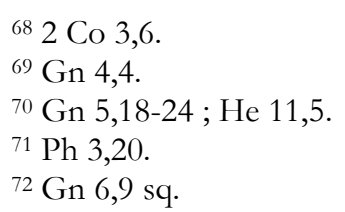


220 création nouvelle. Mais, on le reconnait, l'Église de Dieu fut aimée d'un plus grand lien d'amour et plus chérie que Noé. Assurément puisque Noé fut une préfiguration ${ }^{73}$ de l'Église: celui-là fut sauvé du déluge avec ses fils par un ouvrage en bois ; quant à celle-ci, elle sera sauvée du déluge enflammé de la fin du 225 monde par le bois de la croix salutaire avec une fécondité plus importante. En raison de l'amitié qu'il eut pour Dieu, Noé sauva ses fils pour une descendance terrestre; quant à celle-ci, établie dans l'amitié du Seigneur, elle engendra de nombreux habitants pour les royaumes célestes.

230 Et, proche de nous, il y a un témoin à ce sujet, le grand Isaïe qui prédit sa fécondité à partir du Christ en disant: Il fut livré à la mort et compté parmi les injustes, il porta les péchés de beaucoup et fut livré pour leurs péchés. Réjouis-toi, stérile qui n'enfantais pas; élève la voix, crie, toi qui ne concevais pas, car plus nombreux sont les fils de la délaissée que

235 ceux de l'épouse ${ }^{74}$. En effet, jadis stérile, elle était totalement incapable de concevoir le Verbe de Dieu, mais elle avait été délaissée parce que la perversité des dogmes impies proliférait sur elle comme des épines. Mais maintenant que le Fils de Dieu a souffert pour elle et qu'elle a été de nouveau admise à partager à 240 son côté non les passions charnelles mais les mystères spirituels, elle lui engendra une multitude de fils, même plus que la Synagogue d'Israël qui pensait avoir la loi comme époux. Cependant ce n'est pas la loi qu'elle a comme époux, mais c'est le législateur et elle mérita son union avec celui annoncé par la loi

245 dans des noces spirituelles, comme le dit quelque part l'Apôtre, comparant les choses spirituelles aux choses spirituelles : Les époux doivent aimer leurs épouses comme aussi le Christ aime l'Église ${ }^{75}$.

Et ce n'est pas tout, mais l'Écriture introduit aussi Adam. Elle dit en effet: C'est pourquoi l'homme quitte son père et sa mère et 250 s'attachera à son épouse et ils seront deux en une seule chair. Ce mystère est grand: je veux parler du Christ et de l'Église ${ }^{76}$. Vraiment en effet, grands sont les mystères divins dispensés depuis Adam au sujet du Christ et de l'Église : en effet, de même qu'Adam fut endormi et que, lui prenant une côte, Dieu lui façonna une épouse, ainsi 255 aussi notre Seigneur Jésus-Christ fut endormi pour nous dans la mort, afin que de son côté soit formée la très sainte Église incorporée à lui ${ }^{77}$. Comme donc la femme du côté d'Adam, ainsi aussi l'Église fut faite du côté du Christ. Dans l'Évangile selon Jean nous en possédons un témoignage fort sûr. L'Écriture dit en

260 effet: Et on transperça le côté de Jésus après qu'il a été crucifié. Et lorsqu'il fut endormi pour nous dans la mort, il en sortit de l'eau et du sang et celui qui a vu a rendu témoignage et son témoignage est vrai et il

${ }^{73}$ Épiphane utilise ici le mot typus, décalque latin du terme grec $\tau \dot{\tau} \pi \circ \varsigma$, alors qu'il aurait pu se servir également de figura, forme exclusivement latine.

${ }^{74}$ Is 53,$12 ; 54,1$.

${ }^{75}$ Ep 5,25.

${ }^{76}$ Ep 5,31-32.

77 Gn 2,21-22. 
sait que c'est véridique ${ }^{78}$. En effet, celui qui transperça le côté de Jésus était l'un de ceux qui le crucifièrent et il assuma la décision.

265 L'Écriture dit en effet : Ils regardèrent celui qu'ils ont transpercê79. Et afin de leur montrer que tous leurs actes étaient réalisés à leur encontre et en faveur des nations, le Seigneur Dieu fit couler de cette blessure de l'eau et du sang. Pourquoi en effet de l'eau et du sang sortaient-ils du côté de Jésus mort, si ce n'est parce que cet

270 important et admirable mystère était désormais institué, puisque, comme lorsqu'Adam dormait, Dieu lui prit une de ses côtes et lui fit une épouse, ainsi du côté de Jésus mort pour nous, prenant de l'eau et du sang, il se rebâtissait avec ceux-ci l'Église ? C'est avec l'eau de sa chair qu'elle fut baptisée par lui et glorifiée, avec le 275 sang coulant de son côté qu'elle fut rachetée et unie à lui, et c'est avec l'Esprit qu'elle pourrait être unie parfaitement à sa divinité : Parce qu'ily en a trois - dit l'Écriture - qui témoignent: l'eau, le sang et l'Esprit, et parce que les trois sont $u^{80}$; et celui qui a vu - ajoute-t-elle a rendu témoignage et son témoignage est vrai et il sait qu'il dit la vérite ${ }^{81}$.

280 Qu'est-ce que cela, ô très aimé du Christ et très saint Jean? Pourquoi, parmi toutes tes paroles, affirmes-tu surtout la véracité de cette parole, alors que nous avons la ferme conviction de la véracité et de la sûreté de tous tes dires? Quelle est la richesse de tels témoignages? Jean présentait aux fidèles un témoignage

285 concernant la raison et le dessein pour lesquels le Christ s'est incarné et a souffert, et pour cette raison il a établi une preuve non seulement sur lui-même, mais aussi sur ceux qui avaient vu: en effet, dans le dire de deux ou trois témoins toute affaire sera établie ${ }^{82}$.

Voilà pourquoi le discours concernant l'union du Christ et de

290 l'Église devait être supérieur à tout : en effet, cette eau et ce sang jaillis du côté furent le signe et le lien indissoluble du Christ et de l'Église, comme aussi la côte que prit Dieu à Adam fut le mystère indivisible des noces légitimes et honorables. En effet, l'Écriture dit ainsi: Et Dieu amena son épouse à Adam et Adam dit: Voici 295 maintenant l'os de mes os et la chair de ma chair; elle sera appelée femme, parce qu'elle a été tirée de son mari ${ }^{83}$. Cela aussi l'Apôtre le dit du Christ et de l'Église, à savoir que nous sommes ses membres, tirés de sa chair et de ses os ${ }^{84}$. Et Adam donna comme nom - dit l'Écriture - à sa femme "vie », parce qu'elle est la mère de tous les vivants ${ }^{85}$. Quant à

300 l'Église, c'est d'une façon beaucoup plus appropriée qu'elle sera appelée de ce nom! En effet, tirée de la terre, Ève est la mère de ceux qui vécurent sur terre, quant à celle-ci, fiancée des cieux, elle est la mère des célestes qui reçurent la vie éternelle. C'est pourquoi on a dit: Il quitte son père et sa mère et s'attachera à son épouse

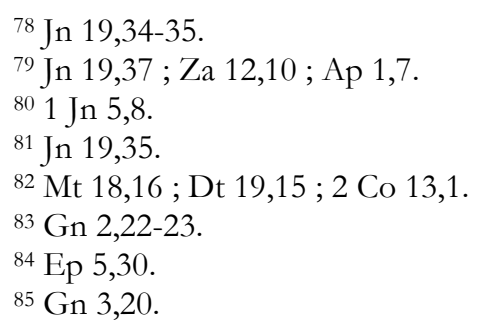


305 et ils seront deux en une seule chairr. Cela l'Apôtre l'a dit particulièrement pour le Christ et l'Église ; de fait, tandis qu'ils étaient deux, le Christ et l'Église furent rassemblés en une seule chair indissociable. En effet, le Fils de Dieu prit sur lui l'humanité tout entière de l'Église de laquelle il fut revêtu et il lui donna en 310 retour sa sainte chair afin de le recevoir dans la communion. Il dit en effet: Prenez et mangez, car ceci est mon corps; et une seconde fois : Prenez, et buvez, car ceci est mon sang ${ }^{87}$. Et de ce fait, ils sont deux en une seule chair incorruptible, en une divinité indicible, en une charité indissoluble, en une gloire insaisissable, en une unité 315 indivisible : voici donc l'amour, voici le baiser du Christ.

Comprends que le Saint-Esprit demandait d'embrasser l'Église ; en effet, en raison de l'attachement de cette dernière, ceux qui avaient jadis été ennemis furent reçus dans l'amour du Dieu clément. En raison de ce baiser, le Seigneur du ciel descendit 320 sur terre afin de transporter glorifiée au-dessus des cieux son Église établie sur terre; en raison de ce baiser, le Christ descendit dans la mort par la mort afin de ressusciter les membres de celleci qui étaient dans la mort et de l'offrir pure au Père ; en raison de ce baiser, les princes de l'apostasie, avalant ce qui les rendait 325 muets, se liquéfièrent dans la langueur de la confusion. Quant à nous qui étions jadis dans les ténèbres, un jour d'une lumière plus importante brilla pour nous ${ }^{88}$.

Qu'il m'embrasse - donc - des baisers de sa bouche : ce baiser et ces noces sont assurément étrangers à toutes les passions et pénétrés 330 d'une totale pureté. En effet, pour ceux qui se comportent bien, l'union ici-bas est beauté et les noces, honorables, mais dans la sainte Église du Christ, la virginité est meilleure que cela. L'Écriture dit en effet: Car je vous ai fiancés à un seul homme, comme une vierge pure à présenter au Christ ${ }^{89}$. Et aucune femme ne s'est 335 abstenue des multiples mariages comme celle-ci s'est préservée pure à l'écart des multiples dieux : la Synagogue des Israélites fait l'objet de toutes sortes de reproches, attaquée par les prophètes et trop souvent blâmée pour s'être débauchée avec des idoles, quant à celle-ci, pour s'assurer la pureté, elle possède les témoins de la 340 vérité qui sont morts pour elle et ont péri au nom de la foi. Comprenant donc que les noces assurément étrangères à la souillure de la chair et non tachées de l'impureté de la débauche participent à l'amour spirituel et garantissent les mystères éternels, elle a préparé les noces de l'époux céleste en se tenant pure loin 345 des péchés, noces certes invisibles aux yeux davantage corrompus de ces hommes, mais visibles pour les anges et pour ceux qui en furent dignes après la résurrection.

Ce n'est donc pas la diversité des tentures qui renforce l'extrême sublimité de cette chambre nuptiale, mais le haut du ciel

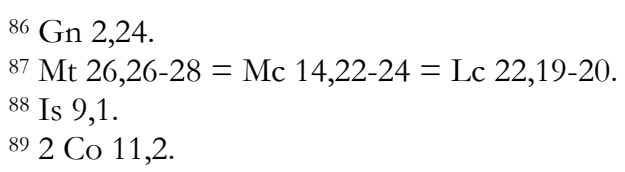


350 empli de gloire et les mystères des voiles ineffables. En effet, on dit: Le haut du ciel est au Seigneur, et il donna la terre aux fils des hommes $^{90}$. Et ces hymnes au grand époux ne sont pas chantés par un esprit terrestre ni par des désirs corporels, mais par centquarante-quatre-mille $^{91}$, selon l'Apocalypse de Jean, qui pourraient

355 être reconnus dignes de l'Église épouse. Et le Seigneur, ce grand époux, ne possède pas des appartements terrestres, mais des chambres célestes, afin que l'épouse dise avec joie: Le roi m'a introduite dans sa chambre ${ }^{92}$. Pour le Seigneur, le grand époux, et pour l'Église, la sainte épouse, ce n'est pas une communion d'un désir charnel, mais la pureté adoratrice de Dieu s'installe dans une intimité confiante entre les époux : si maintenant l'un de ceux qui demeurent dans cette Église vit son mariage avec une pureté parfaite, c'est une image et une figure des noces éternelles de cette gloire. Dans ces chambres nuptiales, ce ne sont pas des décors 365 variés réalisés par l'habileté des hommes, mais les voiles d'un mystère céleste et ineffable; pour cette épouse, on ne fabrique pas des aromates avec des fleurs et des arbres terrestres, mais ils sont faits de la beauté du paradis, appropriés aux festins des âmes saintes. Dans cette chambre nuptiale, les diadèmes ne sont pas en

370 feuilles de métal de faible agrément, mais c'est l'unique et immense couronne de l'incorruptibilité accordée par le Seigneur à ceux qui sont restés fidèlement en elle : en effet, celui qui restera jusqu'à la fin aura la couronne de cette gloire. Et l'abondance de cette gloire ne se trouve pas seulement sur la terre, mais au ciel et 375 sur la terre parce que son époux est le Seigneur du ciel et de la terre. Heureux ceux qui ont conservé sans souillure le vêtement de ces noces qu'est le baptême : sans aucun doute, avec l'époux et l'épouse, sous le regard du Père tout-puissant, ils se nourriront de ces délices ineffables et éternelles.

II. (v. 2) Car tes seins sont meilleurs que le vin.

Les deux seins, il faut les comprendre comme les deux Testaments : ils allaitent les fils de l'Église qui reçoivent à la fois par la langue et par l'esprit les paroles de vérité et croissent d'une vie et d'un âge parfaits. Cette boisson est meilleure que le vin : en 385 effet, elle n'est pas puisée de la terre, mais elle provient des cieux. On dit en effet: Que mon discours soit désiré comme la pluie et que mes paroles tombent comme la rosée $e^{33}$. Donc, ceux qui jouissent d'une contemplation divine provenant des Écritures sont allaités de cette boisson par la langue comme par l'esprit. Et, comme au plus 390 profond de leur ventre, ils la répandent dans leurs cœurs apaisés du trouble de la tristesse grâce à la pénitence et à la rémission de tous leurs péchés. En effet, le cœur ne se réjouira-t-il pas, quand bien même il semble avoir été avec excès accablé par le péché, s'il vient à se repentir et s'il écoute dans l'Ancien Testament le juge

395 dire : Moi, je suis celui qui détruit tes péchés et je ne m'en souviendrai pas

\footnotetext{
${ }^{90}$ Ps $113,16$.

${ }_{91}$ Ap 14,3.

${ }^{92} \mathrm{Ct} 1,4$.

${ }^{93}$ Dt 32,2.
} 
davantage $^{94}$ ? Et qui ne se réjouira pas lorsqu'il entendra dans le Nouveau Testament le Seigneur dire : Toute personne qui vient à moi, je ne la jetterai pas dehors ${ }^{95}$ ? Quiconque boira de ces seins spirituels ne recevra en aucune manière la nourriture de l'impiété et ne sera

400 pas enivré du vin des ennemis, mais son cœur sera rassasié d'un germe de justice. Car tes seins - dit-elle - sont meilleurs que le vin: en effet, de même que les deux seins sont tous deux attachés au cœur, ainsi aussi les deux Testaments proviennent de l'Esprit saint et nous procurent des dons spirituels. Ceux qui en boivent seront 405 enivrés à satiété d'une sagesse équilibrée pour ne plus devoir en aucune manière être sujets aux sollicitations terrestres, mais se laisser façonner par l'ardeur de l'esprit ${ }^{96}$ céleste. Et c'est inscrit, je pense, dans le livre de David : Comme il est excellent, ton breuvage qui m'enivre ${ }^{97}$. On a mis «excellent» pour désigner la puissance. En

410 effet, il ne détruit pas comme l'ivresse qui fait en sorte qu'aveuglé, quelqu'un s'écroule, mais il enrichit plutôt avec exaltation et fortifie, afin que personne ne s'écroule à terre, mais conserve une droiture inébranlable face à Dieu, comme le dit Jérémie dans l'Ancien Testament : Je suis devenu comme un bomme brisé et comme un 415 bumain accablé par le vin face au Seigneur et face à la beauté de sa gloire ${ }^{98}$. En effet, de même que ceux que l'ivresse brise ne semblent pas souffrir quand ils sont accablés - en effet, l'ivresse domine la douleur de l'accablement et le vin chasse la sensation de douleur , de même, le prophète totalement enivré de joie face à la gloire 420 du Seigneur n'endurait pas comme des atteintes les accablements causés par ses adversaires. En effet, l'allégresse donnée par la beauté du Seigneur dominait et la joie procurée par la gloire du Seigneur chassait les douleurs de son esprit. Telle est donc l'ivresse des saints, c'est l'ivresse de ceux qui partagent le repas 425 avec l'époux, c'est la coupe de la connaissance et de l'amour de Dieu. Également enivré de cette ivresse, le saint Apôtre considérait tout le reste comme un désavantage en raison de la supériorité de la connaissance de Dieu ${ }^{99}$; également enivrés de cette ivresse, les saints martyrs sentaient leur douleur allégée, enrichis 430 des dons de l'allégresse divine.

III. (v. 3) Et l'odeur de tes huiles est meilleure que tous les aromates.

Pour exhorter l'Église, le Saint-Esprit recourt à une telle mélodie adressée au Seigneur afin que nous, sentant cette odeur, rejetions complètement la mauvaise odeur des péchés infâmes et 435 tirions à nous la bonne odeur de la justice du Christ ${ }^{100}$. L'odeur - dit-elle - de tes huiles est meilleure que tous les aromates. L'huile, très chers frères, a été créée pour honorer les rois et les prêtres, nous l'avons appris des saintes Écritures. En effet, nous qui sommes très

\footnotetext{
${ }^{94}$ Is 43,25 ; Jr 31,34.

$95 \mathrm{Jn} 6,37$.

${ }_{96} \mathrm{Rm} 12,11$.

${ }_{97}$ Ps 22,5.

$98 \mathrm{Jr} 23,9$.

${ }_{99} \mathrm{Ph} 3,8$.

1002 Co 2,15.
} 
instruits n'ignorons pas, je l'estime, que selon les Écritures, les rois étaient institués à régner par l'onction, et c'est clair pour vous, je le pense, que les prêtres aussi exerçaient à cette époque leur sacerdoce après avoir reçu l'onction d'huile. Puisque, selon la loi, les prêtres ainsi que les rois recevaient l'onction d'huile, l'Écriture divine désigne donc déjà clairement le vêtement de la

445 royauté et du sacerdoce du Fils unique. L'odeur - dit-elle - de tes builes est meilleure que tous les aromates. C'est comme si elle disait: l'odeur de ton règne et de ton sacerdoce est meilleure que toutes les onctions, comme le dit aussi Daniel : Dieu bâtira un royaume qui surpassera tous les royaumes de la terre ${ }^{101}$. Voilà pourquoi elle dit:

450 L'odeur de tes builes est meilleure que tous les aromates, puisque l'huile, frères, en quelque lieu qu'elle soit, répand son odeur à droite comme à gauche. Embrassant donc tout ce qui est au ciel, sur terre et dans la mer, le Christ emplit son règne et sa domination en tous lieux d'un parfum de douceur. Le parfum de ce règne

455 surpasse tout règne : de fait, si Salomon, célébré comme grand roi par l'Écriture et couvert de présents par les rois, même après avoir reçu l'onction ne fut même pas revêtu de la gloire du lis selon la parole du Christ ${ }^{102}$, combien plus les autres rois sont-ils loin de l'honneur suprême du roi céleste ${ }^{103}$. En effet, comme est 460 plus important que la maison celui qui l'a fabriquée, ainsi le Christ est plus important que tous les rois terrestres, puisque c'est lui qui les a créés et qu'ils ont été créés par lui.

IIII. Ton nom est une buile répandue.

Emplie des mystères divins et secrets, l'Écriture révèle encore 465 ici clairement et très ouvertement le nom du grand roi en disant: Ton nom est une buile répandue.

V. C'est pourquoi les jeunes filles t'ont aimé, t'ont tiré en arrière.

En disant ton nom est une buile répandue, l'Écriture divine désigne le Christ lui-même, c'est-à-dire l'oint. En effet, l'huile répandue 470 signifie qu'elle sert pour l'onction: et de fait, l'huile sacerdotale est appelée onction et les rois antiques étaient institués au règne après avoir été oints d'huile. Quand donc elle dit: Ton nom est une buile répandue, elle désigne deux figures ${ }^{104}$. En effet, comme l'huile répandue parfume la maison, ainsi quand notre Seigneur Jésus-

475 Christ descendit sur terre et quand la puissance céleste vint sur les apôtres, le monde entier fut rempli de la bonne odeur de la piété, comme le proclame l'un d'eux, le très saint apôtre Paul : Nous sommes la bonne odeur du Christ parmi ceux qui sont sauvés et parmi ceux qui sont perdus : à coup sûr pour les uns c'est une odeur qui conduit de la 480 mort à la mort, mais pour les autres c'est une odeur qui conduit de la vie à la $v i e^{105}$. Ainsi, l'odeur elle-même de la douceur conduit assurément

\footnotetext{
${ }^{101}$ Dn 2,44.

102 Mt 6,29 = Lc 12,27

103 Mt 6,28-29 = Lc 12,26-27.

104 À la suite d'A. Ceresa-Gastaldo, on traduit modus par «figure», puisqu'il s'agit bien ici d'un cas d'interprétation figurative. Cf. Philonis Carpasii Commentarium in Canticum Canticorum, p. 213.

1052 Co 2,15-16.
} 
pour les uns à la mort, mais pour les autres à la vie : en effet, les apôtres étaient l'odeur de la mort pour leurs persécuteurs et ceux qui les tourmentaient et les attaquaient en justice, mais à l'inverse, l'odeur de la vie pour les fidèles et ceux qui méritaient de recevoir la prédication et manifestaient leur foi par des œuvres de justice. Ton nom est une buile répandue: par là, elle désigne aussi la figure prophétique de Marie qui, en brisant un vase d'huile, a oint notre Seigneur Jésus qui disait: Amen, amen je vous le dis: partout dans le monde où on proclamera cet évangile, on dira aussi en sa mémoire ce qu'elle a fait $^{106}$. Selon moi, elle désigne donc ces deux figures, cette Écriture divine qui dit: Ton nom est une huile répandue. C'est pourquoi les jeunes filles t'ont aimé. C'est comme si elle disait que ton règne et la présence incarnée ont rempli le monde entier d'une odeur de douceur comme une huile répandue.

C'est pourquoi les jeunes filles t'ont aimé, c'est-à-dire les âmes des fidèles: en effet, ne crois pas que la sainte Écriture désigne seulement des jeunes femmes, mais parmi les femmes on en trouve certes des jeunes non de corps, mais plutôt de foi. En

500 effet, on n'envisage pas seulement ce qui concerne le corps : La chair en effet n'est utile en rien, c'est l'esprit qui vivifie ${ }^{107}$. Parmi les jeunes filles, regarde donc cette jeune fille, certes fragile de corps, mais dont l'âme est fidèle et très courageuse, celle qui souffrait d'une perte de sang; lorsqu'elle toucha par derrière le vêtement

505 du Christ, son écoulement de sang s'arrêta soudain, non en raison de la force de son corps, mais grâce à la grande puissance de sa foi ${ }^{108}$. En effet, ce n'est pas en raison de la jeunesse de son corps, mais grâce à la sagesse déjà adulte de sa foi qu'elle a mis un terme à sa souffrance. Cette jeune fille l'a tiré en arrière en touchant par 510 derrière les franges de son vêtement, afin que, par là, fût accompli ce qui a été écrit : C'est pourquoi les jeunes filles t'ont aimé, t'ont tiré en arrière. Donc une autre jeune fille criait également après Jésus, c'est la Chananéenne de race syrophénicienne, jeune de foi, lorsque les disciples disaient: Renvoie-la parce qu'elle crie après nous ${ }^{109}$.

515 Et elle tirait en-arrière Jésus qui lui dit : Il n'est pas bon de prendre le pain des fils et de le jeter aux chiens ${ }^{110}$. Mais elle, adulte d'esprit mais encore adolescente de par la foi, disait: De toute façon, Seigneur, les petits chiens mangent aussi des miettes qui tombent de la table de leurs maîtres $^{111}$. Considère donc la jeunesse de la foi et la puissance de 520 l'humilité : ainsi donc ces deux jeunes femmes, c'est-à-dire celle qui souffrait d'une perte de sang et la Chananéenne de race syrophénicienne tirèrent toutes deux Jésus en arrière pour avoir part à sa puissance : l'une, qui était certes impure selon la loi, pour être purifiée par un don du Seigneur, et l'autre, qui était étrangère, 525 pour obtenir la guérison de sa fille. Avec une si grande énergie,

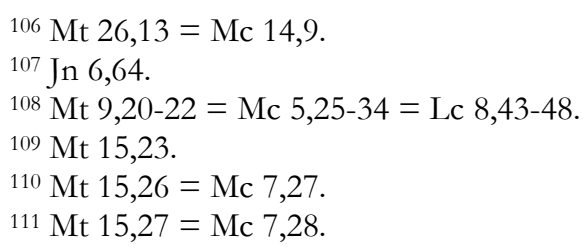


quand bien même elles étaient infirmes de corps, elles méritèrent quand même de puiser un remède à la source du Seigneur, car il semble qu'on a dit vrai à propos de la grande vigueur de leur foi : Lorsque je suis faible, alors je suis fort ${ }^{12}$. En effet, la faiblesse du corps montre fortement dans de telles situations la puissance de la foi.

C'est pourquoi les jeunes filles t'ont aimé: non seulement les femmes adultes guéries grâce à la sagesse de leur foi, mais aussi d'autres jeunes filles plus grandes et plus fortes que celles qui viennent d'être mentionnées et qui ont été guéries, c'est-à-dire les âmes des saints martyrs qui, soustraites au diable par leur sagesse pleinement adulte, pleines d'une sagesse durable et d'une puissance de résistance, ont livré leurs corps et, vêtues de la force inexpugnable et de la cuirasse invincible de la foi ${ }^{113}$, ont reçu la palme de la victoire, conservant la grande puissance de la foi et

540 parcourant rapidement le stade du combat en proclamant cette parole de l'Apôtre : J'ai achevé la course, j'ai gardé la foi : pour ce qui est du reste, elle m'est réservée, la couronne de justice que me donnera ce jour-là le Seigneur, juge juste, et non seulement à moi, mais aussi à tous ceux qui aiment sa venue ${ }^{114}$.

545 VI. (v. 4) Courons vers le parfum de tes huiles.

Une est l'Église et on dit au pluriel : Courons, parce que, quand bien même nous semblons être nombreux, nous sommes un dans le Christ. Vois tous ceux qui courent vers le parfum des huiles du Christ : en effet, là où gisent les reliques des martyrs, nous nous

550 hâtons d'accourir, parce que nous nous efforçons d'aller vers le parfum des huiles du Christ. Ensuite, se réjouissant déjà d'une multitude de fidèles, la mère Église, porteuse du Christ, se présente joyeuse face à son époux, se glorifie en lui et dit :

VII. Le roi m'a introduite dans sa chambre; exultons et réjouissons-nous en toi.

La chambre du roi est le lieu où sont cachés tous les trésors. En effet, la chambre du roi céleste est d'abord sans hésitation le corps qu'il a édifié pour lui, ensuite également le royaume des cieux puisque le Sauveur dit: Heureux ceux qui subissent la persécution pour la justice, car le royaume des cieux est à eux ${ }^{115}$. C'est donc avec justesse et raison qu'il a dit cette parole : en effet, ils sont entrés dans le royaume des cieux parce qu'ils ont subi la persécution pour la justice. Voilà pourquoi ils exultent en elle et disent dans leur joie : Exultons et réjouissons-nous en toi, car ils voient l'éternelle

565 grâce des noces préparées depuis l'origine du monde et reçoivent ce qui leur a été promis. Ensuite, ils ajoutent et disent:

VIII. Nous aimerons tes seins plus que le vin.

C'est-à-dire nous aimerons les deux Testaments par lesquels le roi nous a introduits dans la chambre céleste en nous instruisant.

570 C'est en effet par les deux Testaments que nous avons mérité le

\footnotetext{
1122 Co 12,10.

113 Ep 6,14-17.

$1142 \operatorname{Tm} 4,7-8$.

115 Mt 5,10.
} 
royaume céleste. Vois comment l'Ancien et le Nouveau Testaments encouragent ceux qui le veulent à souffrir pour la justice et pour le nom du Christ et à accéder à un chemin étroit et resserré ${ }^{116}$. Écoute dans l'Ancien Testament la sagesse dire : Lutte jusqu'à la mort pour la vérité ${ }^{117}$. Et tu trouveras le même enseignement dans le Nouveau; écoute le Seigneur lui-même dire dans les Évangiles : Ne craignez rien de ceux qui tuent le corps, mais ne peuvent blesser l'âme ${ }^{118}$. Ensuite de nouveau dans l'Ancien Testament : Écoutez. la parole du Seigneur, vous qui craignez sa parole; à

580 cause de cela, dites "Vous êtes nos frères» à ceux qui vous haïssent et vous rejettent ${ }^{119}$. Écoute encore dans le Nouveau Testament ce qui est dit de la bouche du Seigneur dans les Évangiles : Aimez vos ennemis. Et aussi : Faites du bien à ceux qui vous baïssent ${ }^{120}$. Écoute aussi ce qui est dit de la même façon dans la loi : Si tu passes devant le cheval de 585 ton ennemi qui s'est écroulé sous son fardeau, ne passe pas outre, mais relève$l e^{121}$. Qu'est-ce d'autre sinon cela: Faites du bien à ceux qui vous baïssent? En effet, un seul et même législateur est présent dans l'un et l'autre Testaments, voilà pourquoi on a appelé les deux Testaments les seins qui tirent le lait spirituel d'une unique source 590 intarissable. C'est pourquoi ceux qui sont entrés dans la chambre du roi disent : Nous aimerons tes seins plus que le vin. En effet, que fait le vin qui, lorsqu'on le boit sans mesure, apporte davantage de ténèbres? Mais les Testaments resplendissants réconfortent l'esprit, le fondent dans la foi et le fortifient vers les royaumes 595 célestes.

VIIII. La justice t'a aimé.

Tous les discours des divines Écritures sont certes justes, mais particulièrement celui sur la justice. La justice - dit-elle - t'a aimé : en effet, celui qui n'est pas juste ne pourra pas aimer le Fils 600 unique. La sagesse est en effet une abomination pour le pécheur ${ }^{122}$. Mais est juste celui qui s'abstient de tout mal, prend véritablement plaisir dans la loi de Dieu et s'applique de tout son cœur à aimer ses commandements, comme le dit aussi David: Dans le conseil et l'assemblée des justes, grandes sont les couvres du Seigneur ${ }^{123}$.

605 X. (v. 5) Je suis noire et belle, filles de Jérusalem.

Noire en raison des péchés, belle en raison de la pénitence. On ne pense pas ici à la teinte sombre du corps ni à la beauté physique de cette épouse, mais on la dit noire en raison des injustices, car c'est par elles qu'elle est devenue noire à cause de 610 l'idolâtrie et d'autres tromperies. Je suis noire et belle, filles de Jérusalem: elle appelle filles les âmes des prophètes et elle avoue ses péchés, mais elle resplendit dans la clémence de l'époux, parce

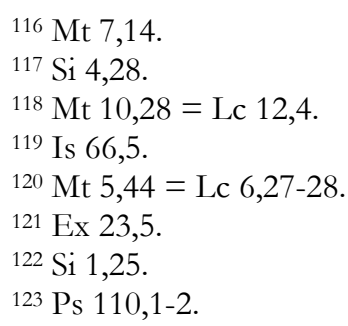


que la pénitence de ses péchés lui est donnée. C’est pourquoi regarde cette femme vraiment noire et belle : depuis le début, en commençant par l'eunuque éthiopien, elle a accueilli la prédication du Fils unique par l'intermédiaire de l'apôtre Philippe ${ }^{124}$. De cela, David dit aussi : L'Éthiopie se hâtera de tendre les mains $^{125}$.

XI. Comme les tentes de Qédar, comme les abris ${ }^{126}$ de Salomon.

620 Qédar signifie région des Ostraciniens ${ }^{127}$. Partout dans l'Écriture divine, on accuse les Qédarites d'idolâtrie, comme le dit aussi Jérémie: Traversez. les îles Chettim, envoyez quelqu'un à Qédar et regardez attentivement si de telles choses se sont produites, si les nations changent leurs dieux ${ }^{128}$. Puisqu'elle a donc commencé à se convertir 625 de la folie de ces idoles, elle dit ouvertement: Comme les tentes de Qédar et les abris de Salomon. Voici ce qu'elle dit à son propre sujet, pour montrer qu'elle est constituée des Juifs et des nations. En effet, ceux qui proviennent des nations, elle les assimile aux tentes de Qédar, et de la même façon, aux abris de Salomon, ceux parmi 630 les Juifs qui ont cru et tous ceux qui apaisent Dieu par le vêtement de la confession.

XII. (v. 6) Ne me regardez pas car je suis noircie, car le soleil m'a méprisée ${ }^{129}$.

C'est comme si elle disait : Ne désespérez pas de moi en raison

635 de la noirceur des fautes, parce que le Christ soleil de justice m'a méprisée. En effet, ce qu'elle disait ne relevait pas du sensible, mais c'était de ce soleil qu'elle parlait. De fait, elle ne dirait pas: Parce que le soleil m'a méprisée. En effet, ceux que ce soleil méprise ne sont pas noircis, mais au contraire, tandis qu'ils vivent à

640 l'ombre, ils sont rendus plus blancs. Quant à elle, vivant dans la folie des idoles avant de venir à la foi et méprisée par le soleil de justice, elle était noire jusqu'à ce que celui dont la beauté surpasse les

${ }^{124}$ Ac 8,26 sq.
${ }^{125}$ Ps 67,32 .
${ }_{126}$ Pellis, dont l'acception première est «peau », signifie également
». Cependant, nous avons décidé de le traduire ici par «abri », pour "tente ». Cependant, nous avons décidé de le traduire ici par «abri »,
éviter la redondance avec tabernaculum, que nous avons rendu par «tente ».

127 Nous avons choisi de traduire le terme Ostracini par « Ostraciniens », bien que nous n'ayons pas trouvé de trace de ce peuple dans les dictionnaires. En revanche, il existait une ville nommée Ostracine ou Ostracina (en grec

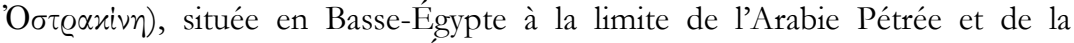
Palestine. Nous supposons qu'Épiphane a voulu faire allusion au peuple de ce lieu. Cf. "Ostracine", in A. ForCELLINI e.a., Lexicon totius Latinitatis, t. VI. Onomasticon. J-Z, Patavii, Typis seminarii, 1940, p. 401 ; "Ostracine», in F. GAFFIOT, Le Grand Gaffiot. Dictionnaire latin-français, Paris, Hachette, 2000, nouvelle éd. revue et augmentée sous la dir. de Pierre Flobert, p. 1112. D’après A. Ceresa-Gastaldo, on peut trouver une importante note sur Qédar et les Ostraciniens dans l'édition de P. F. Foggini. Cf. Philonis Carpasii Commentarium in Canticum Canticorum, p. 216.

$128 \mathrm{Jr} 2,10$.

129 À la suite d'A. Ceresa-Gastaldo, on traduit despexit avec le sens de "mépriser», comme Philon l'entendait également. Cf. Philonis Carpasii Commentarium in Canticum Canticorum, p. 217 (note XII, 1). 
fils des hommes ${ }^{130}$ vienne organiser son apparence en elle. David rend également grâce de sa personne en disant: C'est en effet un signe sur nous que la lumière de ton visage, Seigneur ${ }^{131}$, et ailleurs : L'éclat de notre Seigneur Dieu sera sur nous ${ }^{132}$.

XIII. Les fils de ma mère ont lutté en moi ${ }^{-133}$.

Par les fils de sa mère, c'est-à-dire du royaume céleste, elle veut dire les saints apôtres, afin de montrer plus clairement que la 650 bonne et grande lutte s'est développée grâce à l'inspiration de la paix et du zèle divin, c'est-à-dire celle accomplie par les heureux apôtres. Vois en effet ce que dit Paul : Devant tous j'ai dit à Pierre: Si toi qui es Juif, tu vis à la manière des nations et non de façon juive, comment forces-tu les nations à judaïser ? $^{134}$ C'est donc de cette véritable

655 lutte qu'ils ont lutté en elle, d'où elle dit: Les fils de ma mère ont lutté en moi.

XIIII. Ils m'ont établie comme gardienne dans les vignes.

La vigne se retrouve de nombreuses manières dans l'Écriture divine, mais il faut dire en bref ce qu'on trouve dans l'Évangile au 660 sujet de ceux qui ne rendaient pas de fruits à ceux qui leur avaient été envoyés. L'Écriture dit en effet: Le Seigneur viendra à la vigne, détruira misérablement ces misérables et remettra la vigne à d'autres vignerons qui lui feront produire ses fruits en leur temps ${ }^{135}$. Et le Seigneur confirmait cette parole en leur disant: Le royaume de Dieu vous sera $665 e^{e n l e v e ́} e^{136}$. Ensuite il dit de cette épouse - et il savait que cette épouse lui parlait dans le Cantique - : Il sera donné à la nation qui lui fera produire ses fruits $^{137}$. Les apôtres l'établirent donc comme gardienne dans cette vigne de la foi aux nombreux raisins. Ensuite la Synagogue des Juifs qui accourut de son côté vers l'Église dit ouvertement :

XV. Ma vigne, je ne l'ai pas gardée.

C'est-à-dire les choses qui m'ont été enseignées dans la loi, je ne les ai pas conservées afin d'obtenir la rémission des péchés au moyen de la confession.

675 XVI. (v. 7) Annonce-moi, toi que mon âme a aimé, où tu fais paître, ò̀ tu te reposes à midi.

130 Ps 44,3 .

131 Ps 4,7.

132 Ps 89,17 .

${ }^{133}$ Le texte latin est ambigu : Filii matris meae dimicauerunt in me peut aussi bien signifier « ils ont lutté pour moi » (les apôtres ont combattu pour défendre l'Église) que « ils ont lutté contre moi » (ainsi Paul avant sa conversion, comme le dit clairement Origène). Voir à ce sujet infra, p. 97, note 262. Pour éviter de réduire le sens du texte latin, bien que cela soit difficile à rendre en français, on traduit ici «ils ont lutté en moi». Cette expression évite ainsi d'orienter d'emblée le lecteur vers la compréhension en une «lutte positive » ou en une «lutte négative ».

134 Ga 2,14.

135 Mt 21,40-41 = Mc 12,9 = Lc 20,15-16.

136 Mt 21,43.

137 Mt 21,43. 
Auparavant dans le livre de David, elle dit cette parole: Je t'aimerai, Seigneur, ma puissance ${ }^{138}$. En effet, d'abord aimée par le Seigneur, elle mérita de l'aimer en retour comme le dit l'apôtre

680 Paul : Ce n'est pas parce que nous, nous l'avons aimé, mais parce que luimême nous a aimés et s'est lui-même livré pour nous ${ }^{139}$. Donc aimée, elle aime en retour et dit: Annonce-moi, toi que mon âme a aimé, où tu fais paitre, où tu te reposes à midi. Cela correspond à l'heure de la passion, quand depuis la sixième beure jusqu'à la neuvième les ténèbres se 685 répandirent ${ }^{140}$. Pour cette raison elle a dit: Où tu fais paître, où tu te reposes à midi. En effet, l'incendie des tentations aussi peut considérablement enflammer.

XVII. Afin de ne pas me perdre parmi les troupeaux de tes compagnons.

C'est-à-dire afin de ne pas me perdre parmi les hérésies juives.

690 À cela, il lui répond :

XVIII. (v. 8) Si tu ne te connais pas, belle parmi les femmes.

C'est-à-dire si tu ne sais pas comment tu étais et comment tu es devenue. En effet, on la dit bonne parmi les femmes parce que, parmi toutes les hérésies et les Synagogues, elle seule est belle, ne

695 tenant pas sa beauté d'elle-même, mais de celui dont la beauté surpasse les fils des hommes ${ }^{141}$. De fait, en façonnant en elle une beauté spéciale par le baptême de la régénération, le Fils unique la blâme d'une manière profitable en lui disant: Si tu ne te connais pas.

XVIIII. Toi, sors sur les traces des troupeaux et fais paître tes chevreaux.

En effet, si tu ne sais pas où tu étais auparavant et où tu es maintenant, si tu ne connais pas la beauté que tu as reçue de moi, sors dans les traces des troupeaux et fais paitre tes chevreaux. C'est un discours menaçant et une parole pleine de reproches : en effet, là

705 où se trouve l'ignorance, là aussi suit le reproche. En effet, parce qu'elle a dit au préalable: Afin de ne pas me perdre parmi les troupeaux de tes compagnons, alors il lui reproche comme d'un ton menaçant: Si tu ne connais pas la beauté que tu tiens de moi, sors de tes troupeaux et fais paître tes chevreaux, c'est-à-dire les âmes des pécheurs. En

710 effet, si tu ne connais pas la justice par la grâce que je t'ai moimême donnée, fais paître tes chevreaux.

XX. Dans les tentes des bergers.

C'est-à-dire dans les tentes des rois d'Israël selon la parole de l'Apôtre qui proclame: En effet, si ceux-là n'ont pas échappé, qui 715 rejetèrent celui qui leur a été annoncé sur terre ${ }^{142}$, et tout le reste.

XXI. (v. 9) À ma cavalerie aux chars de pharaon, je t'ai rendue semblable, ma chérie.

Par sa cavalerie, il veut dire la multitude des justes en raison de leur rapidité à embrasser la justice. Aux chars de pharaon, en effet,

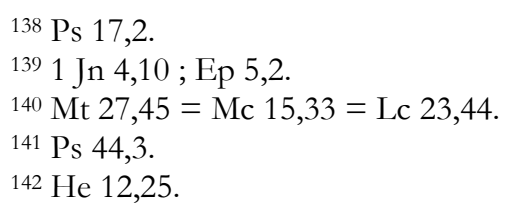


720 signifie que cette foule était un jour attelée aux chars du pharaon spirituel, lorsqu'elle était fouettée par lui dans la course de l'idolâtrie. Donc il dit: Je t'ai rendue semblable à ma cavalerie, alors que tu menais encore cette existence, en ne tenant pas compte des péchés que tu avais commis dans la folie de l'idolâtrie, 725 mais juste après le baptême de la régénération, je t’ai comparée à notre cavalerie. C'est-à-dire au troupeau des justes menant une course rapide dans le stade de la piété. De même, dans l'Évangile le Seigneur a donné à ceux qui ont travaillé une heure seulement un salaire semblable à ceux qui ont porté le fardeau de la journée 730 entière $^{143}$.

XXII. (v. 10) Que tes joues sont belles comme celles d'une tourterelle.

Cet animal a été consacré à la pureté car, même à l'état sauvage, il persiste cependant dans une seule union. De même, cette sainte Église, jadis sauvage, avait cependant le Christ comme 735 unique époux et mari qui lui parlait ainsi, comme le dit encore l'Apôtre: Je vous ai fiancés à un seul homme, le Christ, comme une vierge pure $^{144}$.

XXIII. Ta nuque est comme des cordons.

Il est frappant de constater comme la suite du discours - de 740 sens spirituel - confirme cette idée. En effet, après avoir comparé les nations à la tourterelle en raison de leur état sauvage, il introduisit ceux d'entre les Juifs qui ont cru. Après avoir dit: Tes joues sont comme celles d'une tourterelle, il a aussitôt ajouté : Ta nuque est comme des cordons, afin d'indiquer clairement ceux qui crurent parmi 745 les Juifs en mentionnant le cordon que Juda a donné à Thamar ${ }^{145}$. Il est notoire, en effet, que notre Seigneur Jésus-Christ est né de Juda ${ }^{146}$, selon l'Apôtre. Après avoir raconté son origine, l'époux lui donne aussitôt des parures. C'est pourquoi les apôtres poursuivent par ces paroles :

750 XXIIII. (v. 11) Nous réaliserons pour toi des représentations d'or avec des marques d'argent.

Les représentations d'or ne sont donc rien d'autre, à mon avis, que les saints martyrs de Dieu parce que, éprouvés par le feu, ils ont démontré l'éclat de leur foi. L'Écriture dit en effet: Comme l'or 755 fondu, il les a épronvés et comme les victimes d'un sacrifice, il les a accueillis $^{147}$. Mais afin de déduire qu'on parle de martyrs, vois ce qui suit: Avec des marques d'argent. Les marques, c'est évident, sont les martyrs qui ont supporté les coups de fouet et les tortures pour le Christ, comme en témoigne aussi Paul en disant: Moi je porte les 760 marques de Jésus dans mon $\operatorname{corps}^{148}$. Et le discours se poursuit ainsi :

XXV. (v. 12) Jusqu'à ce que le roi soit dans son lit.

\footnotetext{
143 Mt 20,1-16.

1442 Co $11,2$.

145 Gn 38,18.

${ }^{146} \mathrm{He} 7,14$.

$147 \mathrm{Sg} 3,6$.

148 Ga 6,17.
} 
C'est comme s'il disait : jusqu'à la régénération par le banquet nuptial, jusqu'alors ces représentations d'or sont réunies, c'est-àdire ceux qui non seulement souffrent pour la foi, mais encore, en temps de paix, courent par un chemin étroit et resserré $e^{149}$ et imitent par leurs actes les martyrs. Ensuite l'épouse répondit et dit :

XXVI. Mon nard a donné son parfum.

En effet, tandis que l'époux parlait des martyrs, l'épouse répond en lui adressant des remerciements et dit: Mon nard a 770 donné son parfum, c'est-à-dire toi, tu as réalisé ces actions bienveillantes envers moi. Par le nard, en effet, elle évoque le vase de parfum à propos duquel le Seigneur dit aussi : Arrêtez! Pourquoi êtes-vous désagréables avec cette femme? Elle a réalisé une bonne cuure à mon égard. En effet, en prenant ce parfum, elle l'a fait pour le jour de mon 775 ensevelissement ${ }^{150}$. Comme si elle adressait des remerciements, l'épouse dit donc: Toi, tu m'as donné le parfum de la douceur des martyrs. Le nard, en effet, a donné son parfum, c'est-à-dire ton martyre et ton agréable parfum ont invité les martyrs à souffrir pour toi parce que, le premier, tu as souffert pour nous. On voit 780 clairement par la suite la pertinence du propos.

XXVII. (v. 13) Mon bien-aimé est pour moi un bouquet de gouttes ${ }^{151}$.

Par goutte de myrrhe, elle évoque ainsi le sang et l'eau qui s'écoulèrent du côté de Jésus ${ }^{152}$. Mon bien-aimé - dit-elle - est pour moi un bouquet de gouttes. C'est comme si elle disait : avec l'eau et le 785 sang qui tombèrent goutte à goutte de son côté, lui-même devint mon époux et moi son épouse, avec le sang s'écoulant de son côté, avec lequel j'ai été rachetée par lui et rendue son égale, avec l'eau avec laquelle, issue de sa chair, j'ai été baptisée et glorifiée par lui, et avec l'Esprit avec lequel j’ai été unie totalement à sa 790 divinité ${ }^{153}$.

XXVIII. Au milieu de mes seins, il séjournera.

C'est-à-dire au milieu des deux Testaments, le témoignage de ces mystères séjournera. De l'Ancien, ce qui est rapporté dans le livre d'Isaïe: Comme une brebis, il a été conduit à l'assassinat ${ }^{154}$. Et 795 également du Nouveau, ce que Philippe interprète en rapport avec le Christ à un eunuque ${ }^{155}$.

XXVIIII. (v. 14) Mon bien-aimé est pour moi une grappe de henné ou de fleurs.

Elle appelle grappe de henné l'aspect humain lui-même du Fils 800 unique.

XXX. Dans les vignes d'Engaddi.

${ }^{149} \mathrm{Mt} 7,14$.

${ }^{150}$ Mt 26,10.12 = Mc 14,6.8.

151 Le terme latin gutta, comme le grec $\sigma \tau \alpha x \tau \dot{\eta}$ désigne une qualité particulière de myrrhe : la myrrhe en gouttes ou en larmes.

152 Jn 19,34.

1531 Jn $5,6-8$.

154 Is 53,7 ; Ac 8,32 .

155 Ac 8,26-40. 
Gaddi signifie "précepte ${ }^{156}$ ». En effet, lorsqu'une grappe exhale une odeur dans une vigne en fleurs, elle devient délectable pour ceux qui la regardent. De même, les fidèles du Christ qui ont saisi le début de la foi mais ne possèdent pas encore de fruit mûr, on les compare à une grappe en fleurs. Mais les nations qui ont cru au Christ l'ont vraiment acquise et l'Apôtre m'atteste cela en disant: Les élus l'ont acquise ${ }^{157}$, c'est-à-dire ceux qui ont été choisis parmi les nations et les Juifs. Et parce que l'époux est représenté 810 dans les baptisés, alors l'épouse dit en le louant: Mon bien-aimé est pour moi une grappe de henné ou de fleurs dans les églises. Dans les vignes d'Engaddi, c'est-à-dire en ceux qui ont obtenu l'immense don de cette foi. Il lui offre ensuite des éloges en retour et, charmé ${ }^{158}$ par sa beauté spirituelle, il lui dit :

815 XXXI. (v. 15) Vois comme tu es belle, ma compagne.

Par une double louange, il accroît sa beauté quand il dit pour la seconde fois : Vois comme tu es belle, ma compagne, afin de montrer qu'elle est belle non seulement à l'intérieur, mais aussi à l'extérieur. Elle l'est à l'intérieur par les entendements de la foi 820 venant du cœur, et à l'extérieur par l'honnêteté des yeux et l'accord des pas et de toutes les attitudes conformes à la justice. Vois dans ce qui suit que cela est vrai :

XXXII. Tu as les yeux d'une colombe.

Il ne parle pas simplement des yeux matériels d'une colombe, mais de l'Esprit saint qui descendit sur le Seigneur sous l'apparence d'une colombe ${ }^{159}$. En effet, il a admirablement comparé l'acuité visuelle de son intelligence à une colombe spirituelle. Ensuite, l'épouse dit à l'époux :

156 Nous traduisons ici la leçon du Vaticanus latinus 5704 : praeceptum, et non la correction d'A. Ceresa-Gastaldo : adeptio. Le texte grec de Philon porte

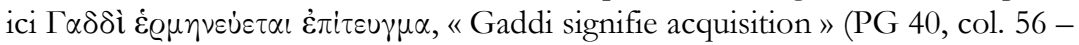

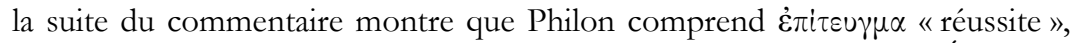
" succès» dans le sens plus précis d' "acquisition», "obtention»). Épiphane

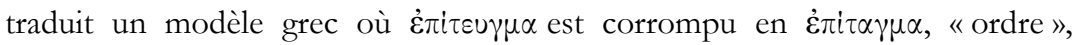
«commandement», qu'il rend par praeceptum. La faute ne pouvant s'expliquer qu'au niveau du grec, il n'y a pas lieu de corriger le texte latin d'Épiphane, même si son commentaire est incohérent (l'incohérence remonte à son modèle grec). Les Pères donnent habituellement à Engaddi le sens de « œil du bouc» ou « œil de l'épreuve ». Cf. Fr. WUTZ, Onomastica sacra. Untersuchungen zum Liber interpretationis nominum hebraicorum des Hl. Hieronymus (Texte und Untersuchungen, III/11 = 41), t. 1, Leipzig, J. C. Hinrichs, 1914, p. 292.548. On arrive au terme $\dot{\varepsilon} \pi i \tau \varepsilon u \gamma \mu \alpha$ en faisant dériver Gaddi du substantif gad qui, en hébreu, signifie «fortune », «chance », «bonheur» (cf. Gn 30,11, où l'anthroponyme Gad est expliqué à partir du substantif homonyme signifiant «bonheur»). Cf. «Gad», in O. ODELAIN et R. SÉGuINEAU, Dictionnaire des noms propres de la Bible, Paris, Cerf - Desclée De Brouwer, 1978, p. 142 ; É. LIPINSKI, «Gad », in P.-M. BOGAERT e. a., Dictionnaire encyclopédique de la Bible, Turnhout, Brepols, 2002, 3e éd. revue et augmentée, p. 524.

${ }^{157} \mathrm{Rm} 11,7$.

158 Le verbe mulcare n'a aucun sens ici. Il faut comprendre mulcere, confondu avec le premier.

159 Mt 3,16 = Mc 1,10 = Lc 3,22. 
XXXIII. (v. 16) Que tu es bon, mon bien-aimé, et que tu es beau!

830 Notre couche est ombragée.

Elle loue de nouveau de multiples manières la beauté de l'époux, comme si elle disait: beau dans les Évangiles, bon dans les prophètes et beau dans les apôtres. Beaux, en effet, sont les pieds de ceux qui prêchent la bonne nouvelle ${ }^{160}$ : bon dans le secours des biens

835 temporels et beau dans la promesse des biens éternels. Notre couche - dit-elle - est ombragée. En effet, quand nous nous inclinons vers la mort, désormais libérés du siècle présent, notre ombre s'élève alors davantage du feu spirituel, selon la parole du prophète : De ses épaules il t'a couvert d'ombre et sous ses ailes tu espéreras ${ }^{161}$. En

840 particulier dans le livre de David, l'Écriture dit : De fait, si je marche au milieu de l'ombre de la mort, je ne craindrai pas les maux, parce que tu es avec $m o i^{162}$.

XXXIIII. (v. 17) Les poutres de nos demeures sont des cèdres.

Observons le déroulement du discours. En effet, après avoir

845 dit: voici qu'il est bon dans les prophètes et beau dans les apôtres, elle dit: Les poutres de nos demeures sont des cèdres. C'est comme si elle disait que les prophètes sont les poutres des Églises. En effet, il a été écrit : Le juste fleurira comme un palmier, il se multipliera comme un cèdre du Liban ${ }^{163}$.

$850 \quad \mathrm{XXXV}$. Nos toits sont des cyprès.

Par eux, elle désigne les saints apôtres selon la parole d'Isaïe : Au lieu de l'épine ${ }^{164}$, le cyprès se lèvera ${ }^{165}$. Puisque donc les poutres sont disposées et cachées à l'intérieur des toits, les toits révèlent la beauté de la maison. Voilà pourquoi elle désigne d'abord les

855 prophètes par les poutres, ensuite, en raison du resplendissant équipement de l'Église conféré par les apôtres, elle dit: Nos toits sont des cyprès, de manière à interpréter cette parole de l'Apôtre: Dieu a placé en premier dans l'Église les apôtres, en second lieu les prophètes $^{166}$. Dans l'Église, en effet, les apôtres l'emportent en éclat 860 sur les prophètes car c'est par eux qu'elle a été appelée épouse. C'est pourquoi elle dit ensuite :

XXXVI. (v. 1) Moi je suis une fleur de la plaine et un lis des vallées.

${ }^{160} \mathrm{Rm} 10,15$; Is 52,7 .

${ }_{161}$ Ps 90,4 .

162 Ps $22,4$.

163 Ps 91,13 .

164 À la suite d'A. Ceresa-Gastaldo, on traduit le terme constipatio par « épine »-conformément à la citation biblique de Is 55,13 - bien que cet usage ne se retrouve pas dans les dictionnaires. Cf. Pbilonis Carpasii Commentarium in Canticum Canticorum, p. 223.

165 Is 55,13 .

1661 Co 12,28 . 


\section{Christologie et ecclésiologie}

\section{Une lecture ecclésiale du Cantique des Cantiques}

Comme mentionné au début de l'article, les Pères ont interprété spirituellement le Cantique dans deux directions complémentaires: ils ont développé d'une part une lecture ecclésiale du chant de Salomon, comprenant la relation entre l'Époux et l'Épouse comme celle entre le Christ et son Église ${ }^{167}$, d'autre part une lecture mystique a vu le jour, lecture selon laquelle l'échange entre les Bien-aimés représente le dialogue entre chaque âme chrétienne et le Verbe ${ }^{168}$. Dans le Commentaire sur le Cantique des Cantiques d'Épiphane le Scolastique, une lecture ecclésiale de cet épithalame est nettement décelable. En effet, dès la préface de l'œuvre, la présence d'une chambre nuptiale dans toute demeure est rappelée, chambre «dans laquelle l'épouse, se reposant avec l'époux, lui dit des secrets d'une intelligence plus élevée ». "Ainsi aussi dans les Cantiques des Cantiques », poursuit le commentaire, "la sainte épouse l'Église dit à son époux les paroles profondes des mystères de la foi ${ }^{169}$ ». Si le Christ n'est pas mentionné explicitement à cet endroit, le lecteur n'aura guère de difficulté à comprendre, dans la suite du commentaire, qu'il s'agit bien de l'union entre le Fils de Dieu et l'Église. Voilà pourquoi sera étudiée la manière dont d'une part le Christ et d'autre part l'Église ont été considérés dans le commentaire, afin de percevoir quelles étaient la christologie et l'ecclésiologie développées ${ }^{170}$. Puisque le Cantique des Cantiques rend compte de la relation entre le Bien-aimé et son Épouse, une place importante sera également accordée à l'union présentée, dans l'œuvre, entre le Fils de Dieu et son épouse, l'Église.

\section{La figure du Christ}

a. Terminologie employée par Épiphane

167 On peut notamment citer Origène. Voir à ce sujet la partie sur le Cantique des Cantiques du chapitre «The Church as the bride of Christ» dans F. LEDEGANG, Mysterium Ecclesiae. Images of the Church and its Members in Origen (Bibliotheca ephemeridum theologicarum Lovaniensium, 156), Leuven, Peeters, 2001, p. 146-163.

168 Cf. supra, p. 46.

169 Préface, 1. 79-83: «[...] thalamus, in quo sponsa cum sponso requiescens secreta altioris intellegentiae ei praeloquitur; sic et in canticis canticorum sancta sponsa ecclesia profunda sacramentorum fidei uerba proprio sponso $[\ldots]$ praeloquitur ».

${ }^{170}$ Comme précisé dans l'introduction, le commentaire d'Épiphane est ici étudié pour lui-même et ne fera pas l'objet d'une comparaison avec l'œuvre grecque de Philon de Carpasia. Quand il est question d'Épiphane, il s'agit donc du commentaire traduit en latin par ce dernier. 
Un moyen d'étudier la présentation du Christ faite par Épiphane est, tout d'abord, de relever les différents termes utilisés dans le commentaire pour désigner Jésus. Voici donc un tableau récapitulatif des divers mots ou expressions présents dans la préface et le premier chapitre de l'œuvre, ainsi que quelques observations.

\begin{tabular}{|c|c|c|}
\hline $\begin{array}{l}\text { Termes désignant le } \\
\text { Christ }^{171}\end{array}$ & Occurrences & Références \\
\hline Christus & 27 & $\begin{array}{l}\text { I, l. 205.231.253.258.280.285.289.291. } \\
297.306 .307 .315 .321 \text {; III, 1. } 453.458 . \\
460 \text {; V, 1. } 469.505 ; \text { VI, 1. 548.549.551; } \\
\text { VIII, 1. } 573 \text {; XXII, 1. } 734 \text {; XXIIII, 1. } \\
\text { 759; XXVIII, 1. } 796 \text {; XXX, 1. 804.807 }\end{array}$ \\
\hline Christus iustitiae sol & 1 & XII, 1. 635 \\
\hline Dominus & 16 & $\begin{array}{l}\text { I, l. 124.138.140.150.228.371.375; II, 1. } \\
\text { 397; III, 1. } 433 \text {; V, 1. } 527 \text {; VIII, 1. } 576 \text {; } \\
\text { XIIII, 1. } 663 \text {; XVI, 1. 679; XXI, 1. 728; } \\
\text { XXVI, 1. } 772 \text {; XXXII, 1. } 825\end{array}$ \\
\hline adjectif dominicus & 1 & VIII, 1. 582 \\
\hline caeli dominus & 1 & I, 1.319 \\
\hline Iesus & 7 & $\begin{array}{l}\text { I, 1. 264.269.272; V, l. 512.515.522; } \\
\text { XXVII, } 1.783\end{array}$ \\
\hline filius & 5 & I, l. 157.163.175.177.185 \\
\hline dei filius & 2 & I, 1.238 .308 \\
\hline filius sponsus & 1 & I, 1.210 \\
\hline unigenitus & 6 & $\begin{array}{l}\text { I, l. } 174 \text {; III, l. } 445 \text {; VIIII, l. 599-600; } \\
\text { X, 1. } 616 \text {; XVIII, 1. } 697 \text {; XXVIIII, } 1 . \\
\text { 799-800 }\end{array}$ \\
\hline verbum & 1 & I, 1.176 \\
\hline dei verbum & 1 & I, 1.236 \\
\hline dominus noster Iesus & 1 & V, 1. 488-489 \\
\hline dominus noster Iesus Christus & 2 & I, 1. $255 ; \mathrm{V}, 1.474-475$ \\
\hline sponsus caelestis & 2 & I, 1. 93.344 \\
\hline magnus sponsus & 1 & I, 1.352 \\
\hline dominus magnus sponsus & 2 & I, $1.355-356.358$ \\
\hline magnus rex & 1 & IIII, 1. 465 \\
\hline caelestis rex & 1 & VII, 1. 557 \\
\hline Saluator & 1 & VII, 1. 559 \\
\hline
\end{tabular}

171 On tient compte ici des termes propres à Épiphane, outre le mot sponsus désignant l'Époux du Cantique. Les citations bibliques utilisées dans le commentaire ne sont donc pas prises en considération. 
On le voit d'emblée, il est tout à fait à propos de parler d'une christologie présente dans le commentaire d'Épiphane, car le vocable le plus employé pour désigner le Fils de Dieu est le terme d'origine grecque Christus (" oint») avec 27 occurrences. L'étymologie du terme est d'ailleurs rappelée: «le Christ luimême, c'est-à-dire l'oint » (Christum eum id est unctum, V, 1. 469).

À l'inverse, le collaborateur de Cassiodore n'use que 7 fois du nom personnel d'origine hébraïque Iesus. Ce terme est utilisé dans le Commentaire sur le Cantique des Cantiques dans deux contextes particuliers: lors de la mort de Jésus sur la croix - Épiphane insiste alors sur l'eau et le sang qui s'écoulent du côté de Jésus (I, 1. 264.269.272 ; XXVII, 1. 783), et lorsque l'hémorroïsse et la syrophénicienne "tirèrent Jésus en arrière » (V, 1. 512.515.522). Remarquons le phénomène suivant: tandis que dans le Nouveau Testament le Fils de Dieu est plus souvent désigné par son nom hébreu (923 occurrences) que par son titre grec (540 occurrences) ${ }^{172}$, Épiphane parle davantage de lui en tant qu'oint, soulignant ainsi sa fonction. En effet, le nom de "Christ» se rapporte à la fonction du Fils de Dieu, tandis que le nom de "Jésus» se rapporte à sa personne. Les deux épisodes du commentaire d'Épiphane où il est question de "Jésus" concernent bien la personne du Fils de Dieu, son aspect humain pourrait-on dire; en revanche, dans la majorité des cas, on remarque le souhait de présenter la fonction que le Christ a reçue de son Père. Par ces quelques observations, on perçoit toute la légitimité d'analyser la christologie présente dans l'œuvre d'Épiphane ${ }^{173}$.

Outre ces deux vocables les plus courants pour le désigner, Jésus est également mentionné de nombreuses fois - 16 occurrences - par le titre dominus, auquel on peut rattacher l'adjectif dominicus. On remarquera encore les quelques cas où le Christ est indiqué par sa relation de fils (filius), et notamment de fils unique (unigenitus). Enfin, les autres termes ou expressions n'apparaissent qu'une ou deux fois dans la section étudiée de l'œuvre; Jésus y est présenté en tant que roi, époux, Verbe ou Sauveur, sans oublier l'expression consacrée «Notre Seigneur Jésus-Christ » (dominus noster Iesus Christus).

\section{b. La bouche du Père}

Dans le deuxième verset du Cantique (Qu'il m'embrasse des baisers de sa bouche, Ct 1,2), on peut voir l'Église demandant d'être embrassée par le Fils unique, comme le dit explicitement Épiphane (ipso unigenito osculari se orat ecclesia, I, 1. 173-174). C'est

172 "Jésus », in O. Odelain et R. Seguineau, Dictionnaire des noms propres de la Bible, p. 201-202.

173 Sur la christologie présente dans les commentaires du Cantique dans l'Église primitive, voir M. W. ELLIOTT, The Song of Songs and Christology. 
alors l'occasion de méditer quelque peu sur le nom de Verbe ${ }^{174}$ donné à Jésus : pour Épiphane, le Fils est la bouche de Dieu, voilà pourquoi on l'appelle Verbe, «puisque le Père exprime toutes ses volontés par l'intermédiaire du Fils ${ }^{175} »$.

\section{c. Incarnation et passion}

À deux reprises, Épiphane mentionne l'incarnation et la passion du Christ. Voici le premier extrait : De omni siquidem causa et dispensatione per quam Christus inbumanatus est atque passus [...] (I, l. 284-286). À la suite d'A. Ceresa-Gastaldo ${ }^{176}$, nous pourrions considérer causa et dispensatione comme un hendiadys, équivalant donc à causa dispensationis ("la cause de l'économie»). Une observation concernant le terme dispensatio utilisé dans le commentaire s'impose: employé dans la langue latine pour traduire le substantif grec oixovouia et traduit habituellement en français par «économie », il désigne le plan de Dieu sur le monde, le "dessein divin du salut et sa réalisation dans l'histoire", en particulier l'incarnation du Fils de Dieu et sa carrière terrestre ${ }^{177}$. Épiphane est donc soucieux de présenter à ses lecteurs ce plan divin (causa et dispensatio), dont l'élément principal est la venue du Fils dans la chair (Christus inhumanatus est) accompagnée de sa mission sur terre, mission qui trouve son achèvement dans la passion (atque passus) ${ }^{178}$.

Quelques lignes plus loin ${ }^{179}$, commentant toujours la demande de l'Épouse, "Qu'il m'embrasse des baisers de sa bouche » (Ct 1,2), Epiphane rappelle à nouveau l'incarnation et la passion du Christ en d'autres termes. En outre, la lecture ecclésiale du Cantique réalisée dans le commentaire est nettement perceptible, car ces deux actions du Fils de Dieu sont toutes orientées vers p. 93.

174 Sur la compréhension antique de cette appellation « Verbe », cf. infra,

175 I, 1. 174-177: « os enim dei est filius : unde etiam, cum deus sit, uerbum appellatur, quoniam omnia quaecumque uult per filium loquitur pater».

176 Philonis Carpasii Commentarium in Canticum Canticorum, p. 210 (voir la note de la ligne 155).

177 K. DuChatelez, «La notion d'économie et ses richesses théologiques », in Nouvelle Revue Théologique, 92 (1970), p. 267-292.

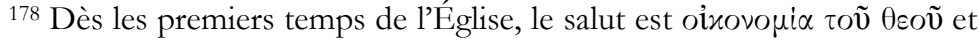
l'incarnation et la mort du Christ son perçues en rapport direct avec cet ordre divin du salut. Cf. K. Delahaye, Ecclesia Mater chez les Pères des trois premiers siècles. Pour un renouvellement de la Pastorale d'aujourd'bui (Unam Sanctam, 46), trad. de l'allemand par P. Vergriete et É. Bouis, Paris, Cerf, 1964, p. 134.138.

179 I, 1. 319-323: "propter hoc osculum caeli dominus in terram descendit, ut ecclesiam suam in terra constitutam glorificatam super caelos eueheret; propter hoc osculum morte descendit in mortem, ut eius membra quae erant in morte resuscitaret eamque patri integram Christus offerret »; «En raison de ce baiser, le Seigneur du ciel descendit sur terre afin de transporter glorifiée au-dessus des cieux son Église établie sur terre ; en raison de ce baiser, le Christ descendit dans la mort par la mort afin de ressusciter les membres de celle-ci qui étaient dans la mort et de l'offrir pure au Père ». 
l'Église. En effet, si le Christ a pris chair en descendant sur terre (caeli dominus in terram descendit), c'est - selon Épiphane - pour élever son Église dans les cieux (ut ecclesiam suam in terra constitutam glorificatam super caelos eneheret). Le collaborateur de Cassiodore nous fait percevoir un double mouvement grâce à l'emploi répété des termes terra et caelum : un mouvement descendant de la part du Christ, du caelum à la terra, et un mouvement ascendant pour l'Église, de la terra au caelum. Ainsi, nous fait remarquer Épiphane, le Sauveur s'est abaissé pour élever son épouse l'Eglise. Ensuite, par sa mort (morte descendit in mortem), le Fils de Dieu a permis la résurrection des membres de l'Église, ensuite offerte au Père (ut eius membra quae erant in morte resuscitaret eamque patri integram Christus offerret). Comme les mots caelum et terra pour l'incarnation, c'est ici le terme mors qui est répété.

En mentionnant ces deux événements majeurs de la vie du Christ - son incarnation et sa passion -, Épiphane reprend le thème de la kénose ${ }^{180}$, thème développé par les Pères à partir de $\mathrm{Ph}$ 2,7-8, où il est dit que le Christ Jésus s'est anéanti lui-même

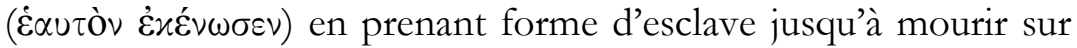
une croix ; il s'agit bien de l'incarnation et de la passion indiquées par Épiphane. En revanche, si l'Apôtre présente l'élévation du

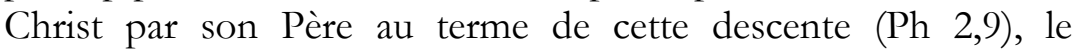
commentaire ne semble pas faire allusion à ce retour du Fils dans la gloire de Dieu; il met plutôt en évidence l'élévation de l'Église auprès du Père ${ }^{181}$ (ut ecclesiam suam in terra constitutam glorificatam super caelos eueheret, I, 1. 320-321; ut [...] eamque patri integram Christus offerret, I, 1. 323).

Dans son commentaire des versets 13 et 14, Épiphane rappelle cette incarnation de façon plus implicite en mettant en avant l'humanité du Christ ${ }^{182}$. En effet, bien qu'il utilise la plupart du temps le titre Christus, le collaborateur de Cassiodore signale

180 Origène développe également le thème de la kénose dans son Commentaire sur le Cantique des Cantiques. Voir J. CHENEverT, L'Église dans le commentaire d'Origène sur le Cantique des cantiques (Studia, 24), Bruxelles-ParisMontréal, Desclée De Brouwer-Bellarmin, 1969, p. 159-207 (chapitre intitulé «L’Église et le Verbe incarné »).

${ }^{181}$ Épiphane a déjà mentionné plus haut cette élévation de l'Église dans les cieux, auprès du Père et du Fils : «suscipiet autem te totam in caelo sponsus, cum aduenerit resurrectionem tibi conferre et omnia membra dormientia de uaginis propriis suscitare : tunc ad thalamos caelestes eueheris et cum filio sponso ipsoque omnipotenti patre ineffabiles epulas perenniter possidebis »; "Mais l'époux te prendra tout entière au ciel, lorsqu'il viendra t'apporter la résurrection et relever de leurs propres enveloppes tous tes membres endormis : alors tu seras emportée vers les chambres célestes et tu jouiras perpétuellement avec le Fils ton époux et le Père tout-puissant luimême de festins ineffables » (I, 1. 206-211).

${ }^{182}$ Contrairement à d'autres commentateurs anciens qui développent le thème de l'incarnation du Christ dans leur commentaire de Ct 1,12-14, Épiphane s'attarde sur cette notion, cela vient d'être vu, dans son paragraphe sur Ct 1,2. En Ct 1,13-14, il rappelle brièvement son humanité. Sur l'incarnation du Christ dans les commentaires anciens de Ct 1,12-14, voir M. W. ELLIOTT, The Song of Songs and Christology, p. 57-63. 
néanmoins cette humanité qu'il voit mentionnée dans la grappe de henné à laquelle la Bien-aimée compare son Époux (Botrum cypri ipsum characterem bumanum unigeniti nominauit, XXVIIII, 1. 799800), ainsi que dans l'eau et le sang s'écoulant de son côté ${ }^{183}$.

\section{d. Royauté et sacerdoce}

En s'attachant à commenter $\mathrm{Ct}$ 1,3 concernant l'odeur des huiles de l'Époux ${ }^{184}$, Épiphane met en avant les fonctions sacerdotale et royale du Christ. Comme vu précédemment, par cette mention fréquente du Fils de Dieu en tant qu'oint (Christus), le commentaire met l'accent sur la fonction de Jésus reçue par son Père $^{185}$. Néanmoins, tandis que le Christ a été consacré par une onction spirituelle pour être prophète, prêtre et roi ${ }^{186}$, il n'est fait mention, dans l'œuvre, que de ces deux dernières fonctions, avec une insistance sur la royauté. Épiphane signale la continuité entre l'ancienne alliance et Jésus. De fait, il rappelle tout d'abord l'usage de l'huile dans l'Ancien Testament, pour l'institution des rois et des prêtres ${ }^{187}$, et mentionne ensuite le «vêtement de la royauté et du sacerdoce du Fils unique » (indumentum regni et sacerdotii unigeniti, III, 1. 444-445). Le collaborateur de Cassiodore souligne alors davantage la fonction royale du Christ: il aime à rappeler sa domination en tous lieux, au ciel, sur terre et dans la mer (Christus igitur quae in caelo et in terra et in mari sunt cuncta complectens, regnum suum et dominationem ubique suanitatis odore complet, III, 1. 452-454). Le commentaire montre ensuite combien la royauté du Fils de Dieu surpasse toute autre royauté (buius regni odor super omne regnum est, III, 1. 454-455), combien le roi céleste l'emporte sur les rois terrestres (ceteri reges summo regis caelestis honore discreti sunt, III, 1. 458459 ; maior est Christus regum omnium terrenorum, III, 1. 460-461). Enfin, la dépendance des rois terrestres par rapport au Christ est soulignée (iste siquidem fecit eos, illi uero ab eo sunt facti, III, 1. 461462).

183 Cf. supra, p. 77.

184 Sur l'interprétation de ce verset dans l'Église primitive, voir M. W. ELLIOTT, The Song of Songs and Christology, p. 53-57.

185 Cf. supra, p. 77.

186 B. De Margerie, Le Christ des Pères : Prophète, Prêtre et Roi (Initiations aux Pères de l’Église), Paris, Cerf, 2000 ; A. M. SCHWEMER, «Jesus Christus als Prophet, König und Priester. Das munus triplex und die frühe Christologie », in M. Hengel - A. M. SCHWEMER, Der messianische Anspruch Jesu und die Anfänge der Christologie (Wissenschaftliche Untersuchungen zum Neuen Testament, 138), Tübingen, J.C.B. Mohr (Paul Siebeck), 2001, p. 165-230.

187 III, 1. 438-442: «Non enim nobis multisciis ignotum hoc iudico quoniam secundum scripturas reges per unctionem regnare constituebantur, sed etiam illud uobis clarum esse conspicio quoniam et tunc sacerdotes unguento uncti sacerdotio fungebantur»; "En effet, nous qui sommes très instruits n'ignorons pas, je l'estime, que selon les Écritures, les rois étaient institués à régner par l'onction, et c'est clair pour vous, je le pense, que les prêtres aussi exerçaient à cette époque leur sacerdoce après avoir reçu l'onction d'huile». 


\section{e. Le premier à aimer}

Autre trait de la personnalité du Sauveur qu'Épiphane se plait à mettre en évidence: son amour initial envers tous. En effet, le Christ nous a aimés le premier et, en raison de cet amour, il s'est livré pour nous, rappelle le commentaire (Non quia nos dileximus, sed quia ipse dilexit nos et tradidit semetipsum pro nobis, XVI, 1. 680681). Si la référence à saint Paul ${ }^{188}$ est explicitement mentionnée (sicut Paulus dicit apostolus, XVI, 1. 679-680), on ne trouve dans l'œuvre aucune trace de saint Jean chez qui l'idée est également formulée, comme l'a relevé A. Ceresa-Gastaldo ${ }^{189}$. Puisque le Fils de Dieu nous a aimés en premier, déduit Épiphane, l'Église se doit donc de l'aimer en retour (Ante enim dilecta haec a domino iterum meruit eum diligere, XVI, 1. 678-679 ; Dilecta igitur iterum diligit, XVI, 1. 681-682). De même, les martyrs sont invités à souffrir pour le Christ, puisque celui-ci, le premier, a donné sa vie pour nous (tuum martyrium et tuus bonus odor inuitanit martyres pati pro te, quoniam primus passus es pro nobis, XXVI, 1. 777-779). Dès le début du commentaire, cet amour du Fils de Dieu envers nous est mentionné, car, à deux reprises, Épiphane parle du Christ comme «le Seigneur qui nous a aimés» (dominum qui nos dilexit, I, 1. 124.138-139), expression que l'on peut à nouveau rattacher à saint Paul et à saint Jean ${ }^{190}$.

\section{La figure de l'Église}

a. Terminologie employée par Épiphane

De même que pour le Christ ${ }^{191}$, il convient tout d'abord, pour étudier la façon dont Épiphane présente l'Église, d'effectuer un relevé des différents termes présents dans le commentaire pour désigner l'ensemble des chrétiens, et d'en dégager quelques observations.

\begin{tabular}{|c|c|c|}
\hline $\begin{array}{c}\text { Termes désignant } \\
\text { l'Eglise }^{192}\end{array}$ & Occurrences & Références \\
\hline ecclesia & 22 & $\begin{array}{l}\text { I, 1. 150.172.183.222.253.258.273.290.292. } \\
\text { 297.300.306.307.309.317.362; II, 1. } 382 \text {; } \\
\text { III, 1. } 432 \text {; VI, 1. } 546 \text {; XIIII, 1. } 669 \text {; } \\
\text { XXXV, 1. } 856.859\end{array}$ \\
\hline sancta ecclesia & 1 & XXII, 1.734 \\
\hline
\end{tabular}

188 Cf. Ep 5,2.

77.

${ }^{189}$ Cf. 1 Jn 4,10. Philonis Carpasii Commentarium in Canticum Canticorum, p.

${ }^{190}$ Cf. Ep 5,2 ; Ap 1,5.

${ }^{191}$ Cf. supra, p. 75 sq.

192 On tient compte ici des termes propres à Épiphane, outre le mot sponsa désignant l'Épouse du Cantique. Les citations bibliques utilisées dans le commentaire ne sont donc pas prises en considération. 


\begin{tabular}{|l|c|l|}
\hline dei ecclesia & 1 & $\mathrm{I}, \mathrm{l} .220$ \\
\hline ecclesia sua [du Seigneur] & 1 & $\mathrm{I}, \mathrm{l} .320-321$ \\
\hline sancta Christi ecclesia & 1 & $\mathrm{I}, 1.331-332$ \\
\hline $\begin{array}{l}\text { sanctissima et ei [le Christ] } \\
\text { concorporata ecclesia }\end{array}$ & 1 & $\mathrm{I}, 1.256-257$ \\
\hline sponsa ecclesia & 1 & $\mathrm{I}, 1.355$ \\
\hline sancta sponsa ecclesia & 2 & Préface, $1.82 ; \mathrm{I}, 1.359$ \\
\hline christofora mater ecclesia & 1 & VI, l. 552 \\
\hline sponsa carissima & 1 & $\mathrm{I}, 1.93$ \\
\hline
\end{tabular}

Rien d'étonnant que le terme le plus employé - avec 23 occurrences - soit celui d'ecclesia. À l'exception de la formule sponsa carissima utilisée une seule fois, toutes les autres expressions dont fait usage Épiphane comportent le substantif ecclesia accompagné d'un qualificatif : l'Église y est dite sainte (sancta) et même très sainte (sanctissima), elle est comprise comme une épouse (sponsa), mais surtout elle est désignée dans sa relation à Dieu et au Christ (dei ecclesia, ecclesia sua [du Seigneur], sancta Christi ecclesia, ei [le Christ] concorporata ecclesia). Parmi les expressions soulignant le lien entre le Christ et l'Église, il faut encore mentionner celle de christofora mater ecclesia (VI, 1. 552) : l'Église est considérée comme une mère ${ }^{193}$, "porteuse du Christ», précise

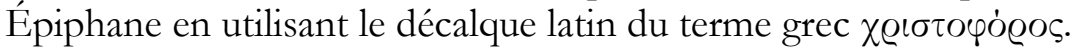
Signifiant qu'une personne est remplie ou inspirée par le Christ, cet adjectif est utilisé par les Pères pour qualifier les chrétiens en général ${ }^{194}$ ou encore certaines personnes spécialement inspirées telles que les apôtres et les martyrs ${ }^{195}$.

b. L’Église, les Juifs et les païens

À plusieurs reprises, Épiphane présente à ses lecteurs l'Église comme issue des Juifs et des gentes (ut ostendat quia et ex Iudaeis et ex gentibus constet, XI, 1. 627 ; qui ex gentibus et ex Iudaeis electi sunt, XXX, 1. 808-809). Voyons donc comment Épiphane conçoit l'Église à laquelle sont incorporés les Juifs et les Nations païennes ${ }^{196}$. Tout

193 La maternité de l'Église sera étudiée par la suite dans la section « Maternité et fécondité ». Cf. infra, p. 91 sq.

194 Selon Ignace d'Antioche et Irénée de Lyon, c'est la naissance du Christ dans le sein de l'Église qui a permis aux chrétiens de devenir «porteurs

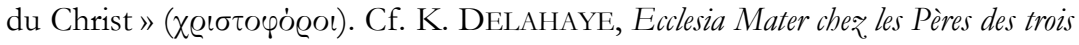
premiers siècles, p. 142.

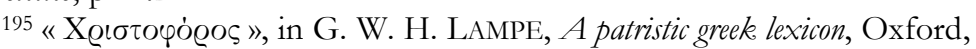
Clarendon Press, 1968, p. 1533.

196 On peut se demander si Épiphane ne s'est pas inspiré de saint Paul pour ses développements sur l'Église issue des Juifs et des nations. En effet, dans les chapitres 9 à 11 de l'épître aux Romains, l'Apôtre s'interroge sur le salut d'Israël et des païens. Pour un commentaire de ces trois chapitres de l'épitre aux Romains, voir M. THEOBALD, «Unterschiedliche Gottesbilder in Röm 9-11 ? Die Israel-Kapitel als Anfrage an die Einheit des theologischen 
d'abord qui est cette Église ? Dans leur commentaire du Cantique, « tant Hippolyte qu'Origène n'hésitent pas à identifier la Bienaimée, telle qu'elle s'exprime dans les premiers versets du poème, avec Israël, perçu comme l'Église de l'Ancien Testament ${ }^{197} »$. Chez le collaborateur de Cassiodore, cette identification semble également présente au début du commentaire. En effet, l'Épouse réclamant les baisers de son Bien-aimé (Ct 1,2) est, pour Épiphane, «l'Église avant son union avec le Seigneur» (ecclesia [...] antequam domino iungeretur, I, 1. 150). Une précision s'impose : cette demande n'est pas formulée par l'Église elle-même, mais par l'Esprit saint qui parle au nom de l'Église (sanctum spiritum pro ecclesia ex tunc praeinterpellantem, I, 1. 149-150). Ainsi, l'Église vétérotestamentaire refuse de se contenter des baisers des prophètes, mais elle veut être embrassée par le Fils de Dieu luimême, insiste à plusieurs reprises le commentaire ${ }^{198}$.

Si l'Église du début de l'œuvre est donc Israël attendant la venue du Christ, Épiphane semble néanmoins passer rapidement à une autre interprétation de l'Épouse du Cantique. De fait, dans ce même passage consacré au deuxième verset du chant de Salomon, il met dans la bouche de l'Église les mots suivants: « En effet, ma mère l'Église disait jadis : Je ne serai pas sauvée de façon médiocre, je rechercherai un médecin grand et parfait» (Mater enim mea ecclesia aliquando dicebat: - Pusillis non saluabor, magnum et perfectum medicum requiram, I, 1. 164-166). L'Église

Diskurses bei Paulus », in U. SCHNELLE (éd.), The Letter to the Romans (Bibliotheca ephemeridum theologicarum Lovaniensium, 226), Leuven, Peeters, 2009, p. 135-177.

197 J.-M. Auwers et W. Gallas, «Les Pères devant le Cantique des cantiques », p. 14. Sur l'Église de l'Ancien Testament dans le commentaire du Cantique d'Origène, voir J. CHENEVERT, L'Église dans le commentaire d'Origène, $\mathrm{p}$. 79-113 ; F. LEDEGANG, Mysterium Ecclesiae, p. 149-151.

${ }^{198}$ I, 1. 156-159: « hoc est filius, ac si diceret: - Osculari nolo ex ore solummodo prophetarum, sed ipse adpropinquet et osculetur me ab osculis oris sui »; «C'est-à-dire le Fils, comme si elle disait : Je ne veux pas être embrassée seulement par la bouche des prophètes, mais qu'il s'approche lui-même et qu'il m'embrasse des baisers de sa bouche»; I, 1. 161-164: "non uult enim per os solummodo prophetarum doceri, sed : - Ipse, inquit, filius adpropinquet et doceat me ab osculis oris sui »; "En effet, elle ne veut pas seulement être instruite par la bouche des prophètes, mais: Que le Fils lui-même, dit-elle, s'approche et m'instruise des baisers de sa bouche»; I, 1. 173-174: «ipso unigenito osculari se orat ecclesia »; «l'Eglise demande d'être embrassée par le Fils unique lui-même»; I, 1. 183-185: «dicebat ecclesia: Osculetur me, ac si diceret: non solum per prophetas, sed etiam per filium sicut et prophetas »; «l'Eglise disait: Qu'il m'embrasse, comme si elle disait: non seulement par les prophètes, mais aussi par le Fils comme aussi les prophètes ». De même, chez Origène, l'Épouse demandant d'être embrassée est «la Synagogue qui implore la venue du Messie » (J.-M. Auwers et W. GaLlas, «Les Pères devant le Cantique des cantiques ", p. 14) ; celle-ci refuse désormais d'entendre le Christ par l'intermédiaire des anges et des prophètes, mais elle désire entendre la propre voix du Fils de Dieu (F. LEDEGANG, Mysterium Ecclesiae, p. 151). Cf. Origène. Commentaire sur le Cantique des Cantiques (Sources Chrétiennes, 375), tome I, texte de la version latine de Rufin, introduction, trad. et notes par L. Brésard et H. Crouzel, avec la collaboration de M. Borret, Paris, Cerf, 1991, p. 180-183 $(\mathrm{I}, 1,7)$. 
qu'Épiphane fait ici parler semble être l'Église d'après la venue du Christ, et celle-ci mentionne sa mère l'Église, c'est-à-dire l'Église d'avant l'incarnation du Fils de Dieu, attendant «un médecin grand et parfait» qui n'est autre que Jésus. Un lien de parenté est ainsi décelable, dans le commentaire d'Épiphane, entre l'Église et la Synagogue ${ }^{199}$, un lien de mère à fille ${ }^{200}$. Tout au long du commentaire, cette filiation entre la Synagogue et l'Église ne cesse d'être présentée en opposant la mère et la fille. Ainsi, dès le début, Épiphane dépeint une Église de l'Ancien Testament indigne d'obtenir l'amour de Dieu, elle qui était « ennemie en raison de la folie des idoles », mais «elle s'efforce de restaurer l'entente», ce qui laisse déjà sous-entendre l'autre Église, celle du Christ ${ }^{201}$. Le collaborateur de Cassiodore met ainsi en avant la conversion et la pureté de l'Église contrastant avec la débauche d'Israël ${ }^{202}$.

L'Église - non plus celle de l'ancienne alliance, mais l'Église d'après l'incarnation du Christ - a été formée, selon Épiphane, à partir des païens (Antequam congregaretur a gentibus ecclesia, I, 1. 182183), conception également présente dans les homélies sur le Cantique d'Origène ${ }^{203}$. Mais, comme mentionné plus haut ${ }^{204}$, outre les "nations", les Juifs tiennent également une place importante parmi le peuple de la nouvelle alliance. Cette double origine de l'Église, Épiphane l'expose clairement en commentant le cinquième verset du Cantique, "Comme les tentes de Qédar, comme les abris de Salomon » : les tentes sont comprises comme les nations et les abris représentent les Juifs qui ont mis leur foi dans le Christ (Eos enim qui ex gentibus uenerunt tabernaculis Cedar adsimilat, pelles uero Salomonis similiter eos qui ex Iudaeis crediderunt, XI, 1. 627-630). Voilà justement ce qui fait la différence selon le commentaire: ne sont pas incorporés à l'Église tous les Juifs et tous les païens, mais bien ceux qui ont cru au Fils de Dieu, et Épiphane considère ceux-ci comme des élus (eos qui ex Indaeis collecti crediderunt, XXIII, 1. 742 ; eos qui ex Iudaeis crediderunt, XXIII,

199 Dans son commentaire du Cantique, Origène présente également la parenté de l'Église et de la Synagogue. On peut relever différents liens : l'Église est sœur de la Synagogue, ou bien elle a pour frère - ou encore pour père - le peuple juif. Cf. J. CHENEVERT, L'Église dans le commentaire d'Origène, p. 125-127.

200 Plus loin, c'est «le royaume céleste » qui est considéré comme la mère de l’Église (Filios matris suae, hoc est caelestis regni, XIII, 1. 648).

${ }^{201}$ I, 1. 152-156: «Vere enim nimis congruum erat ut tantum quaereret amoris diuini pignora quanto eius erat indigna: inimica namque facta fuerat propter idolorum uesaniam, et studet reparare concordiam ».

202 Cette opposition sera davantage analysée dans la section consacrée à la conversion de l'Église. Cf. infra, p. 85 sq.

203 «Ecclesia, quae haec loquitur, nos sumus de gentibus congregati»; «L'Église qui parle ainsi, c'est nous, qui avons été rassemblés de la gentilité », Origène. Homélies sur le Cantique des cantiques (Sources Chrétiennes, 37 bis), introduction, trad. et notes par O. Rousseau, Paris, Cerf, 2007, réimpression de la $2^{\mathrm{e}}$ éd. revue et corrigée, p. 112-113 (II, 3). Origène indique ici une Église issue uniquement des nations, tandis que, dans le reste de son œuvre - et en particulier dans son commentaire de l'Épître aux Romains -, il présente l'Église comme formée par les Juifs et les Gentils. Sur ce sujet, voir F. LEDEGANG, Mysterium Ecclesiae, p. 153-156.

${ }^{204}$ Cf. supra, p. 82. 
1. 744-745; qui ex gentibus crediderunt in Christum, XXX, 1. 806-807; qui ex gentibus et ex Indaeis electi sunt, XXX, 1. 808-809). Pour le collaborateur de Cassiodore, cette conversion au Christ ne se réalise pas d'un seul coup, mais il s'agit d'une progression, pourrait-on dire, dont la première étape est de percevoir «le début de la foi»; ces néophytes sont alors assimilés à "une grappe en fleurs » ne possédant pas encore " un fruit mûr » (sic et bi qui in Christum credentes initium fidei perceperunt, nondum maturum fructum babentes florenti botruo comparantur, XXX, 1. 804-806). Enfin, Épiphane rappelle encore la conversion de certains Juifs au christianisme en montrant une Synagogue courant vers l'Église (Indaeorum synagoga quae particulariter cucurrit ad ecclesiam, XIIII, 1. 669).

\section{c. Péchés et conversion}

Comme signalé dernièrement ${ }^{205}$, Épiphane oppose tout au long de son commentaire la Synagogue et l'Église. C'est alors l'occasion pour lui de développer le thème de la conversion. En effet, dès le début de l'œuvre, l'Église de l'ancienne alliance est considérée comme une ennemie en raison de « la folie des idoles» (inimica namque facta fuerat propter idolorum uesaniam, I, 1. 154-155) et, de ce fait, elle n'est pas digne de l'amour de Dieu (Vere enim nimis congruum erat ut tantum quaereret amoris diuini pignora quanto eius erat indigna, I, 1. 152-154). En revanche, dit Épiphane, cette Église a le désir de "restaurer l'entente » avec le Seigneur (et studet reparare concordiam, I, 1. 155-156). L'image négative accordée à Israël durant toute l'œuvre - les termes inimica et indigna en disent long - est donc déjà perceptible, mais en même temps se dessine également ce souhait de réconciliation avec Dieu qui sera, selon le commentaire, le propre de l'Église du Christ. Et de fait, un peu plus loin, ces ennemis de jadis sont désormais aimés de Dieu, et cela grâce à l'amour dont fait preuve l'Église (in buius [ecclesiae] enim dilectione illi qui aliquando fuerant inimici a clementi deo in caritate suscepti sunt, I, 1. 317-319). Observons dans cette phrase l'insistance sur la relation d'amour entre Dieu et son peuple : ceux qui sont hors de l'Église sont considérés comme des ennemis (inimici), tandis que l'Église montre son amour (dilectio) pour le Seigneur, lui qui entoure d'affection (caritas) les membres de celle-ci ${ }^{206}$. Ce développement peut se rattacher à la présentation faite par Épiphane du Christ en tant que premier à nous aimer ${ }^{207}$, ce qui laisse ainsi percevoir un mouvement de "va-et-vient amoureux » entre d'une part l'Église et d'autre part le Père et le Fils. En effet, comme vu précédemment, le Christ a aimé le premier et, en

205 Cf. supra, p. 84.

206 Épiphane utilise ici dilectio et caritas, termes qui, avec affectio, sont plus courants chez les chrétiens que le substantif amor. Cf. "Amor», in A. BLAISE, Dictionnaire latin-français des auteurs chrétiens, Turnhout, Brepols, 1954, revu spécialement pour le vocabulaire théologique par H. Chirat., p. 78.

207 Cf. supra, p. 81. 
retour, l'Église lui témoigne son amour. Ici, c'est en raison de l'amour dont fait preuve l'Église que Dieu aime son peuple.

Une analyse plus détaillée de cet état de péché de la Synagogue, ainsi que de la façon dont s'opère la conversion de l'Église est maintenant requise. Si Israël est critiqué - notamment par les prophètes - dit Épiphane, c'est en raison de «la débauche des idoles" (synagoga Israhelitarum omni nituperationi subiacet, a prophetis arguitur et propter fornicationem idolorum saepius increpatur, I, 1. 336-338). Quelques considérations sur le terme fornicatio s'imposent d'emblée : dans un sens typiquement chrétien, il signifie l'infidélité à Dieu ou l'idolâtrie, mais dans son acception première il s'agit de

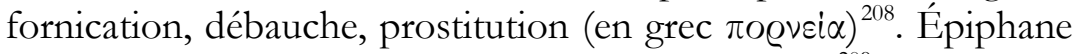
parait jouer ici sur les deux significations du $\operatorname{mot}^{209}$ : pour faire comprendre à ses lecteurs cette attitude du peuple de l'ancienne alliance se détournant du Seigneur (sens second), le collaborateur de Cassiodore présente une analogie avec les femmes contractant plusieurs mariages, attitude qu'Épiphane semble considérer comme de la débauche, de la prostitution ${ }^{210}$ (sens premier). En effet, les multiples unions d'une femme sont ici décriées, en opposition à l'Église rejetant les autres dieux pour se consacrer uniquement au Christ (Non itaque semetipsam se sic abstinuit mulier a multinubiis, sicut haec [ecclesia] mundam se custodinit a multis diis, I, l. 333-336). Le commentaire insiste alors sur la pureté de l'Église (mundam, I, 1. 336 ; munditiae, I, 1. 339), utilisant pour cela une citation de saint Paul ${ }^{211}$ (Desponsaui enim uos uni uiro uirginem mundam praesentare Christo, I, 1. 333-334). Que se cache-t-il derrière cette notion de virginité prônée par Épiphane (in sancta Christi ecclesia melior est uirginitas, I, 1. 331-332)? Outre la virginité physique, le terme virginitas peut également signifier la virginité morale, explique A. Blaise ${ }^{212}$ en poursuivant l'explication de la sorte : «qui ignore l'erreur, cf. fornicatio ». Épiphane semble bien aller dans ce sens : sa condamnation de la fornicatio vient d'être relevée, mais il faut encore mentionner l'opposition établie entre le charnel et le spirituel (Haec igitur audiens nuptias a pollutione quidem carnis extraneas et immaculatas fece libidinis, spiritalis autem caritatis esse participes, I, 1. 341-343). Cette virginité n'est donc pas une virginité physique, mais une disposition morale de l'Église «se tenant pure loin des péchés » (a peccatis mundam se continens sponsi caelestis nuptias comparanit, I, l. 344-345). Le commentaire développe ici un thème

208 «Fornicatio », in A. BLAISE, Dictionnaire latin-français, p. 361.

${ }^{209}$ Ce lien entre idolâtrie et prostitution ne semble pas être propre au commentaire, car, déjà dans l'Ancien Testament, l'alliance entre Yahvé et Israël est représentée par l'image du mariage, le culte des idoles étant considéré comme de la prostitution. Cf. K. Delahaye, Ecclesia Mater chez les Pères des trois premiers siècles, p. 53; F. LEDEGANG, Mysterium Ecclesiae, p. 139 (et particulièrement la note 68 ).

210 Dans l'expression propter fornicationem idolorum, il faut donc comprendre idolorum comme un génitif objectif ; c'est bien la Synagogue qui se prostitue, et non les idoles.

${ }^{211}$ Cf. 2 Co 11,2.

212 «Virginitas », in A. BLAISE, Dictionnaire latin-français, p. 850. 
d'une grande importance dans l'Église primitive: outre la qualité de mère - cet aspect sera abordé dans quelques instants ${ }^{213}-$, les premiers chrétiens tiennent également à considérer l'Église comme une vierge, seconde Ève devant se tenir à l'écart des hérésies et des schismes pour éviter d'être corrompue comme la première le fut par le serpent ${ }^{214}$. La virginité de l'Église peut, à première vue, sembler en opposition avec sa maternité et sa fécondité. Cependant, dans l'Antiquité, l'image de la femme - et celle-ci a été appliquée à l'Église - comprend tous les aspects de l'être féminin (vierge, flancée, épouse, mère et veuve); ces différents aspects ne s'opposent donc pas. Déjà chez saint Paul, l'Église est représentée par l'image de la femme vierge, épouse et mère ${ }^{215}$.

Voilà donc quel est ce grand péché de la Synagogue mis en évidence par Épiphane tout au long de son commentaire, à savoir celui de «forniquer» avec les idoles. Commentant Ct 1,5, le collaborateur de Cassiodore voit dans les tentes de Qédar et les abris de Salomon respectivement les nations et les Juifs ${ }^{216}$; ici encore, l'accusation d'idolâtrie est mise en avant (Vbique Cedarenenses in scriptura diuina de idololatria culpantur, XI, 1. 620-621). En revanche, ce péché semble ici imputé aux nations et non au peuple juif, les tentes de Qédar représentant pour Épiphane "ceux qui proviennent des nations" (Eos enim qui ex gentibus uenerunt tabernaculis Cedar adsimilat, XI, 1. 627-629). Quoi qu'il en soit, l'important est de montrer l'attitude de l'Église qui, à l'inverse d'Israël ou des païens, a rejeté ces idoles pour se convertir (ex idolorum illorum uesania conuerti coepit, XI, 1. 624-625). Même si le verbe coepi, construit avec un infinitif, a souvent un sens redondant - la traduction pourrait alors être, dans ce cas, « elle s'est convertie » plutôt qu'« elle a commencé à se convertir» - , nous serions tentée de garder cette notion de commencement, car, plus loin dans le commentaire, Épiphane semble suggérer, comme mentionné précédemment, une progression dans la conversion, celle-ci ne s'effectuant pas d'un seul coup et une fois pour toutes ${ }^{217}$. Le rejet des idoles pour « se tourner » vers le Christ - tel est bien le sens premier du verbe conuertor ${ }^{218}$-, voilà donc en quoi consiste la conversion de l'Église.

213 Cf. infra, p. 91 sq.

214 J. C. Plumpe, Mater ecclesia. An inquiry into the concept of the Church as mother in early christianity (The catholic university of America studies in christian antiquity, 5), Washington D. C., The catholic university of America press, 1943, p. 7-8. 52.62 .

${ }^{215}$ K. DelahaYe, Ecclesia Mater chez les Pères des trois premiers siècles, p.

${ }^{216}$ Cf. supra, p. 84.

${ }^{217}$ Le commentaire parle des « fidèles du Christ qui ont saisi le début de la foi » (bi qui in Christum credentes initium fidei perceperunt, XXX, 1. 804-805). Cf. supra, p. 85.

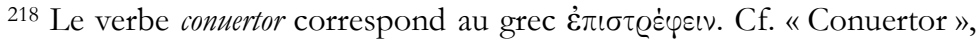
in A. BLAISE, Dictionnaire latin-français, p. 220. Sur la notion de « conversion » au début du christianisme (durant les trois premiers siècles), exprimée par les

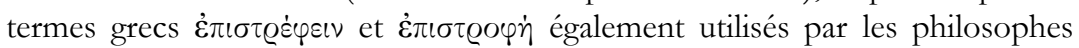


À la fin de ce paragraphe où est mentionné pour la première fois dans le commentaire le verbe conuertor dans ce sens précis de conversion $^{219}$, il est question de «tous ceux qui apaisent Dieu par le vêtement de la confession » (omnes per saccum confessionis placantes deum, XI, 1. 630-631). Par cette confession permettant d'obtenir la rémission des péchés (ut per confessionis modum remissionem impetret peccatorum, XV, 1. 673-674), l'Église peut donc être pardonnée de sa débauche avec les idoles pour se tourner vers le Christ. Outre la confession, Épiphane présente un autre élément qui a permis à l'Église de sortir de son état peccamineux: le baptême de la régénération ${ }^{220}$. En effet, l'opposition est soulignée entre l'état passé et l'état actuel de l'Église (Hoc est nisi cognoueris qualis fuisti et qualis facta sis, XVIII, 1. 692-693 ; Si enim non cognoueris ubi fuisti prius et ubi nunc es, XVIIII, 1. 701-702) qui est désormais belle. Cette beauté, elle ne la possède pas d'elle-même, mais le Christ la lui a donnée (haec sola pulchra est, non ex semetipsa pulchritudinem habens, sed ex specioso forma prae filiis hominum, XVIII, 1. 694-696; si non cognoueris pulchritudinem quam percepisti a me, XVIIII, 1. 702) par le baptême ${ }^{221}$ de la régénération (Nam figurando in ea propriam pulchritudinem unigenitus per lanacrum regenerationis [...], XVIII, 1. 696697). Un peu plus loin, le commentaire fait parler le Fils : celui-ci ne garde pas en mémoire les péchés commis par le peuple de Dieu lorsqu'il adorait les idoles, mais il insiste sur le baptême de la régénération reçu par l'Église (Talem te adbuc existentem equitatui meo assimilaui non reputans peccata quae in idololatriae fecisti uesania, sed continuo per lanacrum regenerationis nostro te equitatui comparaui, XXI, 1. 722-726). Pour le collaborateur de Cassiodore, l'Église est donc assurément meilleure qu'Israël ; "parmi toutes les hérésies et les Synagogues, elle seule est belle» dit-il (inter omnes haereses et synagogas haec sola pulchra est, XVIII, 1. 694). Le lecteur pourrait se demander quelles hérésies Épiphane a ici en tête, mais les quelques lignes précédentes peuvent l'éclairer. En effet, «les

païens, voir P. AUBIN, Le problème de la «conversion ». Étude sur un terme commun à l'hellénisme et au christianisme des trois premiers siècles (Théologie historique, 1), Paris, Beauchesne, 1963. Voir également sur ce sujet l'article plus récent : D. PRAET, «Explaining the Christianization of the Roman Empire. Older theories and recent developments», in Sacris erudiri, 33 (1992-1993), p. 5-119.

219 On retrouve déjà ce verbe en I, 1. 131 (bic amor eos conuersus in inimicitias accusabit), mais il est ici question d'un simple changement et non de conversion au sens strict.

${ }^{220}$ Dans son Commentaire sur le Cantique des Cantiques, Origène aborde également la question de la conversion qui se réalise par la confession de foi et la pénitence, deux éléments qui, d’après J. Chênevert, "réfèrent à la pratique baptismale ». Cf. J. CHENEVERT, L'Église dans le commentaire d'Origène, p. 142 (et plus largement les p. 141 à 147 pour le thème de la conversion). Sur le baptême de la régénération dans le commentaire d'Épiphane, voir également infra, p. 103 sq.

221 On pourrait s'étonner du fait suivant: le terme utilisé ici pour «baptême» est lanacrum, alors que baptisma et baptismus - transposant le grec $\beta \dot{\alpha} \pi \tau \iota \sigma \mu \alpha$ - l'ont emporté assez tôt sur lanacrum (mot populaire) et sur tinctio (utilisé dans la langue littéraire). Cf. « Baptisma », in A. BLAISE, Dictionnaire latinfrançais, p. 110. En fait, Épiphane utilise lauacrum pour traduire le terme $\lambda$ oṽ $\varrho o v$ du commentaire grec de Philon. 
troupeaux de tes compagnons » parmi lesquels l'Épouse craint de se perdre (Ct 1,7) sont interprétés comme les hérésies juives ${ }^{222}$ (Hoc est ne forte cum indaicis baeresibus efficiar operta, XVII, 1. 689). Une fois de plus, l'ancienne et la nouvelle alliance paraissent donc être opposées.

Cette thématique du péché et de la conversion de l'Église, Épiphane la met particulièrement en avant dans le commentaire des versets 5 et $6^{223}$ du premier chapitre du Cantique où la Bienaimée se dit «noire et belle ${ }^{224}$ " (Fusca sum et formosa, filiae Hierusalem, Ct 1,5), «noircie car le soleil l'a méprisée » (Ne videatis me quoniam ego sum infuscata, quia despexit me sol, Ct 1,6). Bien entendu, précise d'emblée le commentaire, il ne faut pas entendre cette noirceur ou cette beauté dans un sens physique (non est autem corporis fuscatio neque carnalis huius sponsae iterum putetur pulchritudo, X, 1. 606-608). Si l'Église est noire, c'est à cause de ses péchés de jadis ${ }^{225}$, mais elle est également belle grâce à la pénitence (Fusca propter peccata, formosa propter paenitentiam, X, 1. 606). Épiphane rappelle alors cet état peccamineux - dû à l'idolâtrie, mais également aux «autres tromperies» (fuscam eam dicit propter iniquitates, quoniam in ipsis erat fuscata per idololatriam ceterasque fallacias, $\mathrm{X}, 1.608-610$ ) - que l'Église ne cherche pas à cacher (confitetur quidem peccata, X, 1. 611-612). Celle-ci est ensuite rendue belle, «elle resplendit dans la clémence de l'époux» grâce à la "pénitence de ses péchés» (splendescit autem in sponsi clementia, quoniam ei datur paenitentia peccatorum, X, 1. 612-613). Le paragraphe se termine sur la mention de l'eunuque éthiopien à qui Philippe ${ }^{226}$ a annoncé la Bonne Nouvelle avant de le baptiser ${ }^{227}$ (dum inter ipsa

${ }^{222}$ L'adjectif indaicis, a fait remarquer A. Ceresa-Gastaldo, est un ajout

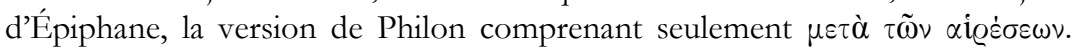
Cf. Philonis Carpasii Commentarium in Canticum Canticorum, p. 218 (note de la ligne 2 du paragraphe XVII).

223 Sur l'interprétation de ces versets dans l’Église primitive, voir M. W. ELLIOTT, The Song of Songs and Christology, p. 125-131.

224 Notons que la version du texte biblique utilisée par Épiphane (version revue par Jérôme avant la rédaction de la Vulgate et se basant sur les Hexaples d'Origène; cf. supra, p. 50) conserve la conjonction (fusca sum et formosa), tout comme la Septante et la Vetus Latina, tandis que d'autres versions dont la Vulgate introduisent une opposition (sed). Cf. G. GAETA, « Nera e bella. L'esegesi antica di Cantico 1,5-6», in Annali di storia dell'esegesi, 2 (1985), p. 116.

225 On retrouve également cette association entre couleur noire et péchés notamment chez saint Jérôme. Cf. J.-M. COURTES, "Traitement patristique de la thématique "éthiopienne" ", in J. DEVISSE, L'image du noir dans l'art occidental. II. Des premiers siècles chrétiens aux "grandes découvertes». 1. De la menace démoniaque à l'incarnation de la sainteté, Fribourg (Suisse), Office du Livre, 1979 , p. 26.

226 Contrairement à ce que dit Épiphane, il s'agit ici du diacre Philippe, un des sept collaborateurs des apôtres, et non de son homonyme appartenant au groupe des Douze. Cf. "Philippe", in O. OdELAIN et R. SEguineAU, Dictionnaire des noms propres de la Bible, p. 297 ; «Sept (Les) », in O. ODELAIN et R. SEguineau, Dictionnaire des noms propres de la Bible, p. 340. M. Giacomelli, note A. Ceresa-Gastaldo, avait déjà relevé cette erreur dans le commentaire grec de Philon de Carpasia. Cf. Philonis Carpasii Commentarium in Canticum Canticorum, p. 216. 227 Cf. Ac 8,26-40. 
principia ab eunucho Ethiope praedicationem suscepit unigeniti per Philippum apostolum, X, 1. 614-617). À l'endroit où le commentaire évoque la noirceur de l'Épouse - même si cette couleur ne doit pas être entendue dans un sens physique -, un personnage à la peau noire intervient néanmoins. Volonté délibérée ou simple coïncidence ? Selon J.-M. Courtès, les exégètes anciens ont porté leur attention sur ce passage néotestamentaire pour plusieurs raisons : nous avons affaire au premier baptême d'un non-Juif, à la seule mention d'un Éthiopien dans le Nouveau Testament, au « début absolu de l'évangélisation universelle ». Voilà pourquoi il intervient dans les doctrines baptismales et apostoliques ${ }^{228}$. Outre la simple similitude de couleur avec l'Épouse du Cantique, l'hypothèse suivante peut être émise quant à l'intervention de l'Éthiopien dans le commentaire : la présence des Gentils dans l'Église aurait voulu être mise une fois de plus en évidence, ainsi que l'importance du baptême qui vient juste d'être mentionnée ${ }^{229}$. Si Épiphane nous a offert ici une interprétation assez simple de la couleur de l'Épouse, il va entrer, deux paragraphes plus loin, dans une explication plus profonde de cette noirceur due aux péchés.

La Bien-aimée se dit « noircie car le soleil l'a méprisée » (ego sum infuscata, quia despexit me sol, Ct 1,6). À première vue, cette affirmation semble dénuée de sens, car les personnes non atteintes par le soleil ont habituellement la peau pâle et non colorée. Mais Épiphane éclaire son lecteur, comme il l'a déjà fait pour le verset $5^{230}$ : il s'agit de dépasser une compréhension sensible pour voir dans le soleil le «Christ soleil de justice » ([...] despexit me Christus iustitiae sol. Non enim erat sensibile quod dicebat, sed de isto erat sole quod loquebatur, XII, 1. 635-637) et ainsi comprendre ce «processus inverse ${ }^{231} »$ par rapport à celui du soleil visible. Le commentaire établit alors une nette distinction entre la teinte blanche des personnes vivant à l'ombre (non enim fuscantur quos despicit sol iste, sed magis, dum umbra pascuntur, candidiores fiunt, XII, 1. 638-640) et la teinte noire de l'Épouse - l'Église - vivant à l'écart du Christ (a iustitiae sole despecta fusca consistebat, XII, 1. 641-642). Une trace du principe herméneutique d'Épiphane est ici décelable: le collaborateur de Cassiodore refuse une interprétation purement charnelle, mais souhaite s'élever à une compréhension spirituelle de l'Écriture. Enfin, est encore soulignée l'opposition entre ancienne et nouvelle alliance : avant l'incarnation, l'Église vivait dans le péché en adorant les idoles (fuscationem delictorum, XII, 1. 635; in idolorum nesania ante fidem conuersata, XII, 1. 640-641), jusqu'à ce que le Fils de Dieu «vienne organiser son apparence en elle» (donec speciosus forma prae filiis

228 J.-M. COURTES, «Traitement patristique de la thématique "éthiopienne" », p. 20.

${ }^{229}$ Cf. supra, p. 88.

${ }^{230}$ X, 1. 606-608: « non est autem corporis fuscatio neque carnalis huius sponsae iterum putetur pulchritudo »; « on ne pense pas ici à la teinte sombre du corps ni à la beauté physique de cette épouse ».

231 J.-M. COURTES, "Traitement patristique de la thématique "éthiopienne" ", p. 15. 
hominum ueniens suam speciem in ea formaret, XII, 1. 642-643). L'interprétation de ce sixième verset du Cantique semble directement influencée par celle d'Origène dans son Commentaire sur le Cantique des Cantiques" ${ }^{232}$, commentaire contenant "un ensemble d'interprétations autour du thème de la négritude qui a servi de modèle à toute l'exégèse postérieure, aussi bien grecque que latine ${ }^{233} »$. En effet, l'Alexandrin met également en garde ses lecteurs contre une compréhension charnelle de ce passage : il ne s'agit pas de la noirceur du corps, mais de celle de l'âme ${ }^{234}$, et le soleil n'est autre que le Christ «Soleil de justice ${ }^{235}$ ", voilà pourquoi son effet est contraire à celui du soleil visible ${ }^{236}$. En revanche, Origène se base sur une explication quelque peu différente de l'action du soleil visible, opposant les personnes atteintes par les rayons droits et celles touchées par les rayons obliques $^{237}$.

\section{d. Maternité et fécondité}

Dans le Commentaire sur le Cantique des Cantiques, un portrait de l'Église en tant que mère (mater ecclesia, VI, 1. 552) est dressé, mère dont la fécondité est mise en avant (fecunditatem eius, I, 1. 231). Nous n'avons pas ici affaire à une conception isolée, car la notion de «Mère Église » s'est répandue assez tôt dans le christianisme primitif (dès le $\mathrm{II}^{\mathrm{e}}$ siècle). En effet, le fait de voir mentionnée dans les Écritures l'Église comme épouse du Christ a engendré l'idée

232 Sur l'interprétation de Ct 1,6 chez Origène, voir J. CHENEVERT, L'Église dans le commentaire d'Origène, p. 132-134 ; J.-M. COURTES, "Traitement patristique de la thématique "éthiopienne" », p. 14-15; G. GAETA, "Nera e bella », p. 117-118.119-120 ; J. C. KING, Origen on the Song of Songs as the Spirit of Scripture. The Bridegroom's Perfect Marriage-Song (Oxford Theological Monographs), Oxford, University Press, 2005, p. 87-89.

233 J.-M. COURTES, «Traitement patristique de la thématique "éthiopienne" », p. 14. Sur l'exégèse antique de Ct 1,5-6, voir l'article de G. GAETA, « Nera e bella ».

234 «In quo ostendit non de nigredine corporis fieri sermonem [...]. Contrarii uero ordinis est animae nigredo »; "Elle nous montre là qu'il n'est pas question de la noirceur du corps [...]. Mais d'un ordre contraire est la noirceur de l'âme », Origène. Commentaire sur le Cantique des Cantiques (SC, 375), p. 298-299 (II, 2, 2-3).

235 Origène. Commentaire sur le Cantique des Cantiques (SC, 375), p. 300-303 (II, 2, 5-9).

236 «Sol uero spiritalis, qui est sol iustitiae, in cuius pennis sanitas esse dicitur, e contrario [...]»; "Mais pour le Soleil spirituel, qui est "le Soleil de justice", dont on dit qu'il porte "la guérison sur ses ailes", c'est le contraire [...] », Origène. Commentaire sur le Cantique des Cantiques (SC, 375), p. 302-305 (II, $2,10)$.

237 «Sic ergo sol quidem iste visibilis ea corpora quibus a libramine summo insederit infuscat et urit, ea uero quae procul sunt et ab ista collibratione longius posita conseruat in candore suo nec omnino urit ea, sed illuminat »; "Ainsi donc, ce soleil visible certes brunit et brûle les corps qu'il domine de son apogée, tandis que ceux qui sont au loin et à une plus longue distance de ce rayonnement vertical, il les garde dans leur blancheur, ne les brûle pas du tout mais les illumine ", Origène. Commentaire sur le Cantique des Cantiques (SC, 375), p. 302-303 (II, 2, 10). 
de la maternité de celle-ci ${ }^{238}$. En outre, déjà dans l'Ancien Testament, Jérusalem et Israël étaient considérés comme une mère ${ }^{239}$. Dès le début du commentaire d'Épiphane, plusieurs personnages de l'ancienne alliance sont présentés comme des préfigurations de l'Église ${ }^{240}$. Parmi ceux-ci, on retrouve Abel, lui qui a réalisé des offrandes de moutons pour le Seigneur (in oblationibus ouium, I, 1. 191). C'est alors l'occasion de mettre en avant la maternité de l'Église : comme Abel a offert des moutons à Dieu, celle-ci lui a offert ses fils, des "moutons doués de raison » (hanc rationales oues domino id est suos filios offerentem, I, 1. 192193). Les fils de l'Église, ce sont les fidèles, c'est-à-dire les chrétiens, dont la multitude fait la joie ${ }^{241}$ de la mère (gaudens multitudine fidelium, VI, 1. 551-552). Mais, notons-le, le grand nombre des fils n'enlève rien à l'unité de l'Église. De fait, même si les chrétiens s'expriment au pluriel en raison de leur nombre, précise Épiphane, ils sont « un dans le Christ »; l'Église est donc bien " une » (Vna est ecclesia et pluraliter ait : Curremus, quia licet multi esse videamur, unum tamen sumus in Christo, VI, 1. 546-548). Ce thème de l'unité de l'Église n'est pas propre au commentaire; dès la seconde moitié du $\mathrm{II}^{\mathrm{e}}$ siècle et la première moitié du $\mathrm{III}^{\mathrm{e}}$ siècle, les

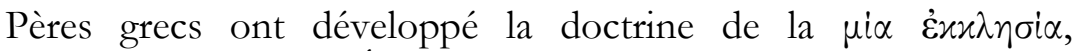
concevant ainsi l'Église universelle comme une unité, contrairement aux diverses sectes philosophiques ${ }^{242}$. L'Église primitive a d'ailleurs lutté contre les hérétiques et les schismatiques pour conserver cette unitée ${ }^{243}$. Parmi ces Pères grecs,

238 J. C. Plumpe, Mater ecclesia, p. 5.16-17.124 ; F. LeDEGANG, Mysterium Ecclesiae, p. 216. Sur l'origine du concept de mater ecclesia et son développement chez les Pères, voir K. DelahaYE, Ecclesia Mater chez les Pères des trois premiers siècles; J. C. PlumPe, Mater ecclesia. Sur l'Église en tant que mère chez Origène, voir F. LEDEGANG, Mysterium Ecclesiae, p. 203-218.

${ }^{239}$ K. Delahaye, Ecclesia Mater chez les Pères des trois premiers siècles, p. 55 ; J. C. Plumpe, Mater ecclesia, p. 1-3 ; F. LeDegAng, Mysterium Ecclesiae, p. 208. Sur la maternité de Jérusalem - aussi bien la Jérusalem céleste que la terrestre développée par Origène, voir F. LEDEGANG, Mysterium Ecclesiae, p. 203-206.

240 On peut relever évidemment l'Épouse du Cantique, mais aussi Abel, Énoch, Noé et Ève.

${ }^{241}$ Le thème de la joie de la mère Église causée par ses enfants se retrouve également chez Origène. Voir à ce sujet F. LEDEGANG, Mysterium Ecclesiae, p. 213-214.

242 J. DANIELOU, « MIA'EKK $\Lambda$ ' $\Sigma$ IA chez les Pères grecs des premiers siècles ", in 1054-1954. L'Église et les Églises. Neuf siècles de douloureuse séparation entre l'Orient et l'Occident. Études et travaux sur l'Unité chrétienne offerts à Dom Lambert Beauduin, vol. I (Irénikon), Paris, Éditions de Chevetogne, 1954, p. 129-130. Sur l'unité de l'Église, à défaut d'une synthèse récente, on lira avec intérêt: Y. CONGAR, L'Église, une, sainte, catholique et apostolique (Mysterium salutis. Dogmatique de l'histoire du salut, 15), Paris, Cerf, 1970, p. 13-121.

243 A. Birmele, "Unité de l'Église », in J.-Y. LACOste (éd.), Dictionnaire critique de théologie (Quadrige / Dicos Poche), Paris, Presses Universitaires de France, 2007, $3^{\text {e }}$ éd. revue et augmentée par O. Riaudel et J.-Y. Lacoste, p. 1458. Il semblerait à propos de rapprocher le thème de la virginité de l'Église et celui de son unité, tous deux évoqués par Épiphane. En effet, par ces deux concepts, la volonté de conserver l'Église à l'écart des schismes et des hérésies est mise en avant. Cf. supra, p. 87. 
on peut citer Origène dont le Commentaire sur le Cantique des Cantiques rend également compte de cette doctrine ${ }^{244}$.

Cette fécondité de l'Église doit être davantage examinée car, selon le collaborateur de Cassiodore, il ne s'agit pas d'une fécondité de tout temps; ici encore, ce sera l'occasion d'une opposition entre la Synagogue et l'Église. D'après Épiphane, l'Église de jadis - c'est-à-dire de l'ancienne alliance - a été mise de côté en raison de la "perversité des dogmes impies ${ }^{245}$ ", voilà pourquoi elle était stérile (Sterilis enim erat haec aliquando nec penitus dei concipiens uerbum; deserta autem quia sicut spinis peruersitate et dogmatibus impiis pullulabat, I, 1. 235-238). Considérons la proposition nec penitus dei concipiens uerbum: il peut être tentant de traduire simplement « elle ne comprenait pas du tout la Parole de Dieu », mais il semble possible d'entendre cette phrase d'une seconde manière. En effet, outre «saisir par l'intelligence, comprendre ", le verbe concipio peut également signifier « recevoir la fécondation, concevoir»; puisqu'il est ici question de la fécondité de l'Église - l'Église de l'Ancien Testament est considérée comme stérile -, nous serions d'avis de prendre en considération cette seconde signification du verbe. Dans ce cas, «concevoir la Parole de Dieu » n'aurait guère de sens, mais il s'agirait du Christ, le Verbe de Dieu, qu'Épiphane a déjà nommé de cette manière un peu plus haut $(\mathrm{I}, 1.176)$. Mais le collaborateur de Cassiodore aurait-il pu dire cela? Aurait-il pu considérer l'Église comme la mère du Christ? Cette conception ne semble pas improbable. En effet, au début de la chrétienté, l'Église n'a pas été vue uniquement comme l'épouse du Christ telle que la présentait l'Apocalypse, mais elle a également été considérée comme sa mère et appelée par ce titre ${ }^{246}$. En réalité, il ne faut pas opposer d'une façon si nette les deux significations du terme uerbum. Dans le Nouveau Testament et dans la Patristique primitive, le mot $\lambda \dot{o} \gamma o \varsigma$ - dont uerbum est la traduction latine possède une double signification : il s'agit à la fois de la Parole de prédication (uerbum praedicationis) et de Jésus-Christ, Verbe fait chair (uerbum incarnationis). Ainsi, les deux significations sont étroitement liées ${ }^{247}$. Dans le Commentaire sur le Cantique des Cantiques, ce double sens est peut-être également présent; il faudrait donc, dans ce cas, éviter de le réduire. Quoi qu'il en soit,

244 Dans son Commentaire sur le Cantique des Cantiques, l'Alexandrin présente l'unité de l'Église malgré les nombreuses assemblées répandues dans le monde entier. Cette unité est double; elle «résulte de la diversité fonctionnelle et de la variété qualitative au sein des membres». Cf. J. CheneVERT, L'Église dans le commentaire d'Origène, p. 224-227. Sur le thème de l'unité de l'Église dans d'autres œuvres d'Origène, voir F. LEDEGANG, Mysterium Ecclesiae, p. 77-84.665-670.

245 À la suite d'A. Ceresa-Gastaldo, nous considérons peruersitate et dogmatibus impiis comme un hendiadys. Cf. Philonis Carpasii Commentarium in Canticum Canticorum, p. 209 (note de la ligne 115).

246 J. C. Plumpe, Mater ecclesia, p. 4.

${ }^{247}$ K. Delahaye, Ecclesia Mater chez les Pères des trois premiers siècles, p. 141. 
l'opposition entre la Synagogue et l'Église est une fois de plus soulignée : tandis que la première était stérile, la seconde a donné naissance à de nombreux fils, "même plus que la Synagogue d'Israël » précise Épiphane (multitudinem ei genuit filiorum, et ultra synagogam Israhel, I, 1. 241-242). Ce passage de la stérilité à la fécondité s'effectue parallèlement au passage de l'ancienne à la nouvelle alliance : parce que le Christ a souffert pour elle, l'Église a pu enfanter (Dei uero filio pro ea nunc passo, I, 1. 238-239); elle tire sa fécondité du Fils de Dieu (fecunditatem eius de Christo, I, 1. 231). Loin d'être le seul ${ }^{248}$, Épiphane perçoit déjà une annonce de la fertilité de l'Église chez Isaie qu'il cite ici pour appuyer son $\operatorname{argumentation}^{249}$.

Deux éléments développés dans cette thématique de la maternité et de la fécondité de l'Église doivent encore être mentionnés. D'abord, Épiphane considère la manière dont sont nourris les fils de cette mère qu'est l'Église. Se situant dans la lignée d'Hippolyte ${ }^{250}$, le collaborateur de Cassiodore voit dans les seins de la Bien-aimée ainsi que dans ceux du Bien-aimé évoqués à plusieurs reprises dans le Cantique - une préfiguration des deux Testaments ${ }^{251}$. Comme les seins nourrissent les petits enfants de lait, les deux seins du Cantique - c'est-à-dire l'Ancien et le Nouveau Testament - nourrissent les fils de l'Église de lait

${ }^{248}$ Les Pères primitifs ont très souvent appliqué le passage d'Is 54,1-7 à l'Église. Cf. K. Delahaye, Ecclesia Mater chez les Pères des trois premiers siècles, p. 55.

249 I, 1. 230-235: «Vicinus autem testis est nobis de his magnus Isaias, qui fecunditatem eius de Christo prophetauit dicens : In morte traditus est et inter iniquos deputatus et ipse peccata multorum portanit et propter peccata eorum traditus est. Laetare, sterilis quae non pariebas; erumpe uocem, clama, quae non concipiebas, quia multi filii potius desertae quam habentis nirum», "Et, proche de nous, il y a un témoin à ce sujet, le grand Isaïe qui prédit sa fécondité à partir du Christ en disant : Il fut livré à la mort et compté parmi les injustes, il porta les péchés de beaucoup et fut livré pour leurs péchés. Réjouis-toi, stérile qui n'enfantais pas; élève la voix, crie, toi qui ne concevais pas, car plus nombreux sont les fils de la délaissée que ceux de l'épouse». Cf. Is 53,1254,1 .

${ }^{250}$ La tradition d'interpréter les deux seins comme les deux Testaments remonte à Hippolyte. Cf. P. MELONI, Il profumo dell'immortalità, p. 299.

251 Il n'est pas rare que les exégètes anciens voient dans les membres doubles les deux Testaments ou deux alliances. Épiphane interprète de la même façon les narines de l'Épouse (Ct 7,5) : il voit dans les narines de l'Église «l'apôtre Paul aspirant le souffle vivifiant de l'un et l'autre testament pour le transmettre au corps entier» (Nares sponsae tropice sanctum Paulum designant apostolum, quoniam duorum testamentorum respiramenta ipse ei contradidit; nares enim duobus riuulis spiritum adtrabentibus uitam largiri probantur hominibus: similiter et sanctus Paulus tamquam duabus naribus ueteri nouoque testamento uniuersum orbem terrarum quodammodo niuificare dinoscitur, éd. Ceresa-Gastaldo p. 172). Les deux mâchoires du Bien-aimé $(\mathrm{Ct} 5,13)$ représentent également, selon Épiphane, les deux Testaments (Maxillas dicit duo testamenta quae unguento fidei odorem suauitatis inspirant; germinant autem et unguenta fialae, id est sancta euangelia ex confectione prophetarum et legis, quibus unguentis utentes odorem naribus ingerunt, quatenus fetorem sceleratorum respuant peccatorum, éd. Ceresa-Gastaldo p. 150). Cf. J.-L. CHRETIEN, Symbolique du corps. La tradition chrétienne du Cantique des Cantiques (Épiméthée), Paris, PUF, 2005, p. 102.178. 
spirituel $^{252}$ (Duo ubera duo testamenta dicenda sunt, a quibus etiam filii lactantur ecclesiae, II, 1. 381-382). Ce lait spirituel provient d'une seule et même source puisque, dans l'ancienne comme dans la nouvelle alliance, c'est bien le "seul et même législateur» (unus enim et isdem legislator, VIII, 1. 587) qui est à l'œuvre (unde et duo testamenta ex uno perenni fonte ubera nocata sunt affluentiam spiritalis lactis habentia, VIII, 1. 588-590). La nourriture offerte par l'Ancien et le Nouveau Testaments, ce sont «les paroles de vérité », considérées à la fois comme une nourriture physique (reçue "par la langue ») et comme une nourriture spirituelle (reçue "par l'esprit») (lingua simul et mente uerba ueritatis accipientes, II, 1. 382-383; hoc poculo lactabuntur sicut lingua sic mente, II, 1. 388-389). Pour finir, une généalogie peut se dégager du commentaire. En effet, la maternité de l'Église vient d'être relevée, mais il faut également se rappeler que cette dernière est l'épouse du Fils de Dieu. Ainsi, le Christ et l'Église sont le père et la mère des chrétiens ${ }^{253}$. Épiphane résume admirablement ces liens de parenté en mentionnant dans une même phrase les enfants (fidelium), la mère (mater ecclesia) et l'époux de celle-ci (sponsum suum), tout ceci dans la joie et la gloire ${ }^{254}$ (Deinde iam gaudens multitudine fidelium christofora mater ecclesia circa sponsum suum laeta consistens in eo gloriatur, VI, 1. 551-553).

\section{e. Beauté}

Lorsque le Bien-aimé appelle par deux fois son Épouse «belle » (Ecce speciosa proxima mea, ecce speciosa, Ct 1,15), Épiphane met l'accent sur cette répétition (per geminatam laudem; secundo, XXXI, 1. 816.817) révélant selon lui une double beauté, c'est-àdire une beauté interne et une beauté externe. La première est due aux «entendements de la foi venant du cœur» (et intrinsecus quidem intellegentiis fidei a corde nenientibus, XXXI, 1. 819-820), tandis que la seconde provient de toutes les actions de la Bien-aimée guidées par la justice (extrinsecus autem oculorum honestate et compositione

${ }^{252}$ Dans ce passage, les deux seins, préfiguration des deux Testaments, sont les seins de l'Époux, alors qu'en d'autres endroits du commentaire, les seins de l'Épouse annoncent également les deux sections de la Bible. La conclusion suivante pourrait être tirée - mais était-ce clairement l'intention du commentaire en mentionnant la nourriture des croyants à ce moment? - : les chrétiens ne sont pas allaités par leur mère l'Église mais par le Christ. Hippolyte a également interprété les mamelles du Christ comme les deux Testaments; pour K. Delahaye, l'auteur «exprime par là que le Christ luimême est le contenu, la véritable source du salut, mais que ce salut est présenté aux hommes de façon maternelle, justement comme le lait des mamelles » (K. Delahaye, Ecclesia Mater chez les Pères des trois premiers siècles, p. 181). Ainsi, cette conception développée par Hippolyte a-t-elle peut-être été reprise dans le commentaire d'Épiphane.

${ }^{253}$ On retrouve également chez Origène l'idée selon laquelle le Christ est père. Cf. F. LEDEGANG, Mysterium Ecclesiae, p. 203-204.

${ }^{254}$ L'Église est ici mentionnée dans deux de ses aspects de femme : elle est mère et épouse. En effet, dans l'Antiquité, l'image de la femme comprend tous les aspects de l'être féminin (vierge, fiancée, épouse, mère et veuve). Cf. K. Delahaye, Ecclesia Mater chez. les Pères des trois premiers siècles, p. 52. 
gressuum et ceterarum iustitiae conuenientium actionum, XXXI, 1. 820821). Ainsi sont mises en avant la foi profonde et l'observation de la justice dont fait preuve l'Épouse-Église. Pour Épiphane, il faut le noter, l'Église ne possède pas cette beauté d'elle-même, mais elle l'a reçue du Christ ${ }^{255}$ (haec sola pulchra est, non ex semetipsa pulchritudinem habens, sed ex specioso forma prae filiis hominum, XVIII, 1. 694-696; si non cognoueris pulchritudinem quam percepisti a me, XVIIII, 1. 702). On peut déceler ici la conception antique du rôle réceptif de la femme dans ses relations avec l'homme. De fait, pour les Pères, l'Église ne possède rien d'elle-même, mais «comme Épouse du Christ, [elle] n'a tout que parce que, et pour autant que le Christ le lui donne ${ }^{256} »$.

\section{f. L'Esprit-Saint}

Après avoir loué la beauté de sa Bien-aimée, l'Époux compare les yeux de celle-ci à ceux d'une colombe (Oculi tuae columbae, $\mathrm{Ct}$ 1,15). Ici encore, le collaborateur de Cassiodore ne manque pas d'interpréter ces quelques mots dans un sens ecclésial, rappelant d'emblée - comme il l'a déjà fait - qu'il ne faut pas s'en tenir à une compréhension sensible (Columbae siquidem non simpliciter sensibiles oculos dicit, XXXII, 1. 824), mais s'élever à une interprétation spirituelle de ce passage, ${ }^{257}$ car il s'agit bien de voir ici une "colombe spirituelle» et non simplement charnelle (spiritali columbae, XXXII, 1. 827-828). Cette colombe spirituelle, c'est l'Esprit-Saint; voilà une interprétation que s'autorise Épiphane par la mention du passage évangélique du baptême du Christ $^{258}$ où l'Esprit est descendu sur lui comme une colombe (spiritus sancti qui super dominum in specie columbae descendit, XXXII, 1. 825-826). Il est alors aisé de comprendre l'intention présente dans le commentaire : derrière l'Épouse aux yeux de colombe se cache l'Église habitée par le Saint-Esprit ${ }^{259}$.

\section{g. Hiérarchie}

Dans l'ultime verset du premier chapitre du Cantique (Ct 1,17), l'Épouse - s'adressant à son Bien-aimé - effectue une description de leur demeure. Cette description va permettre d'aborder quelque aspect de la hiérarchie au sein de l'Église. En effet, les poutres de cèdres sont interprétées comme les prophètes, " poutres des Églises » (Tigna domuum nostrarum cedri, ac si diceret quia

255 Le Christ a donné cette beauté à l'Église par le baptême de la régénération. Cf. supra, p. 88. 171-172.

${ }^{256}$ K. Delahaye, Ecclesia Mater chez les Pères des trois premiers siècles, p.

257 Ce même principe est décelable en XII, 1. 636: «Non enim erat sensibile quod dicebat»; "En effet, ce qu'elle disait ne relevait pas du sensible ». Cf. supra, p. 90.

258 Cf. Mt 3,16 ; Mc 1,10 ; Lc 3,22.

${ }^{259}$ Dès le II ${ }^{\mathrm{e}}$ siècle, un lien étroit est décelable entre l'Église et l'Esprit. Cf. K. Delahaye, Ecclesia Mater chez les Pères des trois premiers siècles, p. 151. 
et prophetae tigna sunt ecclesiarum, XXXIIII, 1. 846-848), et derrière les toits de cyprès, le commentaire voit les apôtres (Trabes nostrae cupressi. Per has sanctos monstrat apostolos, XXXV, 1. 850-851). Mais Épiphane n'en reste pas là : à l'aide de quelques considérations relatives à la construction d'une maison ${ }^{260}$, il va rendre compte de la hiérarchie existant entre ces deux groupes - apôtres et prophètes - sur base d'une citation paulinienne. Les poutres, faitil remarquer, se situent en dessous du toit, ainsi une maison est dite belle par son toit (Quoniam igitur tigna a trabibus interius componuntur atque celantur, pulchritudo nero domus trabibus indicatur, XXXV, 1. 852-854). C'est pourquoi les prophètes sont assimilés aux poutres, tandis que les toits représentent les apôtres, car ceuxci ont assemblé pour l'Église un "resplendissant équipement» (propter splendidum ornamentum ecclesiae per apostolos ei collatum, XXXV, 1. 855-856). L'interprétation est alors explicitement rattachée à saint Paul ${ }^{261}$ (ut illud interpretaretur apostoli: Posuit deus in ecclesia primum apostolos, secundo prophetas, XXXV, 1. 857-859). Cette supériorité des apôtres par rapport aux prophètes, Épiphane l'explique par le fait que "c'est par eux qu'elle [l’Église] a été appelée épouse » (Super splendent enim apostoli prophetis in ecclesia, quoniam per eos sponsa uocata est, XXXV, 1. 859-860).

Ce rôle des apôtres vis-à-vis de l'Église, le commentaire l'a déjà mentionné auparavant. En effet, sans savoir en détail en quoi cela consiste, le lecteur est informé d'une «bonne et grande lutte» menée par les apôtres ${ }^{262}$ (bonam magnamque dimicationem pace creuisse

${ }^{260}$ En ce qui concerne la compréhension de l’Église par les premiers théologiens, certains distinguent trois images fondamentales (la maison, le corps et la femme) et voient dans les images de la construction - de la maison et de la cité - la structure de l'Église. K. Delahaye, quant à lui, tout en reconnaissant l'importance de ces trois images dans la Patristique primitive, voit l'Église représentée d'une double façon dans le corps et la femme; les images de la construction sont alors intégrées dans celle du corps. Cf. K. Delahaye, Ecclesia Mater chez les Pères des trois premiers siècles, p. 51-52. Notre propos ici n'est pas de défendre l'une ou l'autre de ces conceptions (deux ou trois images signifiant l'Église), mais il nous faut remarquer que, dans le commentaire, l'image de la construction de la maison sert à rendre compte d'une certaine hiérarchie dans l'Église, à savoir entre les prophètes et les apôtres.

261 Cf. 1 Co 12,28. Notons que saint Paul place en troisième position des personnes chargées de l'enseignement dont on ne trouve aucune mention chez Épiphane. Celui-ci semble avoir été fortement influencé par ce passage de la lettre aux Corinthiens (1 Co 12,12-31) car, juste avant cette hiérarchie, l'apôtre développe le thème de la diversité des membres et de l'unité du corps, insistant sur l'unité des chrétiens formant le corps du Christ. Or, cette thématique de l'unité de l'Église est développée dans le commentaire d'Épiphane. Cf. supra, p. 92.

${ }^{262}$ Dans son commentaire de Ct 1,6 Origène interprète également les fils de la mère de l'Épouse qui ont combattu en elle comme les apôtres du Christ qui ont combattu dans l'Église : "Possumus ergo Apostolos Christi accipere filios matris sponsae ", Commentaire sur le Cantique des Cantiques, II, 3, 4 (SC 375, p. 318). Parmi ces apôtres, Origène pense tout spécialement à Paul, tout d'abord persécuteur des chrétiens : "Pour comprendre comment les fils de sa mère ont combattu contre elle, il faut considérer Paul persécuteur de l'Église. Les persécuteurs de l'Église se sont repentis, et ses adversaires, revenus 
et zelo inspirante dinino, id est quam beati apostoli perfecerunt, XIII, 1. 649-651). Ces mêmes apôtres, nous dit Épiphane, ont attribué à l'Église le rôle de gardienne de la «vigne de la foi aux nombreux raisins » (haec igitur ab apostolis posita est custos in ista ninea fidei multos unarum fructus habenti, XIIII, 1. 667-668). On peut déceler une fois de plus, semble-t-il, l'image positive accordée à l'Église en contraste avec Israël : le commentaire mentionne la parabole des vignerons homicides ${ }^{263}$ et assimile la nation portant du fruit à l'Épouse du Cantique, c'est-à-dire l'Église (XIIII, 1. 665-6667). Ainsi, est-il possible de conclure, les mauvais vignerons représentent l'ancienne alliance à qui le royaume de Dieu a été enlevé (Dominus autem confirmabat uerbum ad eos dicens: Auferetur a nobis regnum dei, XIIII, 1. 663-665) pour être donné à l'Église par les apôtres.

\section{L'union du Christ et de l'Église}

\section{a. Mort du Christ et naissance de l'Église}

Le premier point important à mentionner dans l'étude de l'union entre le Fils de Dieu et son épouse l'Église telle que présentée dans le Commentaire sur le Cantique des Cantiques est la naissance de l'Église à partir du Christ mort. En effet, Épiphane voit dans la création de la première femme à partir de la côte d'Adam une préfiguration de la naissance de l'Église à partir du côté du Christ (Quia nero sicut ex latere Adam mulier, sic et ecclesia ex latere Christi facta est, I, 1. 257-258). Lors de la mort de Jésus sur la croix - mort décrite par Épiphane comme un sommeil comparable à celui d'Adam (dominus noster Iesus Christus pro nobis soporatus est mortem, I, 1. 255-256) -, de l'eau et du sang

aux étendards de leur sœur, ont prêché la foi qu'ils avaient essayé de détruire »; "Vide mihi Paulum ecclesiae persecutorem et intelliges quomodo filius matris eius pugnauerit contra eam. Persecutores ecclesiae egerunt paenitentiam et aduersarii eius rursum ad sororis signa conuersi praedicauerunt fidem, quam ante destruebant ", Homélies sur le Cantique des cantiques, I, 7 (SC 37 bis, p. 92-94). Épiphane interpréterait-il ce verset de la même façon qu'Origène? Le collaborateur de Cassiodore renvoie également explicitement aux apôtres (Filios matris suae, hoc est caelestis regni, dicit sanctos apostolos, XIII, 1. 648-649) et à saint Paul (Vide enim quid Paulus dicit, XIII, 1. 652). De plus, il parle d'une « bonne et grande lutte » (bonam magnamque dimicationem, XIII, 1. 650) : voudrait-il souligner par là que les apôtres ont d'abord mené une «mauvaise » lutte contre l'Église en tant que persécuteurs des chrétiens, et qu'après s'être convertis, ils ont mené une «bonne lutte» en faveur de l'Église? En effet, comme relevé précédemment (cf. supra, p. 69, note 133), le texte latin est ambigu et peut laisser sous-entendre une lutte en faveur de l'Église ou une lutte contre l'Église. À noter également: chez l'un et l'autre commentateurs, il s'agit bien d'une mère céleste pour l'Église : le «royaume céleste» chez Épiphane (caelestis regni, XIII, 1. 648) et la "Jérusalem céleste » chez Origène ("Hierusalem caelestem », Commentaire sur le Cantique des Cantiques, II, 3, 5 [SC 375, p. 318]). Voir à ce sujet F. LEDEGANG, Mysterium Ecclesiae, p. 163.209-210; J.-M. AuwERS, L'interprétation du Cantique des Cantiques, p. 189-192.

${ }^{263}$ Mt 21,33-46 ; Mc 12,1-12 ; Lc 20,9-19. 
s'échappèrent du côté du Christ, éléments qui ont permis l'édification de l'Église (ex latere mortui pro nobis Iesu accipiens aquam et sanguinem in his sibi reaedificaret ecclesiam, I, 1. 272-273). Le collaborateur de Cassiodore situe donc l'Église en relation avec le Fils de Dieu dès sa naissance. En outre, comme vu de nombreuses fois précédemment, il oppose l'Église de l'Ancien Testament et celle de la nouvelle alliance en parlant de l'Église « avant son union avec le Seigneur» (Et in hoc igitur intellege sanctum spiritum pro ecclesia ex tunc praeinterpellantem antequam domino iungeretur, I, l. 149-150). Israël n'a pas pu contracter cette alliance avec le Fils de Dieu, tandis que l'Église du Nouveau Testament y est parvenue. On le voit suite à l'analyse de ces éléments, le commentaire met en avant la dimension historique de cette union entre le Christ et son Église.

Outre l'eau et le sang s'écoulant du côté de Jésus lors de sa mort, Épiphane mentionne encore un troisième élément scellant cette union des époux - l'Esprit - et va donner à chacun d'eux une signification. L'eau jaillie du côté du Fils de Dieu permet le baptême ${ }^{264}$ et la glorification de l'Église (aqua quidem ex eius carne qua baptizata est ei atque clarificata, I, 1. 273-274), le sang offre le rachat du peuple de Dieu ainsi que son union au Christ (sanguine uero ex eius latere currenti quo redempta est eique coniuncta, I, 1. 274-275), et par l'Esprit, l'Église peut participer à la divinité du Seigneur (spiritu autem quo dininitati eius compararetur atque perficeretur, I, 1. 275276). Ces trois éléments, le commentaire les emprunte explicitement à saint Jean ${ }^{265}$. Plus loin, Épiphane revient sur ces

264 D'après P. Lundberg, la croix a une place importante dans la conception baptismale de l'Église primitive ; elle constitue le centre même du baptême. Plusieurs Pères considèrent que l'eau baptismale a été sanctifiée par la croix et, pour l'Église primitive, l'effet du baptême provient directement de la croix. Cf. P. LundBerg, La typologie baptismale dans l'ancienne Église (Acta seminarii neotestamentici Upsaliensis, 10), Leipzig-Uppsala, Alfred LorentzLundequistska Bokhandeln, 1942, p. 167-200. Voir également J.-M. PRIEUR, La croix chez les Pères (du IIe au début du IVe siècle) (Cahiers de Biblia Patristica, 8), Strasbourg, Université Marc Bloch, 2006. Nous pourrions nous demander si le Commentaire sur le Cantique des Cantiques ne garde pas la trace de cette conception, car, selon cette œuvre, l'eau du baptême est issue du côté du Christ mort sur la croix. Plus loin, Épiphane établit encore ce lien entre la naissance de l'Église et la croix: dans son commentaire de Ct 3,7 («Voici le lit de Salomon »), Épiphane rappelle que le Christ n'a pas d'endroit où reposer la tête (cf. Mt 8,20) et explique que, lorsque le Fils de Dieu prit l'Église comme épouse, il put trouver un lieu de repos dans l'Église qui devint pour lui le lit de Salomon, "c'est-à-dire de celui qui a pacifié les cieux et la terre ». (Assimilatur lectus Salomonis ecclesiae; antequam enim acciperet eam intellegibilis Salomon dicebat: Filius hominis non habet ubi reclinet caput suum. Quando uero accepit eam, facta est iam lectus Salomonis, hoc est eius qui pacificanit coelestia simul atque terrestria, éd. CeresaGastaldo p. 112). Or cette dernière phrase qualifiant Salomon rappelle Col 1,20 où la croix est clairement mentionnée, comme le fait remarquer M. W. ELLIOTT, The Song of Songs and Christology, p. 62-63.

265 I, 1. 277-278 : "Quia tres - inquit - sunt qui testificantur : aqua et sanguis et spiritus, et quia tres unum sunt», "Parce qu'il y en a trois - dit l'Écriture - qui témoignent: l'eau, le sang et l'Esprit, et parce que les trois sont un»; I, 1. 280 : « Quid est istud, o Christi carissime et sanctissime Iohannes? ", "Qu'est-ce que cela, ô très aimé du Christ et très saint Jean ? ». Cf. 1 Jn 5,7-8. 
éléments et sur leur signification respective (sanguine quidem ex eius latere fluenti quo ei redempta et coaequata sum, aqua uero per quam a carne eius ei baptizata sum atque clarificata, spiritu nero quo dininitati eius copulata sum et consummata, XXVII, 1. 786-790). En ce qui concerne le sang, notons-le, l'explication change quelque peu: ce liquide permettait tantôt l'union des époux (eique coniuncta, I, 1. 275), tandis que maintenant l'égalité de l'Église et du Christ est mise en avant (ei $[\ldots]$ coaequata sum, XXVII, 1. 787). Lors de cette deuxième mention du sang, de l'eau et de l'Esprit, Épiphane insiste bien sur le statut d'épouse et d'époux que prirent l'Église et le Christ au moment de la mort de ce dernier ${ }^{266}$ (ex aqua uel sanguine quae stillanit ex eius latere ipse mibi factus sponsus est et ego ei sponsa, XXVII, 1. 784-786).

\section{b. Les noces}

Le grand principe herméneutique présent dans l'œuvre d'Épiphane est le suivant : une dépréciation des éléments charnels en vue d'une compréhension spirituelle. Ce principe est notamment décelable lorsque le commentaire évoque les noces du Christ et de l'Église, préfigurées par la relation des Époux du Cantique. Le collaborateur de Cassiodore refuse de voir les plaisirs de la chair et la débauche ${ }^{267}$ (tunc etiam uniuersa carnis desideria damnabuntur, I, 1. 211-212; haec igitur audiens nuptias a pollutione quidem carnis extraneas et immaculatas fece libidinis, I, 1. 341342), mais il parle de noces spirituelles (spiritales nuptiae, I, 1. 212213) - pleines d'un amour spirituel (spiritalis caritatis, I, 1. 343) que ne peuvent voir les hommes, mais seulement les anges et les ressuscités ([nuptias] illorum magis corruptis quidem hominum oculis inuisibiles, angelis uero et his qui post resurrectionem digni fuerunt uisibiles, I, 1. 345-347). Parallèlement à l'opposition entre le charnel et le spirituel, le terrestre et le céleste sont également en contraste; Épiphane en rend notamment compte dans sa mention de la chambre du Seigneur (et domino buic magno sponso cubilia non terrena, sed cubicula sunt caelestia, I, 1. 355-357). De même, le commentaire établit une distinction entre Ève, "tirée de la terre » et mère des terrestres, et l'Église, «fiancée des cieux » et mère des célestes (Eua enim e terra sumpta mater eorum est qui in terra wixerunt, baec autem de caelestibus desponsata mater est caelestium qui uitam perpetuam perceperunt, I, 1. 301-303). Enfin, Épiphane résume admirablement

266 Dans le Banquet des dix vierges de Méthode de Philippes, c'est également dans la mort que le Christ prend l'Église pour épouse. Cf. K. Delahaye, Ecclesia Mater chez. les Pères des trois premiers siècles, p. 168.

${ }^{267}$ Cette interprétation semble se rapprocher de celle faite par Origène pour l'ensemble de ce livre biblique : en effet, tandis que l'Alexandrin reconnait pour la plupart des passages bibliques un sens littéral et un sens spirituel, il refuse de lire le Cantique des Cantiques selon la lettre, offrant uniquement une interprétation spirituelle de cet écrit. Certains y ont alors vu la volonté de la part d'Origène de dénigrer la dimension corporelle (sexuelle) du mariage. Concernant le débat à ce sujet, voir J. C. KING, Origen on the Song of Songs, p. 7794. 
cette union entre le Fils de Dieu et son épouse l'Église, communion non pas "d'un désir charnel», mais emplie de "la pureté adoratrice de Dieu » (Magno sponso domino et sponsae sanctae ecclesiae non est desiderii carnalis communio, sed munditia dei cultrix media fiducialiter inter sponsos adsistit, I, 1. 358-361).

Outre cette opposition entre charnel et spirituel ainsi qu'entre terrestre et céleste, il est également intéressant d'analyser la façon dont le commentaire considère l'union du Christ et de l'Église. Plusieurs éléments pertinents se retrouvent dans la fin du premier paragraphe de l'œuvre (I, 1. 289-315). Tout d'abord, Épiphane qualifie cette union de "lien indissoluble» (insolubile vinculum Christi et ecclesiae, I, 1. 291). Liée à cette indissolubilité, on remarque également l'unicité de ce mariage : le Christ est le seul et unique époux de l'Église (in una coniunctione, XXII, 1. 733 ; haec sancta ecclesia [...] solum tamen Christum sponsum habebat et virum, XXII, 1. 734735). Ensuite, le collaborateur de Cassiodore s'inspire largement de saint Paul pour établir un parallélisme entre l'union d'Adam et Ève et celle du Christ avec l'Église : tout comme Adam a dit de sa femme "Voici maintenant l'os de mes os et la chair de ma chair » (I, 1. 294-295 ; cf. Gn 2,23), de même les chrétiens sont les membres du Christ, « ses membres, tirés de sa chair et de ses os » selon l'apôtre ${ }^{268}$ (Hoc et apostolus de Christo et ecclesia dicit, quia membra eius sumus ex carne eius et ex ossibus eins, I, 1. 296-298). Ensuite, le premier homme et la première femme furent «deux en une seule chair» (I, 1. 305 ; cf. Gn 2,24), comme l'Église et le Fils de Dieu " furent rassemblés en une seule chair indissociable » (facti sunt in unam inuiolabilem carnem, I, 1. 307-308). Encore une fois, Épiphane se base ici sur saint Paul ${ }^{269}$ (dixit hoc apostolus in Christum et ecclesiam praecipue, I, 1. 305-306), mais il n'en reste pas à cette simple mention de l'apôtre; il s'attache à expliquer comment il faut comprendre cette "seule chair indissociable » dans laquelle sont unis le Christ et l'Église. En effet, d'après le commentaire, le Fils de Dieu revêt l'humanité de l'Église, et en échange, il lui donne "sa sainte chair afin de le recevoir dans la communion » (adsumpsit enim filius dei de ecclesia totum hominem quo indutus est et retribuit ei rursus ad communionem eius sanctam carnem suam ad percipiendum eum, I, l. 308-310). Épiphane n'hésite pas à citer les paroles mêmes du Christ lors de l'institution de l'eucharistie (I, 1. 311-312 ; cf. Mt 26,26-28). Notons-le d'emblée, le terme eucharistia - désignant soit l'action de rendre grâces sur le pain et le vin, soit le pain et le vin eucharistiques - n'apparaît pas, mais Épiphane utilise communio pouvant indiquer aussi bien l'eucharistie que l'union, la liaison, dans ce cas précis entre le Christ et son Église ${ }^{270}$. Aussi, même si les paroles de Jésus concernant son corps et son sang sont retranscrites, le commentaire conçoit la communion uniquement

${ }^{268}$ Cf. Ep 5,30.

${ }^{269}$ Cf. Ep 5,31-32.

270 «Eucharistia », in A. BLAISE, Dictionnaire latin-français, p. 318 ; "Communio », in A. BLAISE, Dictionnaire latin-français, p. 177-178 ; P.-M. GY, « Eucharistie », in J.-Y. LACOSTE (éd.), Dictionnaire critique de théologie, p. 519. 
au moyen de la chair du Christ $^{271}$. Après cette mention de l'eucharistie ${ }^{272}$, l'union " en une seule chair incorruptible » (Et ita factum est ut sint duo in carne una incorruptibili, I, 1. 312-313) est de nouveau rappelée, union qu'Épiphane se plaît à décliner en une série de substantifs et d'adjectifs ${ }^{273}$.

Pour terminer cette section consacrée aux noces du Christ et de l'Église, il est intéressant de relever la présence du terme sacramentum par lequel Épiphane désigne cette union. Comme la côte d'Adam, à partir de laquelle Evve fut créée, est - dit le commentaire - «le mystère indivisible des noces légitimes et honorables " (sicut etiam costa quam accepit deus ex Adam sacramentum fuit indiuisibile legitimarum et honorabilium nuptiarum, I, 1. 292-293), ainsi l'eau et le sang s'écoulant du côté de Jésus représentent l' "important et admirable mystère » de l'union entre celui-ci et l'Église (Cur enim aqua et sanguis ex latere mortui Iesu exibat, nisi quia iam magnum hoc aedificabatur et mirabile sacramentum, I, 1. 268-270). Plus loin, ce mariage est encore qualifié de «mystère céleste et ineffable » (caelestis et ineffabilis sacramenti, I, 1. 366). C'est ensuite l'occasion pour Épiphane de mentionner les différents éléments présents dans la chambre nuptiale - aromates et diadèmes - qui ne sont pas d'une banalité terrestre, mais dignes du Seigneur et de son épouse l'Église ${ }^{274}$.

271 On pourrait se demander s'il ne s'agit pas là d'une preuve de la communion uniquement au corps du Christ et non à son sang. En revanche, la communion au calice, encore présente à ce moment chez les Grecs, a progressivement disparu en Occident vers le XII ${ }^{e}$ siècle seulement. Cf. P.-M. GY, «Eucharistie », p. 521. Que l'on prenne en considération le commentaire grec de Philon ou sa traduction latine par Épiphane, la communion exclusive au corps du Christ ne pouvait donc être d'application.

272 L'eucharistie, dans sa dimension sacrificielle, trouve pour C. Chavasse une place importante dans le thème du mariage. En effet, la relation entre Israël et Yahvé est perçue, dans l'Ancien Testament, comme un mariage scellé par les sacrifices offerts à Dieu. De même, l'eucharistie en tant que sacrifice est la communion de l'Église entière avec son époux le Christ. C. CHAVASSE, The bride of Christ. An enquiry into the nuptial element in early christianity, Londres, The religious book club, 1940, p. 106-109.

273 I, 1. 313-315: " in diuinitate inenarrabili, in caritate insolubili, in gloria incomprehensibili, in unitate indiuisibili », « en une divinité indicible, en une charité indissoluble, en une gloire insaisissable, en une unité indivisible ».

274 I, 1. 366-373: «huic sponsae aromata non ex terrenis floribus arboribusque conficiuntur, sed ex pulchritudine paradisi praeparantur animarum sanctarum epulis opportuna; in illo thalamo diademata non de bratteis pusillam delectationem habentibus, sed una et maxima illic incorruptionis corona consistit, quam reddit dominus his qui in eam fideliter permanserunt: corona enim gloriae illius erit ei qui permanserit usque ad finem ", "pour cette épouse, on ne fabrique pas des aromates avec des fleurs et des arbres terrestres, mais ils sont faits de la beauté du paradis, appropriés aux festins des âmes saintes. Dans cette chambre nuptiale, les diadèmes ne sont pas en feuilles de métal de faible agrément, mais c'est l'unique et immense couronne de l'incorruptibilité accordée par le Seigneur à ceux qui sont restés fidèlement en elle : en effet, celui qui restera jusqu'à la fin aura la couronne de cette gloire ». 
c. L'Église unie au Fils et au Père

Comme vu dans la section précédente, Épiphane met en avant l'union entre ces époux particuliers que sont le Christ et l'Église. En outre, à l'un ou l'autre endroit du commentaire, l'Église semble également établie dans l'intimité du Père. En effet, lorsque le Christ viendra ressusciter tous les membres de l'Église (cum aduenerit resurrectionem tibi conferre et omnia membra dormientia de uaginis propriis suscitare, I, 1. 207-209), il l'emmènera au ciel (suscipiet autem te totam in caelo sponsus, I, 1. 206-207; tunc ad thalamos caelestes eueheris, I, 1. 209-210) où tous deux pourront participer avec le Père à de merveilleux festins (cum filio sponso ipsoque omnipotenti patre ineffabiles epulas perenniter possidebis, I, 1. 210-211). Le commentaire souligne donc la fonction de médiation détenue par le Christ : c'est par lui que l'Église peut aller vers le Père. Un peu plus loin, le collaborateur de Cassiodore rappelle ce banquet auquel participent les époux «sous le regard du Père tout-puissant», et il semble y apporter une restriction : tous les membres de l'Église ne pourront pas y prendre place, mais seulement les chrétiens n'ayant pas souillé leur baptême (Beati qui sine pollutione uestimentum nuptiarum istarum quod est baptisma seruauerunt: isti procul dubio cum sponso et sponsa in conspectu omnipotentis patris epulabuntur illis ineffabilibus deliciis et aeternis, I, 1. 376-379). Nous sommes ici dans une perspective eschatologique, car cette relation entre le Père et l'Église pourra s'établir après la résurrection de tous les chrétiens à la fin des temps.

\section{d. Le salut de l'Église}

Le Commentaire sur le Cantique des Cantiques montre également comment, par ces noces, le Christ apporte le salut à son épouse l'Église ${ }^{275}$. Tout d'abord, comme cela vient d'être mentionné, le Fils de Dieu ressuscitera l'Église, c'est-à-dire tous les chrétiens ; Épiphane paraphrase cette résurrection par l'image de membres endormis que le Christ viendra "relever de leurs propres enveloppes " (cum aduenerit resurrectionem tibi conferre et omnia membra dormientia de naginis propriis suscitare, I, 1. 207-209). Rappelons que cette résurrection aura lieu lors de la dernière venue du Christ dans la gloire. Ensuite - et cela a également déjà été évoqué - le commentaire considère le baptême comme le vêtement des noces entre le Christ et l'Église (uestimentum nuptiarum istarum quod est baptisma, I, 1. 376-377). Les chrétiens recevant le baptême, semble donc vouloir dire Épiphane, participent à ce mariage et sont, tout comme l'Église, unis au Christ. Plus loin dans l'œuvre, on voit même le Seigneur "représenté dans les baptisés » (sponsus in eis qui baptizantur figuratur, XXX, 1. 809-810). Or - cela a été relevé

275 Selon C. Chavasse, le salut et la rédemption sont deux thèmes importants liés au mariage ; avant de pouvoir recevoir son épouse, le futur mari doit la sauver. Ainsi, dans le mariage du Christ et de l'Église, le Fils de Dieu " rachète » son épouse et la sauve, notamment par sa mort sur la croix. C. CHAVASSE, The bride of Christ, p. 102-105. 
précédemment $^{276}$ - le baptême, qui est un baptême «de régénération » (lauacrum regenerationis, XVIII, 1. 697 ; XXI, 1. 725) permet d'être pardonné de ses péchés ; il s'agit donc bien d'une forme de salut ${ }^{277}$. Enfin, cette régénération peut également avoir lieu, selon le collaborateur de Cassiodore, par le banquet des noces (regenerationem per epulas nuptiarum, XXV, 1. 762-763). Il semblerait s'agir du banquet déjà mentionnée ${ }^{278}$, à savoir le banquet auquel participeront le Père, le Fils et l'Église, c'est-à-dire l'ensemble des chrétiens qui ont vécu conformément à leur baptême. Ce banquet eschatologique - car il a bien lieu après la résurrection de la fin des temps - permet donc, d'après Épiphane, d'obtenir la régénération.

Il est intéressant d'examiner ce terme regeneratio utilisé à plusieurs reprises dans le commentaire : employé par les chrétiens dans deux sens, il peut s'agir d'une part de la résurrection, du renouvellement, de la régénération du monde à la résurrection, et d'autre part de la régénération spirituelle (par le baptême), de l'admission à la grâce ${ }^{279}$. Épiphane semble bien se servir des deux acceptions du mot, car il parle tantôt du «baptême de la régénération ", tantôt de la régénération lors du banquet des noces, banquet ayant lieu après la résurrection des membres de l'Église ${ }^{280}$. Ainsi, toute l'existence chrétienne est habitée par cette régénération, depuis le baptême jusqu'à la résurrection. Par les noces du Christ et de son épouse telles que présentées dans le Commentaire sur le Cantique des Cantiques, le Fils de Dieu peut donc apporter le salut à chacun des membres de l'Église, un salut atemporel pourrait-on dire car il ne s'arrête pas à la mort, mais il s'offrira encore après la résurrection ${ }^{281}$. Le commentaire paraît ainsi être l'écho de la pensée des Pères primitifs pour qui l'Église,

276 Épiphane a montré comment, par le baptême, l'Église a reçu le pardon de ses péchés commis jadis lorsqu'elle vivait dans l'idolâtrie. Cf. supra, p. 88 .

277 Tout comme le salut et la rédemption, le baptême est, pour C. Chavasse, un élément essentiel dans la thématique du mariage. C. CHAvASSE, The bride of Christ, p. 105-106.

${ }^{278}$ Cf. supra, p. 103.

279 «Regeneratio », in A. BLAISE, Dictionnaire latin-français, p. 706-707.

280 I, 1. 206-211: "suscipiet autem te totam in caelo sponsus, cum aduenerit resurrectionem tibi conferre et omnia membra dormientia de uaginis propriis suscitare: tunc ad thalamos caelestes eueheris et cum filio sponso ipsoque omnipotenti patre ineffabiles epulas perenniter possidebis », " mais l'époux te prendra tout entière au ciel, lorsqu'il viendra t'apporter la résurrection et relever de leurs propres enveloppes tous tes membres endormis : alors tu seras emportée vers les chambres célestes et tu jouiras perpétuellement avec le Fils ton époux et le Père tout-puissant lui-même de festins ineffables ».

${ }^{281}$ Dans l'Église primitive, on considérait que l'action salvatrice de Dieu se développait en quatre étapes (création originelle, monde du péché originel, pleine réalité dans le Christ et achèvement final). L'Église s'insérait dans ces quatre étapes. Cf. K. DelaHAYE, Ecclesia Mater chez les Pères des trois premiers siècles, p. 137. Même s'il est difficile de retrouver ces étapes dans le commentaire d'Épiphane, un développement chronologique est néanmoins décelable, du baptême à la résurrection. 
dans l'image de la mère - et cette image est largement développée dans l'œuvre d'Épiphane -, est l'intermédiaire de ce processus entre Dieu et l'homme qu'est le salut ${ }^{282}$. Cependant, cette fonction de médiation, l'Église ne la possède pas d'elle-même, mais «à cause de son union mystérieuse avec le Christ ${ }^{283}$ ». Chez Épiphane, cette union du Fils de Dieu et de l'Église ne manque pas d'être visible. "Si, pour la Patristique primitive, cette action salvatrice de Dieu trouve son expression dans le lien du Christ et de l'Église, cette action de Dieu dans le Christ n'est pas comprise tellement comme une affaire entre Dieu et l'homme individuel, mais comme une entreprise menée par Dieu avec l'humanité tout entière », dit K. Delahaye au sujet des Pères des trois premiers siècles ${ }^{284}$. Même si cette conception de l'action salvatrice de Dieu remonte à l'Église primitive, elle semble cependant encore présente dans le Commentaire sur le Cantique des Cantiques: par cette union du Christ et de l'Église, l'ensemble des chrétiens peut obtenir la regeneratio donnée par Dieu.

\section{Conclusion}

Bien que la présente étude ait envisagé uniquement la préface et le premier chapitre du Commentaire sur le Cantique des Cantiques d'Épiphane le Scolastique, la traduction française réalisée ainsi que les différentes analyses permettent de tirer plusieurs conclusions relatives à la christologie et à l'ecclésiologie développées dans cette œuvre latine. Tout d'abord, il semble tout à fait à propos de parler d'une christologie présente dans le commentaire d'Épiphane. En effet, le terme le plus utilisé pour nommer le Fils de Dieu est son titre grec d'oint - ici transposé en latin (Christus) - soulignant la fonction que Jésus a reçue de son Père. Dans sa présentation du Christ, Épiphane fait notamment intervenir le thème de l'économie divine et de la kénose : le plan de Dieu sur le monde - exprimé par le terme dispensatio, traduction latine de l'oixovoria grecque - s'effectue, rappelle le collaborateur de Cassiodore, par l'incarnation et la passion de Jésus. Bien que le terme ne figure pas dans le commentaire, l'abaissement - la kénose - réalisé par le Christ en prenant la condition humaine et en mourant sur une croix est cependant perceptible. Étant donné l'utilisation fréquente que fait Épiphane du titre d'oint pour désigner le Fils de Dieu, on pourrait s'attendre à ce que la triple fonction de prêtre, prophète et roi de Jésus soit mise en évidence. Cependant, l'œuvre mentionne uniquement les

\footnotetext{
$131-132$.

${ }^{282}$ K. Delahaye, Ecclesia Mater chez les Pères des trois premiers siècles, p. 169.

${ }^{283}$ K. Delahaye, Ecclesia Mater chez les Pères des trois premiers siècles, p. 135.

${ }^{284}$ K. Delahaye, Ecclesia Mater chez les Pères des trois premiers siècles, p.
} 
fonctions sacerdotale et royale, avec une insistance sur cette dernière.

Même si le commentaire est consacré à la relation entre le Christ et son épouse l'Église, l'ecclésiologie est cependant davantage développée par rapport à la christologie. Tout d'abord, Épiphane nous renseigne sur l'origine de l'Église : l'Église de la nouvelle alliance est, d'après lui, la fille de la Synagogue, Église de l'ancienne alliance qui n'a pas été digne de recevoir le Fils de Dieu en raison de son idolâtrie. Pour Eppiphane, l'origine de l'Église d'après la venue du Christ est double : elle a été formée par le rassemblement des Juifs et des nations (gentes). Tout au long du commentaire, l'insistance est fortement soulignée sur le passage de l'Église de l'ancienne à celle de la nouvelle alliance; le commentaire ne cesse d'opposer la Synagogue à l'Église, mettant en avant la conversion de cette dernière. Épiphane rappelle l'infidélité d'Israël envers Dieu - le culte des idoles - par l'image de la prostitution (fornicatio), image déjà employée dans l'Ancien Testament. L'Église, à l'inverse, est considérée comme une vierge "se tenant pure loin des péchés", car elle se consacre à son seul époux le Christ. Rejetant les idoles, l'Église s'est donc convertie. Cette conversion - qui a pu avoir lieu par la confession et le baptême de la régénération - se trouve admirablement résumée dans le commentaire du cinquième verset du Cantique où la Bienaimée se dit «noire et belle »: l'Église est noire en raison des péchés passés, mais belle parce qu'elle s'est convertie au moyen de la pénitence. Un aspect important également développé dans l'ecclésiologie est celui de la maternité et, lié à elle, celui de la fécondité. Selon une conception datant déjà du $\mathrm{II}^{\mathrm{e}}$ siècle, l'Église est considérée comme la mère de tous les chrétiens ${ }^{285}$. Mais cette multitude de fils n'enlève rien à l'unité de l'Église ; ici encore, il ne faut pas voir une conception nouvelle, mais le commentaire reprend la doctrine de la $\mu$ i $\alpha \dot{\varepsilon} \varkappa x \lambda \eta \sigma_{\alpha} \alpha$ élaborée aux $\mathrm{II}^{\mathrm{e}}-\mathrm{III}^{\mathrm{e}}$ siècles ${ }^{286}$. C'est encore une fois l'occasion pour le collaborateur de Cassiodore d'opposer la Synagogue, stérile, et l'Église, mère de nombreux enfants. Si l'Église est la mère des chrétiens, Épiphane semble également la considérer comme la mère du Christ, maternité déjà reconnue au début de la chrétienté. L'Église est donc présentée, dans le commentaire, à la fois comme vierge, épouse et mère, trois aspects pouvant à première vue paraitre contradictoires, mais il n'en est rien. En effet, l'image de la femme comprenait, dans l'Antiquité, toutes les dimensions de l'être féminin qui n'étaient nullement en opposition ${ }^{287}$. Comme beaucoup l'ont fait avant lui, Épiphane a ainsi appliqué à l'Église l'image de la femme en ses différents aspects.

${ }^{285}$ J. C. Plumpe, Mater ecclesia, p. 5.16-17.124. p. $129-130$.

${ }^{286} \mathrm{~J}$. DANIELOU, MIA'EKK $\Lambda \mathrm{H} \Sigma \mathrm{IA}$ chez les Pères grecs des premiers siècles, ${ }^{287}$ K. Delahaye, Ecclesia Mater chez les Pères des trois premiers siècles, p. 52. 
L'union du Christ et de l'Église telle qu'elle est exposée dans le Commentaire sur le Cantique des Cantiques a également été étudiée. En effet, outre une présentation de chacun de ces époux, Épiphane s'est également attaché à mettre en avant les liens existant entre eux. Tout d'abord, la dimension historique de cette alliance est soulignée : l'Église est née de la mort du Christ sur la croix et c'est par le sang et l'eau jaillissant du côté de ce dernier - mais également par l'Esprit - que cette union a pu être scellée. Ensuite, selon le principe herméneutique développé par Épiphane, c'est-àdire une interprétation spirituelle des Écritures, le commentaire souligne combien il s'agit de noces spirituelles; il ne faut en aucun cas y voir l'expression d'un désir charnel. L'indissolubilité du lien est également rappelée, ainsi que l'union des époux « en une seule chair», union qualifiée de sacramentum. Épiphane n’hésite pas, pour exposer son point de vue, à établir un parallélisme entre d'une part, Adam et Ève et d'autre part, le Christ et l'Église. Enfin, il ne faut pas oublier de mentionner la dimension salvifique de ce lien entre le Fils de Dieu et son épouse. En effet, lors de sa dernière venue dans la gloire, le Christ viendra ressusciter tous les membres de l'Église. Ces chrétiens, explique Épiphane, se couvrent du vêtement de ces noces entre l'Église et son époux, vêtement qui n'est autre que le baptême de régénération permettant d'être pardonné des péchés. Mais les fils de la mère Église peuvent également obtenir la régénération par la participation au banquet qui réunira, à la fin des temps, le Père, le Fils et l'épouse de celui-ci. À travers ce commentaire du Cantique, Épiphane montre à quel point l'ensemble de l'existence chrétienne - depuis le baptême jusqu'à la résurrection - est habité par l'offre de salut faite par Dieu à tout chrétien. À la suite des Pères de l'Église primitive qui ont appliqué à l'Église l'image de la mère, le commentaire semble donc attribuer un rôle de médiation à celle-ci, médiation entre Dieu et l'homme dans le processus du salut ${ }^{288}$.

Voici donc les quelques grands principes concernant l'ecclésiologie et la christologie développées dans la préface et le premier chapitre du Commentaire sur le Cantique des Cantiques d'Épiphane le Scolastique. Même si, comme mentionné précédemment $^{289}$, ce premier chapitre est le plus intéressant pour saisir la méthode développée par Épiphane, l'étude de la suite du commentaire serait d'un grand intérêt pour compléter ces observations. De même, la comparaison avec le commentaire grec de Philon de Carpasia permettrait de mettre en lumière la part respective de chacun de ces deux auteurs dans la composition et la traduction de cette interprétation du « plus beau Chant ».

${ }^{288}$ K. Delahaye, Ecclesia Mater chez les Pères des trois premiers siècles, p. ${ }^{289}$ Cf. supra, p. 53. 